\title{
Estimating and Comparing Market Efficiency Frontiers
}

by

\section{Yali $\mathrm{Mu}$}

Born in Anhui, China

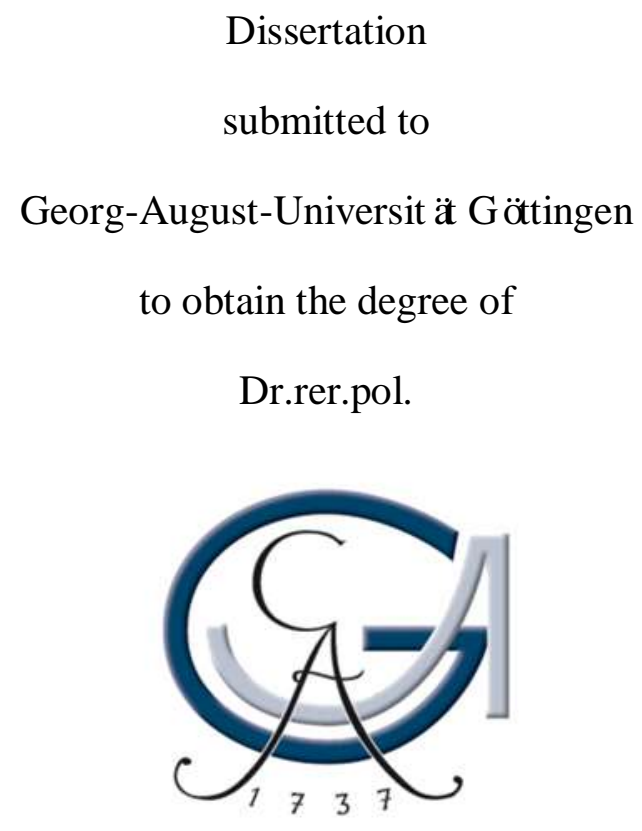

Chair of Agricultual Policy

Department of Agricultural Economics and Rural Development

Faculty of Agricultural Sciences

July 2021, Göttingen 
1. Name of referee: Prof. Dr. Stephan von Cramon-Taubadel

2. Name of co-referee: Prof. Dr. Bernhard Brümmer

3. Name of co-referee: Prof. Dr. Funing Zhong

Date of Defense: September 10, 2021 


\section{ACKNOWLEDGMENTS}

This research would not have been possible without financial support from the Erasmus Mundus ALPHABET project for my master's exchange from Nanjing Agricultural University (NAU) to the University of Göttingen, and the China Scholarship Council for my Ph.D. study in Göttingen.

I am greatly indebted to Jing Lan from NAU and Xueqin Zhu from Wageningen University, who interviewed me and elected me as the master exchange student from NAU to Göttingen. I also thank Funing Zhong, Shuyi Feng, and Jing Zhu, who contribute to economics research, especially in rural areas of China, for being role models of our younger generation. I would probably have never crossed with pursuing a $\mathrm{Ph} . \mathrm{D}$. degree without your inspiration.

I am grateful to my first supervisor for this Ph.D. program, Stephan von Cramon-Taubadel, for arranging excellent office(s), which enabled me to undertake this research and your valuable supervision, suggestions, and comments. Thank you for explaining everything step by step and encouraging me "it is a good start," "one step ahead." Thank you for checking each step patiently. If I were the dog for the example of your market integration analysis course, you would be the host with a leash for steering me on track during my Ph.D. life. Thank you for not being drunk so that I am not lost on a random walk but moving forward with progress. Thank you for always showing me the bright side of the coin.

I would like to express my sincere gratitude to my second supervisor, Bernhard Brümmer, for your excellent suggestions since my first doctoral seminar on broadening my research perspective and your guidance on frontier analysis step by step in R. I am very grateful for having the chances to present my research ideas and results in your efficiency courses and getting your profound discussions and advice. I also thank you for lending me books and replying to my emails.

I additionally thank Ph.D. students from the Colleage of Public Administration in NAU for drawing and updating the maps, and master students for some data collecting. And specially thank Manuel Dorste, a scientific assistant in the chair of Agricultural Policy, for providing invaluable contributions of data collection and excels processing for the EU markets. I am also grateful for the consultative time from senior colleagues from the Department of 
Agricultural Economics and Rural Development and the Department of Economics. And thank Stephan von Cramon-Taubadel and Funing Zhong again for shaping this dissertation.

I am thankful to IT and all the members of the administrative staff at the university who always made sure that all the technical and bureaucratic issues were solved. Special thanks to Antje Wagener, Nina Enke from the department and Robert from GFA for helping out with administrative matters.

I also owe special thanks to all my colleagues and friends inside and outside Göttingen not only for discussion of work and life but also for the great companionship and good times. Please forgive me for not typing your names here, cause if I do, I have to turn over the contracts book and check if I spell your names correctly. Then I am gonna miss you all so much. So I thank you all from my deep heart and hope you all the best.

I thank my parents Chunqian $\mathrm{Mu}$ and Zhiying Han, without whom I would never have enjoyed the privilege of growing up and living by my own willing. I thank your unconditional love and unwavering belief in me. To my younger brother Fei Mu, I am so grateful to have you in our family. You are a gift to me and our relatives. Thank you for bringing happiness and fun, for companying our family members.

Last but certainly not least, I wish to thank pigs and myself. Thank pigs for making me start my research from a fascinating point.

And thank myself for insisting on finishing this work. Ph.D. is life but just a tiny piece of the whole life. I look forward always,

"You may as well be bold to love someone, to climb a mountain, to pursue a dream."

- Bigfish and Begonia 


\section{Table of Contents}

I General Introduction ................................................................................................1

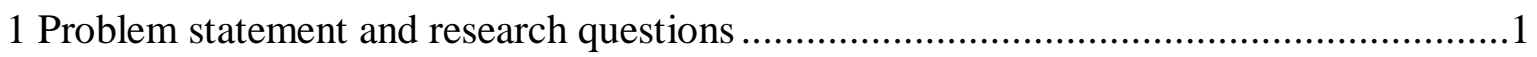

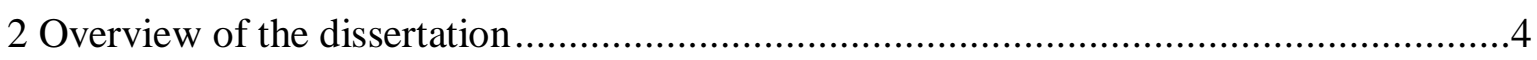

II Literature Review on the Law of One Price .....................................................................8

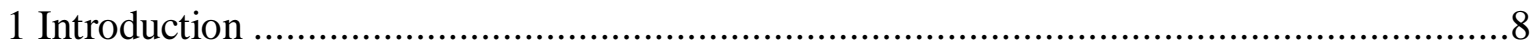

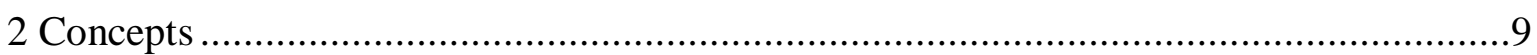

2.1 Price Relationships in Spatial Markets .................................................................9

2.2 Relationships between spatial arbitrage, market integration, and the LOP ............11

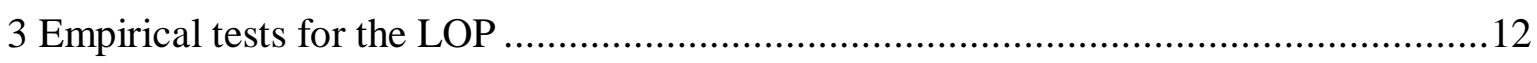

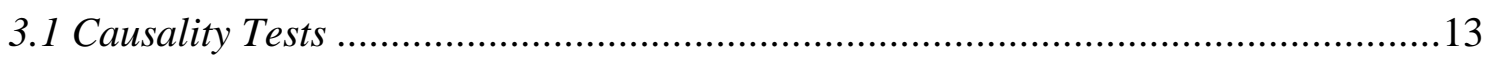

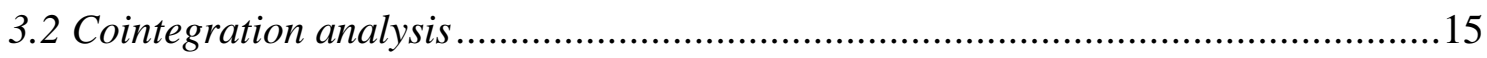

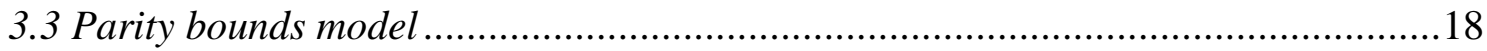

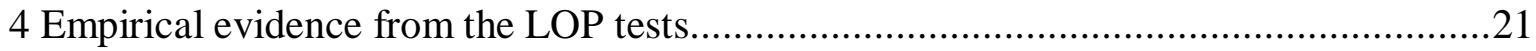

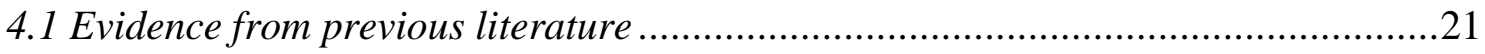

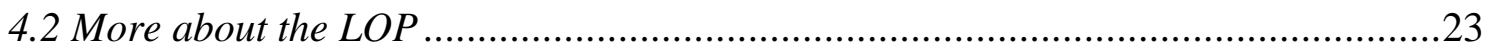

5 Additional issues: the role of transport costs and trade flow ........................................24

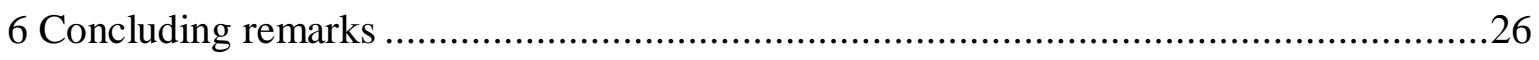

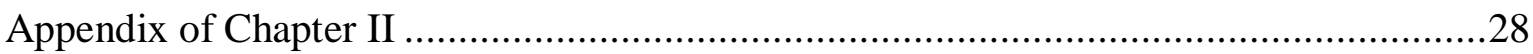

III Estimating Dynamic Market Efficiency Frontiers............................................................31

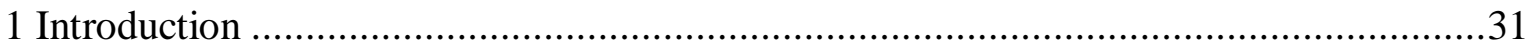

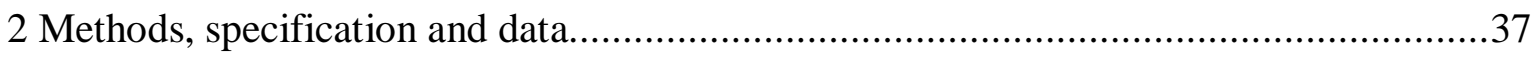

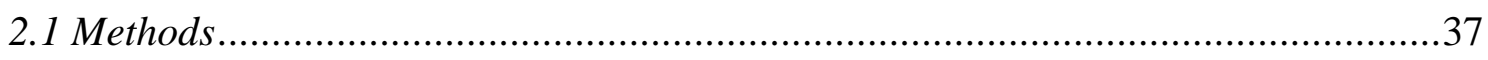

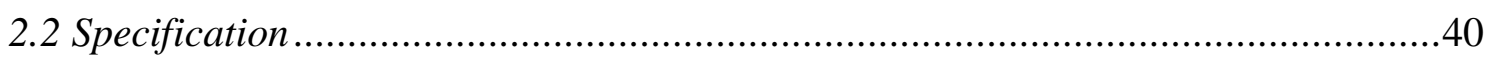

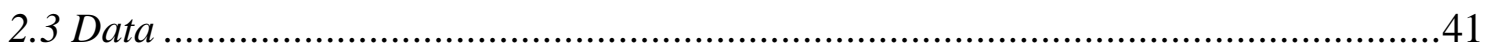

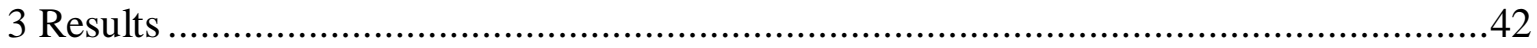

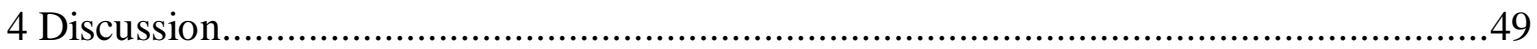

5 Conclusions and suggestions for future research................................................. 51

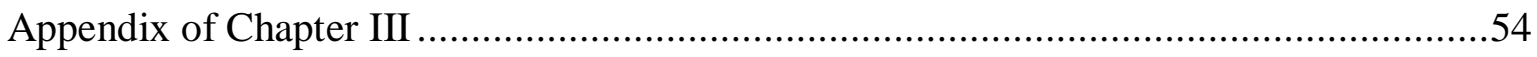

IV Comparing Market Efficiency Frontiers.......................................................63

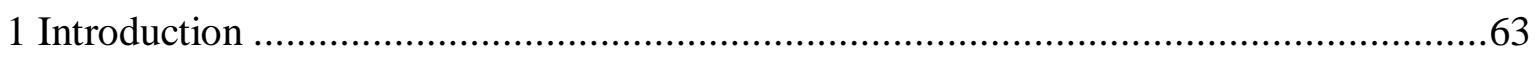

2 Hog market characteristics of China and the EU ........................................................6

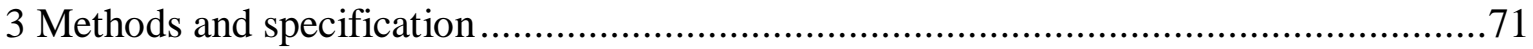

3.1 Measurement and determinants of market efficiency ......................................... 72

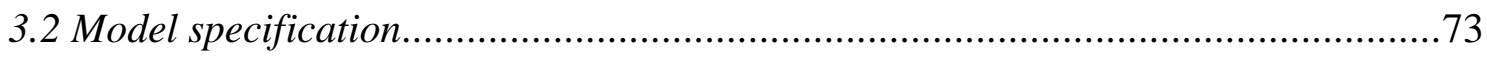

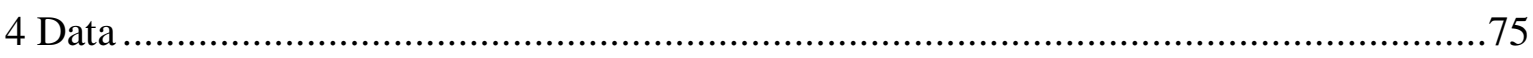

4.1 Price series data ...................................................................................... 75 
4.2 Measure of market efficiency frontier................................................................. 75

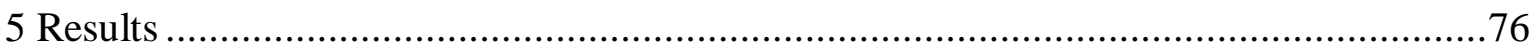

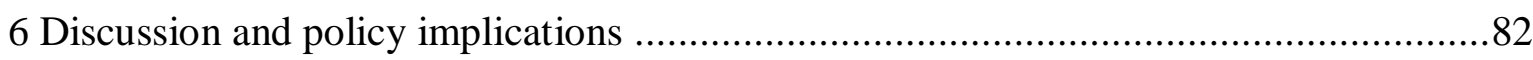

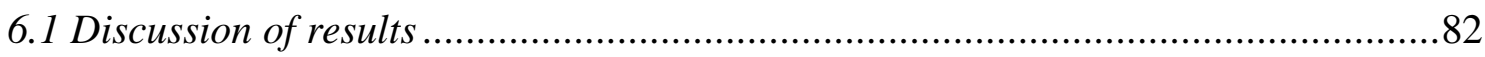

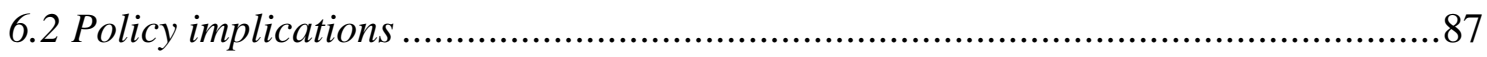

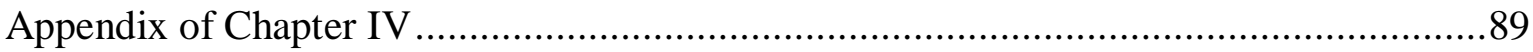

V Measuring Time-Varying Market Efficiency .................................................................99

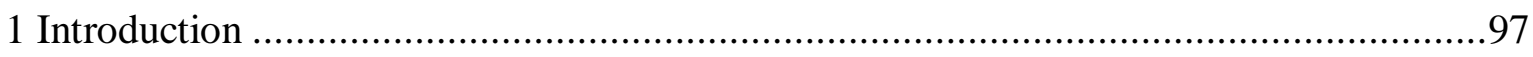

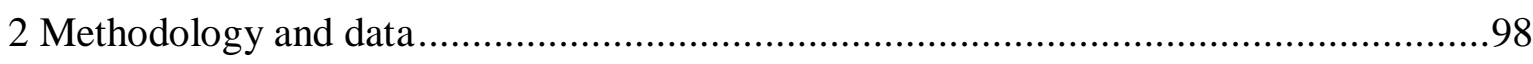

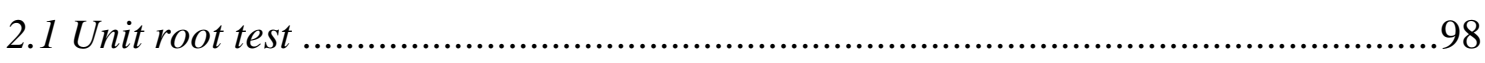

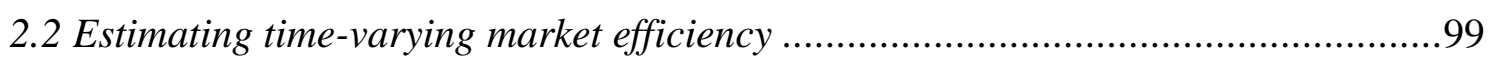

2.3 Stochastic frontier of time-varying market efficiency ........................................... 101

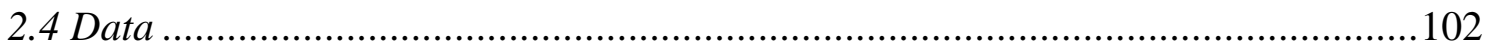

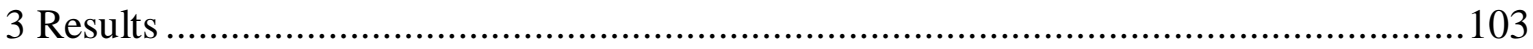

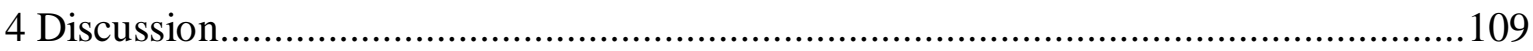

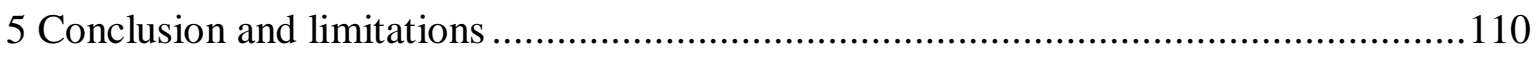

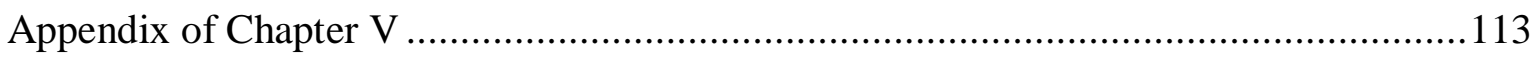

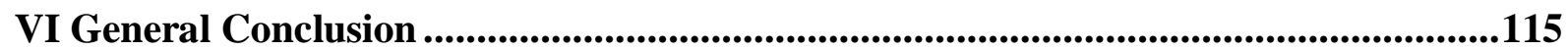

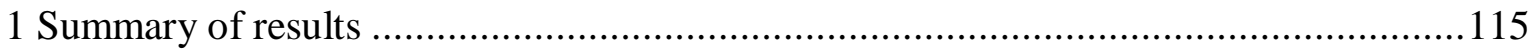

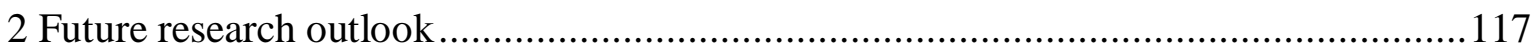

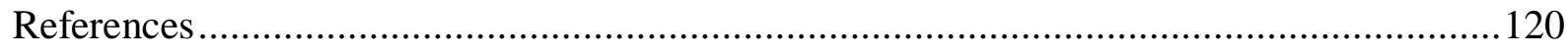

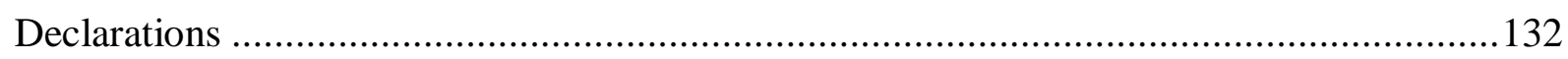




\section{General Introduction}

This dissertation aims to propose a new procedure for benchmarking market efficiency and apply the proposed method to markets in China and the European Union (EU). It contains one article reviewing the literature testing the Law of One Price (LOP) and three articles dealing with quantitative analyses of estimating and comparing market efficiency frontiers. This research contributes to an extensive strand of market integration and efficiency literature that analyzes how prices are passed on and how the market is integrated between spatially separated markets, either interregionally, i.e., between markets within a country, or internationally, i.e., between markets of different countries. Moreover, it combines the cointegration analysis with frontier estimation methods.

\section{Problem statement and research questions}

The Law of One Price (LOP) maintains that the actions of profit-seeking traders will lead to a long-run equilibrium whereby price differences should be no more than the costs of spatial arbitrage (von Cramon-Taubadel and Goodwin, 2021). An enormous literature has tested the LOP using different models (such as causality tests (Richardson, 1978); parity bound models (Sexton et al., 1991); cointegration methods (Asche et al., 1999, 2004)) to investigate the long-run equilibrium relationship between prices at spatially separated markets.

Cointegration methods (precisely error correction models, ECMs) make it possible to simultaneously analyze both the long-run equilibrium relationship between prices at different locations and the error correction mechanism that restores this equilibrium relationship whenever it is disturbed by shocks. Previous literature employs increasingly sophisticated forms of ECMs (von Cramon-Taubadel, 1998; Abdulai, 2000; Goodwin and Piggott, 2001; Gonzalo and Pitarakis, 2006; Brümmer et al., 2009; Guney et al. 2019; Vollmer et al. 2020).

Researchers who test the LOP or employ cointegration methods put efforts to conclude market integration and efficiency. However, conclusions are often drawn based on a static concept of market efficiency - given a set of demand and supply conditions on two (or more) spatially separated markets, and trade costs between them, they are either in equilibrium and therefore efficient, or not.

However, market efficiency has two additional dynamic dimensions. First, trade costs vary over time and space due to technology (Goodwin et al., 2002), infrastructure (Zant, 2018; Donaldson, 2018), and institutions. Second, since moving commodities between markets take 
time, trade and prices cannot adjust instantaneously to shocks that disturb equilibrium (Ravallion, 1986). Both of these dimensions of efficiency draw attention to the fact that market efficiency is a relative concept.

Even if tests enable us to conclude that two markets are in spatial equilibrium and therefore efficient in a static sense, it is only by comparing them with other pairs of markets that we can determine whether there is scope for increasing efficiency by lowering trade costs and/or increasing the speeds at which price signals are transmitted between them. Hence, to assess the efficiency of a pair of markets we need benchmarks derived from the observation and analysis of other pairs of markets.

Several studies (Kouyaté et al. 2016; Kouyaté and von Cramon-Taubadel; 2016; Svanidze and Götz, 2019a, 2019b) have employed a two-step procedure to measure and benchmark market efficiency. In the first step, measures of the strength or speed of price transmission are estimated using the cointegration methods. In the second step, standard regression analysis with these estimates as dependent variables is used to explain variations in the estimated strength or speed of price transmission. However, they are based on standard regression techniques that focus on explaining variation around mean measures of price transmission. Few studies mentioned above account for the fact that the first-step measures of price transmission are estimated more precisely than others and should therefore have a correspondingly greater influence on the results of the second-step of the procedure. Only Svanidze and Götz (2019a) employ bootstrapping techniques to address this issue.

Therefore, at the core of this dissertation, is a newly proposed method for benchmarking dynamic market efficiency to identify the strongest and most rapid examples of price transmission and applications. The main innovation is that the combination of cointegration analysis and stochastic frontier models. Frontier estimation light up this research at least in two aspects. First, the frontier analysis identifies the strongest and most rapid examples of price transmission that can be attained in a given setting and attempts to explain why price transmission between markets is sometimes closer to or farther from this benchmark. Second, stochastic frontier methods provide a straightforward and intuitively appealing means of accounting for the fact that the measures of price transmission generated from conventional cointegration methods are estimates when entering into the benchmarking procedure. 
China and the European Union (EU) are well-suited to illustrate the strengths and weaknesses of the proposed benchmarking approach and are considered economically relevant for several reasons:

China and the EU have been essential players on pork markets around the globe. Since 2013, the EU-28 has been the biggest pork exporter, with pig meat exports reaching 7.74 million tonnes accounting for $67 \%$ of global pig meat exports (ITC, 2021). While China is the biggest pork importer, with pig meat imports amounting to 7.74 million tonnes accounting for $67 \%$ of global pig meat imports (ITC, 2021). China is the largest pig producer, followed by the EU, at a distance, by the USA. Pigs account for the largest livestock population in both China and the EU. In 2017, the overall pig meat production amounted to 23 million tonnes from around 255 million slaughtered pigs in the EU-28 (Eurostat, 2021). And the overall production was 55 million tonnes produced from approximately 702 million slaughtered pigs in China (The Ministry of Agriculture of China, 2018).

Pigs and pork are traded across regions by various distances in China or the EU. Trade costs vary between markets due to geographic distance, road and rail infrastructure, etc. The international markets in different hog-producing member states of the EU are with an average distance of $1610 \mathrm{~km}$ (up to $5100 \mathrm{~km}$ ), while interprovincial markets within the hog-producing provinces of China are with a relatively large average distance of $1890 \mathrm{~km}$ (up to $4400 \mathrm{~km}$ ). The advantage of the large geographic size of China and the EU makes it appealing to build samples with hundreds of observations, which is vital for benchmarking market efficiency which requires comparing market pairs across space.

The structures of the pig industry in both China and the EU are particular and have changed at an unprecedented speed especially in recent years. The pork production system in China is still extensive with different densities of raised pigs (Gilbert, M. et al., 2015) from various sized farms (such as large commercial, medium-sized specialized) and small backyards (Tian and von Cramon-Taubadel, 2020). Moreover, the Chinese pig industry is not highly vertically integrated (Zhang et al., 2019), while the pig industry in the EU is more vertically integrated (Gilbert, M. et al., 2015). These structural differences could have had different influences on Chinese hog markets from the EU in terms of the degree to which price and price shocks are spatially transmitted.

In addition, the pig sector is fragile and distressingly affected by major veterinary crises, which would have had impacts on both supply and demand sides for meat products. Policy 
interventions such as border controls, trade bans, and animal welfare regulations during pig transportation are very likely to have triggered an impact on pig markets as well. Pig markets have been intervened less than other livestock markets in the EU (Serra et al., 2006). Market orientations by the Chinese government are often, for example, the state has restructured pork production toward large-scale tightening environmental regulations (Gilbert, M. et al., 2015) and has also implemented direct pork purchase, stocks release designed to stabilize the market (Dong et al., 2019).

Pork is a major part of meat consumption of daily diet nutrition intake. Emphasizing to increase pork production of China and the EU meets increasing nutrition demands and contributes to global food security. That postulates spatially efficient regional markets increasing gains from trade (e.g., increase trade volumes, lower trade costs) and restoring to spatial equilibrium more rapidly whenever there is a shock.

Other differences such as climate and weather differences, national dietary and cultural context, market information flows (futures market) motivate for investigating and comparing market integration and market efficiency across member states in the EU and provinces in China.

During the recent two decades, the changes experienced by the pig sector and the large data set coupled with the modern developed methodological strategies make it novel to extend market efficiency analysis in a dynamic sense and build the potential market efficiency benchmarks for both Chinese and the EU hog markets.

\section{Overview of the dissertation}

Chapter II reviews the literature which has been developed for testing the LOP. Then three articles from Chapter III to V benchmark market efficiency.

\section{Literature Review on the Law of One Price}

This chapter reviews the theoretical and empirical framework for the test of the LOP between spatially separated locations. The conceptual issues are presented first, then empirical tests and evidence from the LOP literature are reviewed, general considerations and conclusions are presented at the end.

Most studies essentially aim at verifying whether the LOP holds (often the strong form with price differences being trade costs.) between spatially separated markets utilizing time series 
econometric techniques. However, empirical result interpretation remains elusive, either with different conclusions after estimating different models based on the same dataset, or with different interpretations of results under the same testing procedures.

In the case of agricultural commodity markets, deviations from the strong form of the LOP will be caused by two types of 'friction': trade costs and trade delays. Rather than focusing on the simple acceptance or rejection of the LOP, it is more fruitful to compare actual adherence to the LOP with benchmarks. The idea of benchmark the LOP is proposed in this article based on spatial equilibrium conditions and Gardner's (1975) model.

\section{Estimating dynamic market efficiency frontiers}

Previous studies of price transmission for agricultural commodities more or less draw conclusions based on a static concept of efficiency. Market efficiency, however, also has two additional dynamic dimensions: the magnitude of the gains from trade that can be realized in equilibrium and the speed with which equilibrium and thus efficiency is restored following shocks.

A benchmarking procedure is proposed in this article. Rather than using standard regression techniques to explain variation in estimated measures of the strength and speed of price transmission, stochastic frontiers are estimated: first, estimating a stochastic frontier establishes a within-sample benchmark for market efficiency against which performance can be measured; Second, stochastic frontier methods offer a convenient way of accounting for the fact that the measures of price transmission generated in the first step of the benchmarking procedure are estimates.

The proposed method is illustrated first using monthly data on pork prices on 30 provincial markets in China from 2000 to 2017. In the first step standard, ECM methods are used to estimate elasticities of price transmission (magnitude of market efficiency) as well as adjustment parameters that measure the speed of transmission (speed of restoring market efficiency) between individual markets. In the second step dynamic of market efficiency (magnitude and speed of restoring market efficiency) are benchmarked using stochastic frontier techniques and covariates such as the geographic distance and border between the markets. 


\section{Comparing market efficiency frontiers}

To supplement the previous article and to further explore the strengths and limitations of the proposed method in the first empirical article, the work is extended to a different agricultural commodity during the same period in two different economic systems.

For this article, monthly hog prices of 30 provinces in China (yuan $/ \mathrm{kg}$ ) and 23 member states in the EU (Euro/kg) between July 2004 and December 2017 are employed to benchmark the magnitude of market efficiency at interprovincial level and international level separately. So in the first step following the previous article, price transmission elasticities are estimated using empirical models based on the nature of price series (stationary or nonstationary), in the second step, stochastic frontier models are estimated for the magnitude of market efficiency.

The stochastic frontier of the estimated elasticity of price transmission defines for any given provincial or member-state distance the maximum magnitude of market efficiency and thus the minimum of trade costs that can be attained in China or the EU. In addition, interprovincial (China) or international (the EU) border dummy is included to examine the border effects (such as trade impediment). This method is appealing in this article not only because it enables us to compare specific market-pair deviations from the frontier within China or the EU after accounting for the measurement errors of first-step estimates, but also it provides two straightforward benchmarks, one for China and one for the EU.

\section{Measuring time-varying market efficiency}

In this article, spatial price transmission and market efficiency in the Chinese provincial pork markets are illustrated based on the time-varying vector error correction model (VECM).

The previous two chapters assume that the elasticities and adjustment parameters that have been constant over the study period and are based on time-invariant estimation methods that do not take into account whether the trade infrastructure, shocks, and other sources of nonconstant parameters may affect markets in the price transmission process which changes over time.

In this article, a further application is designed to generate time-varying speeds of adjustment of price transmission using VECM in state-space form (Adämmer and Bohl, 2015, 2018) for each pork market pair of China. Frontier techniques for different periods then are applied to study how the market efficiency frontier has shifted over time. The time-varying price transmission analysis has already been the subject of several studies in the agricultural 
commodity price discovery context (e.g. Vollmer et al., 2020). We propose to explore whether it can also be used to generate insights and extend the literature in our market efficiency benchmark applications.

Chapters III to V form the core of this thesis. Results are summarized and conclusions are drawn in the final Chapter VI, which closes with several points for future research as well. 


\title{
II Literature Review on the Law of One Price
}

\begin{abstract}
Author: Yali Mu
"The more nearly perfect a market is, the stronger is the tendency for the same price to be paid for the same thing at the same time in all parts of the market: but of course if the market is large, allowance must be made for the expense of delivering the goods to different purchasers; each of whom must be supposed to pay in addition to the market price a special charge on account of delivery." (Marshall, 1890, p. 325)
\end{abstract}

\section{Introduction}

Following Fackler and Goodwin (2001, p. 978), the strong version of the LOP states that when a trade occurs, the price in the importing location equals the price in the exporting location plus trade costs (e.g. an obvious component, transport costs), which is exactly the perfect commodity arbitrage condition (Isard, 1977; Smith, 1988; Dawson and Dey, 2002), the presumption being that trade is continuous. ${ }^{1}$ In the weak version of the LOP, price differences are no smaller than trade costs: when spatial arbitrage condition holds, the prices have a proportional relationship, price levels differ due to factors such as transport costs, quality differences (Asche et al., 1999) and other factors relevant to the overall costs of trade between spatially separated markets (von Cramon-Tabaudel and Goodwin, 2021).

It is well confessed that, though expressing this concept which reflects the glut conviction in its adherence (Fackler and Goodwin, 2001), its assumptions prove to be quite restrictive. It is only expected to adjust spatial price relations in a frictionless undistorted world (Conforti, 2004), but unlikely to hold in practice. Some factors such as distance, border, policies, market power, and imperfect flows of information that prevent prices on spatially separated markets from convergence. In the case of commodity markets, deviations from the strong form of the LOP will be caused by two types of 'friction': trade costs and trade delays. Trade costs also vary over time and space due to changes or differences in many factors. Moreover, since moving commodities between markets take time, trade cannot adjust instantaneously to shocks that disturb equilibrium (Ravallion, 1986).

\footnotetext{
${ }^{1}$ There are some different versions of the LOP according to different literature. In this dissertation, the strong and weak version of the LOP are defined by following Fackler and Goodwin (2001, p. 978).
} 
The testing work of the LOP by using causality (static or dynamic or both), cointegration models, and switch regime models has been very appealing for decades. It is the strong form of the LOP with continuous trade that is often tested by taking the LOP as an example of a steady-state relationship of prices which is proportional in the long run. The underlying hypotheses being tested are the same. The differences are the empirical techniques employed to measure and test.

Despite all the different empirical methods developed to test the LOP, empirical evidence is mixed. Some studies claim that commodity prices reflect the LOP while others find significant deviations. Most find violations of the LOP and conclude that it does not hold. And all the studies suffer from the limitation of available data such as high frequent trade costs and trade flows. Even if tests enable us to draw conclusions that the LOP holds or fails for some market pairs, it is only by comparing with other market pairs we could determine if the adherence extent to the LOP could be improved. Hence, we need to move one step more, to assess the benchmark which is the largest adherence to the LOP derived from comparable observations.

This chapter aims to provide a theoretical framework overview of price relationships between spatially separated markets to understand the development of empirical methods in the existing LOP study, and to assess the innovations in this research. The conceptual issues are given in section 2. Sections 3 and 4 review the methodology in empirical tests and evidence found from the tests for the LOP. In section 5, additional concerns about transport costs and trade flows are described. Section 6 concludes.

\section{Concepts}

\subsection{Price Relationships in Spatial Markets}

Economists often use prices to define markets (Vinuya, 2007). Trade links spatially separated markets. This linkage is held by the underlying economic mechanism - arbitrage condition. If price differences surpass arbitrage costs, rational middlemen would take advantage of this opportunity and take actions to remove redundant price differences by trading the commodity from markets where commodity prices are low to a market where commodity prices are relatively high. Arbitrage condition involved in empirical evaluations of price relationship is often expressed as follows,

$$
P_{t}^{A}-P_{t}^{B} \leq \tau_{A B}
$$


The price difference between $A$ and $B$ at time $t$ should be at most the trade costs $\tau_{A B}$ at the same time (von Cramon-Taubadel and Goodwin, 2021). ${ }^{1}$ Where $P_{t}^{A}$ and $P_{t}^{B}$ represent a homogeneous commodity price in market $A$ and $B$ at any given time $\mathrm{t}$, and $\tau_{A B}$ represents the expense of trading the commodity (e.g. transporting, packing, loading, and offloading).

Note the terminology trade costs. In this dissertation, trade costs are used to refer to all the costs besides the costs of traded commodities themselves, that are involved in moving that commodity from one market to another for sale. Physical transport costs are part of the total trade costs, other costs associated with hedging, contracting (Barrett, 2001), loading and unloading (von Cramon-Taubadel and Goodwin, 2021), and administrative issues are also incurred during commodity trade conducted between spatially separated markets. Transaction costs or transfer costs are also used in some other literature, they all include transport costs, but many other types of costs as well.

Figure 1: Price and Trade

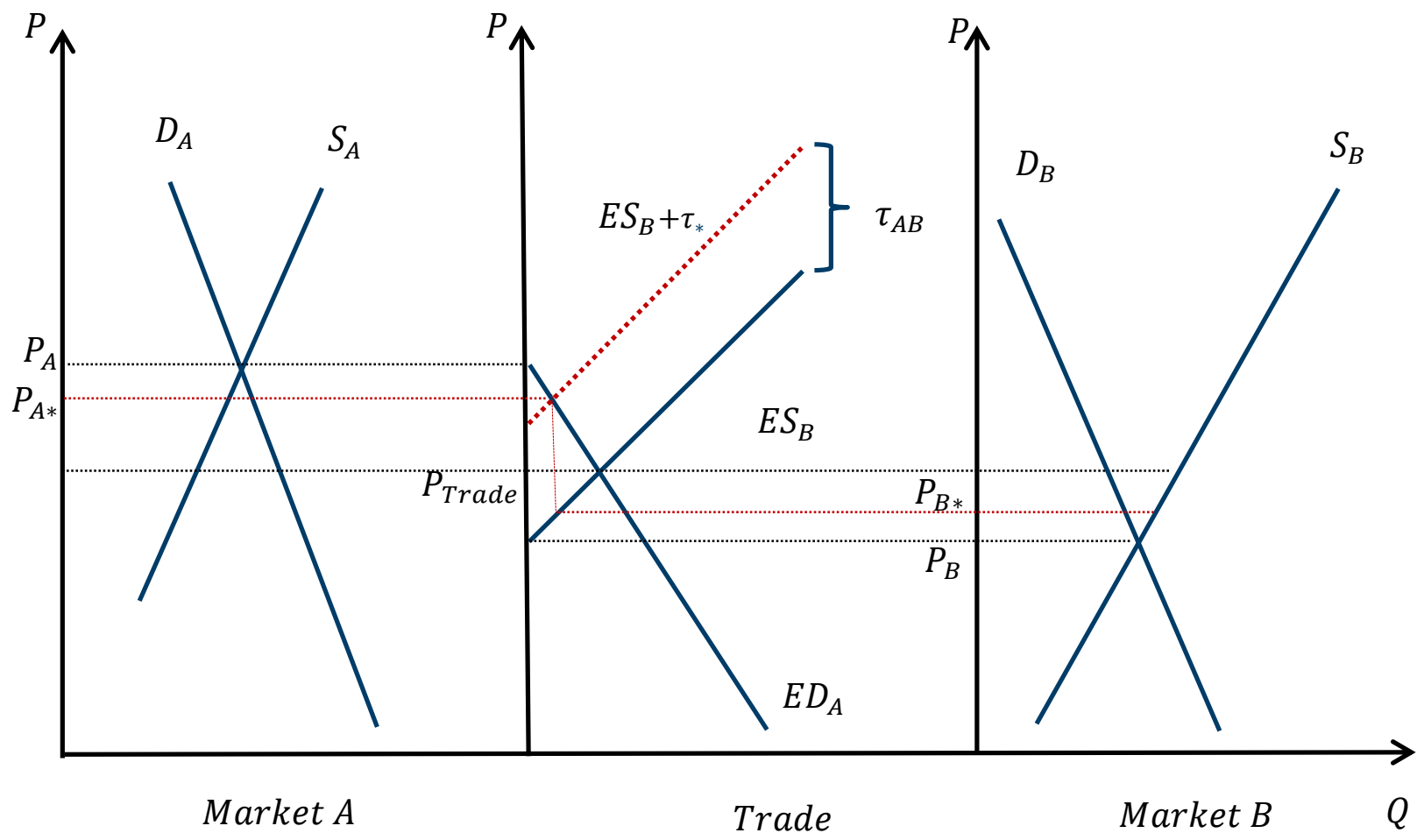

Source: Own expression based on von Cramon-Taubadel's (2019) lecture notes.

1 Arbitrage conditions implied by delivery lags that extend beyond a single time would be modified to $\mathrm{E}\left(\left(\mathrm{P}_{\mathrm{t}+1}^{\mathrm{A}}-\mathrm{P}_{\mathrm{t}+1}^{\mathrm{B}}\right) \mid \Omega_{\mathrm{t}}\right) \leq \tau_{\mathrm{AB}}, \Omega_{\mathrm{t}}$ represents the information set available to agents at time $\mathrm{t}$ (von Cramon-Taubadel and Goodwin, 2021). 
Figure 1 illustrates the concept of the LOP and dynamic market integration of a homogeneous commodity between spatially separated markets $A$ and $B$. One of the markets has a lower arbitrage price (market $B$ ), the other market has a higher arbitrage price (market $A$ ). We get a trade price $\left(P_{\text {Trade }}\right)$ in trade equilibrium condition, in this case, we are ignoring trade costs prices are the same everywhere. In reality, we consider some trade costs, we have a certain price in market $B\left(P_{B *}\right)$ and the price in market $A\left(P_{A *}\right)$ is lower by the trade costs $\left(\tau_{A B}\right)$. This is where perfect integration happens if we follow Barrett's (2001). There is a certain volume of trade going on between $A$ and $B$ and they are in spatial equilibrium.

Generally, this also holds for a set of $N$ markets among which trade occurs at fixed transport cost under spatial competitive equilibrium. If the trade takes place, such equilibrium holds for any two markets under the set with $N$ markets which are spatially integrated.

\subsection{Relationships between spatial arbitrage, market integration, and the LOP}

As shown in equation (1), the spatial arbitrage condition expresses that the price differences of a homogeneous commodity in different markets will differ by no more than the cost of trading the commodity between markets $\left(\tau_{A B}\right)$. It is an equilibrium concept (Fackler and Goodwin, 2001) and is expected to hold approximately, deviations from it should be the nature of transitory (e.g. delays in transport).

The LOP follows from the spatial arbitrage condition directly. As discussed in section 2.1in this chapter, the weak version of the LOP is exactly the arbitrage condition, while the strong version is equation (1) taken with an equality sign (the presumption being that trade is continuous).

As Barrett (2001) points out, economists typically define market integration in terms of the LOP; if the LOP holds between two markets, then they are integrated, and vice versa. As explicitly clarified by Barrett and Li (2002, p.292), market integration only reflects the tradability of commodities, regardless of the absence or presence of spatial market equilibrium and efficiency. Or say, market integration is an indicator of trade with volume (Thompson et al., 2002).

To indicate the degree of price co-movements and the extent to which shocks are transmitted among spatially separated markets, Fackler and Goodwin (2001, p.978) give the following item: 


$$
R_{A B}=\frac{\delta P_{B}}{\delta \varepsilon_{A}} / \frac{\delta P_{A}}{\delta \varepsilon_{A}}
$$

$\varepsilon_{A}$ is a shock on $A$, and $R_{A B}$ is the ratio of price transmission between market $A$ and market $B$. Two markets are perfectly integrated if $R_{A B}=1$. The fundamental idea is that if shocks of prices are transmitted, then trade exits, and $A$ and $B$ are integrated. But this indicator still relies on price data only, while market integration could be assessed sufficiently only if trade data are accessible (Barrett and Li, 2002).

As also explained by Barrett and Li (2002), efficiency is an indicator based on price, such as the LOP which is a static equilibrium concept. Market efficiency also has two important dynamic dimensions, one is the magnitude of trade costs and the other refers to the speed with which equilibrium and thus efficiency is restored following shocks. If we consider market efficiency to be synonymous with equilibrium (Barrett, 2001), according to Barrett and Li (2002), there are four combinations of integration and equilibrium that can hold between two markets. Of these, perfect integration and segmented equilibrium are efficient with no unrealized potential Pareto improvements, while imperfect integration and segmented disequilibrium are not efficient with potential Pareto improvements.

The following hierarchy holds for the conceptual issues defined in this section (Fackler and Goodwin, 2001, p.979):

Perfect market integration $\Rightarrow$ Strong Version LOP $\Rightarrow$ Weak Version LOP

\section{Empirical tests for the LOP}

Most studies utilize time series econometric techniques that test for the LOP. The developed techniques include causality tests in static or dynamic, cointegration models (often regarded as the standard tool for analyzing spatial market relationships), and switching regime models that incorporate data on prices, trade costs, and trade volumes:

- Causality tests (static and dynamic);

- Cointegration analysis;

- Parity bounds model.

Collectively, these techniques offer a framework for assessing if changes in one price are transmitted to the other price completely and instantaneously. Each of the above tests is used to look for evidence on the LOP, thus providing particular insights into its nature (a list of 
some typical literature of the LOP can be found in Appendix). For each of these approaches, a brief description of the concept is provided, underlying its main equations in this section.

\subsection{Causality Tests}

From the 1970s, the two most popular procedures have been done to see the violations of the LOP on various agricultural commodities. First, causality tests with static models for price levels (Richardson, 1978; Protopapadakis and Stoll, 1983; Jabara and Schwartz, 1987; Smith, 1988; Giovannini, 1988):

$$
P_{t}^{B}=\beta_{0}+\beta_{1} P_{t}^{A}+e_{t}
$$

A commodity price in one market $B\left(P_{t}^{B}\right)$ is regressed on the same commodity's price in another market $A\left(P_{t}^{A}\right)$. The LOP holds if $\beta_{1}=1$ and the constant term $\beta_{0}=0$ with exception of the arbitrary deviations caused by the error term $\left(e_{t}\right)$; in most cases, $\beta_{0}$ is non-zero interpreted as constant trade costs ${ }^{2}$ or quality differences.

Second, dynamic models for price lag levels (Ravallion, 1986; Protopapadakis and Stoll, 1986) considering that the price adjustment takes time:

$$
P_{t}^{B}=a+\sum_{j=1}^{m} b_{j} P_{t-j}^{B}+\sum_{i=0}^{n} c_{i} P_{t-i}^{A}+e_{t}
$$

Specifications in equation (4) could distinguish short- and long-run effects. There is a relationship, or in statistical terms that $P_{t}^{A}$ causes $P_{t}^{B}$, if a joint test that all $c_{i}=0$ is rejected. ${ }^{3}$ The LOP holds in a static sense which is exactly shown in equation (3) if $c_{0}=1, c_{i}=0$, and $b_{j}=0, \forall_{i j}>0$; in a dynamic sense if $\sum b_{j}+\sum c_{i}=1$.

The above causality methods of testing the LOP typically assume that parity holds contemporaneously. These approaches overlook the fact that commodity arbitrage (especially for international trade) takes place over time and across space. So they have, for the most part, neglected the role of expectations and trade costs. Since price linkages are not

\footnotetext{
${ }^{2}$ If the price series are in their logarithmic terms, $\beta_{0}$ is assumed to present the proportional trade costs; If not, $\beta_{0}$ is assumed to present the addictive trade costs.

${ }^{3}$ If we interchange price variables by putting $P_{t}^{A}$ as the dependent price series in equation (4), that the null hypothesis $P_{t}^{B}$ causes $P_{t}^{A}$. Markets are independent if there is no causality found.
} 
contemporaneous and may involve delivery lags, agents have expectations that they might formulate about prices at the time of delivery. ${ }^{4}$

For improvement, Goodwin et al. (1990a, 1990b) test the LOP in a rational expectation version. Rational expectation models are also causality tests, the difference is that price expectations are involved when the test for the LOP. First, they follow the standard version of testing the LOP as Richardson (1978) and then exploit a model which attempts to study the role of expectations instead of contemporaneous prices (domestic and foreign). They express the expectations in an augmented version of of the LOP as: ${ }^{5}$

$$
P_{t}^{B}=E_{t}\left\{\theta_{0}+\beta_{t}^{j}\left(P_{t+j}^{A}\right)^{\theta_{2}}-\theta_{3} T W_{t}\right\}
$$

Parameter vector $\gamma=\left\{\theta_{0}, \theta_{2}, \theta_{3}\right\}$ is to be estimated, $T W_{t}$ is the observable freight rate. Adherence to the LOP is proved if values of $\theta_{2}$ are not significantly different from one.

Note that, for causality tests, price series should be stationary. Still, in most of the previous work done by using causality tests, the stationarity property of their price series is not so clear. If price series are not stationary, the LOP would be over-rejected by using causality methods, as critical values for the hypothesis are increased (Asche et al., 2004). So when price series show nonstationary probability characteristics (through a Dickey-Fuller test (DF) in equation $(6)^{6}$ or the Augmented Dickey-Fuller test (ADF) in equation $\left.(7)^{7}\right)$, the above econometric approaches are no longer valid, regression estimates of the standard errors on the estimates of $\beta_{0}$ and $\beta_{1}$ in equation (3) will be inconsistent.

$$
\Delta P_{t}=\gamma_{0}+\rho P_{t-1}+\epsilon_{t}
$$

Where $\Delta$ represents first differences, for example $\Delta P_{t}=P_{t}-P_{t-1}$. The lag length $k$ is chosen in the $\mathrm{ADF}$ test to generate a white noise $\epsilon_{t}$,

$$
\Delta P_{t}=\gamma_{0}+\gamma_{1} T+\rho P_{t-1}+\sum_{r=1}^{k} \alpha_{r} \Delta P_{t-r}+\epsilon_{t}
$$

\footnotetext{
${ }^{4}$ Commodity delivery lags necessarily raise at least three issues of: (a) price expectations, since agents must formulate expectations about prices at the time of delivery, (b) the uncertainty and information-gathering costs, which may be a significant determinant of trade costs, and (c) the possibility of non-contemporaneous price linkages (Fackler and Goodwin, 2001).

${ }^{5}$ Equation (5) is expressed as $P_{t}^{B}=\beta_{0}+E_{t}\left\{\left(P_{t+j}^{A}\right)^{\beta_{1}}\right\}-\beta_{2} T W_{t}$ in Goodwin et al. (1990b).

${ }^{6}$ See Baffes (1991), p. 1267

${ }^{7}$ See Baffes (1991), p. 1267; Gordon and Hannesson (1996), equation (3); Asche et al. (2004), equation (5); Vinuya (2007), equation (3). Time trend $T$ can be omitted, as showed in Ardeni (1989), p665; Asche et al. (1999), equation (8).
} 
To determine whether $P_{t}$ is non-stationary by using DF test or ADF test, one tests the null hypothesis of non-stationarity by testing whether $\rho=0\left(H_{0}: P_{t}\right.$ is not $\left.I(0)\right)$ against the alternative of stationarity $\rho<0$ and significantly different from $0\left(P_{t}\right.$ is $\left.I(0)\right)$. First, the DF test or $\mathrm{ADF}$ test is used on prices and then duplicated for the first differences of prices. Once prices are confirmed to be $I(1)$ with rejecting the null hypothesis at the conventional significance level on the first differences of the prices, they are regarded as possible cointegration candidates (Vinuya, 2007).

\subsection{Cointegration analysis}

Cointegration analysis is a dynamic regression based on a point location model. Indeed, commodity price series are often $I(1)$, which need to be differentiated before becoming stationary. Cointegration methods presuppose that time series exhibiting non-stationary will be linked by a long-run relationship with stationary residuals, which is the case of the LOP holds in the long-run despite short-run piece variations.

A two-step Engle and Granger (1987) procedure has been developed to carry out the estimation (Ardeni, 1989; Baffes, 1991; Zanias, 1993; Gordon and Hannesson, 1996) by confirming the non-stationarity and integration order of price series. First, one estimates the equilibrium relationship among the variables using OLS for equation (3). Second, the residuals $\left(e c_{t}\right)$ from equation (3) are tested for non-stationarity by running equation (6) or (7). In particular, the LOP presumes that the LOP holds with the cointegration parameter being one (Baffes, 1991). In this case, the time-series property of the residual term $e c_{t}$ is tested (testing whether $\hat{Z}_{t}$ is $I(0)$ in equation $(8)^{8}$ or say $\widehat{e c}_{t}$ is $I(0)$ in equation (3)). If the residual is stationary, $P_{t}^{A}$ and $P_{t}^{B}$ are in long-run and stable equilibrium,

$$
Z_{t}=P_{t}^{B}-P_{t}^{A}
$$

However, the two-step procedure is not possible for a statistically direct test for the LOP since it has no well-defined limitation of distributions. Moreover, the results from Engle and Granger tests might depend on which price one normalizes in the regression (Asche et al., 1999; Dawson and Dey, 2002; Asche et al., 2004), and the first step OLS estimation may result in "spurious regressions" with low Durbin-Watson (DW) statistic below one (Ardeni, 1989). Normal statistical inference and tests for the LOP are invalid when a negative

\footnotetext{
${ }^{8}$ Then $\Delta P_{t}$ in equation (7) and (8) could be written as $\Delta Z_{t}, \Delta Z_{t}=\gamma_{0}+\gamma_{1} T+\rho Z_{t-1}+\sum_{r=1}^{k} \alpha_{r} \Delta Z_{t-r}+\epsilon_{t}$ (Gordon and Hannesson ,1996, p. 232 note c in table 3).
} 
relationship between price series shows up, though cointegration tests for a relationship between two substituted commodities are possible (Asche et al., 1999).

The Johansen approach is desired over the procedure proposed by Engle and Grange (1987) and has been verified to be appealing in some literature developed to testing the LOP recently (Vinuya, 2007). Johansen (1988) develops a method for producing test statistics (i.e., likelihood ratios) with exactly limited distributions and allows for a "direct" test for the LOP in a bivariate or multivariate setting (Goodwin, 1992; Asche et al., 1999) by carrying out the following vector autoregressive (VAR) representation: ${ }^{9}$

$$
P_{t}=\sum_{i=1}^{k-1} \Pi_{i} P_{t-i}+\Pi_{k} P_{t-k}+\mu+\varepsilon_{t}
$$

Where each $\Pi_{i}$ is a $N \times N$ matrix of parameters, $\mu$ is an $(\mathrm{N} \times 1)$ vector of constant terms, and $\varepsilon_{t}$ is an $\mathrm{N} \times 1$ vector of noises with a mean zero, covariance matrix $W$ and normal over time (independently and identically distributed). Equation (9) could be expressed in an error correction form: ${ }^{10}$

$$
\Delta P_{t}=\sum_{i=1}^{k-1} \Gamma_{i} P_{t-i}+\Gamma_{k} P_{t-k}+\mu+\varepsilon_{t}
$$

Where $\Gamma_{i}=-I+\Pi_{1}+\Pi_{2}+\ldots+\Pi_{i}$ and $i=1, \ldots, k-1 . \Gamma_{k}$ is the long-run solution to equation (9). If $P_{t}$ is $I(1), \Delta P_{t}$ must be $I(0)$, the first $k-1$ elements are also stationary. $\varepsilon_{t}$ are also assumed to be stationary. Thus $\Gamma_{k}$ is a matrix of zeroes, $P_{t}$ includes cointegrating vectors. $r$ is the rank of $\Gamma_{k}$, which determines the combination numbers of $P_{t}$.

There are three possible ranks: (a) $r=N$, the prices are $I(0)$; (b) $r=0$, no linear combination occurs, $P_{t}$ are stationary; and (c) $0<r<N, r$ stationary linear combinations of $P_{t}$ exist.

A rank of $N-1$ in a multivariate system with $N$ price series means that prices are driven by only one stochastic trend. For $0<r<N, \Gamma_{k}$ could be decomposed such that $\Gamma_{k}=\alpha \beta^{\prime}$, where $\alpha$ (adjustment vector) and $\beta$ (cointegrating vector) are both $N \times r$ matrixes. ${ }^{11}$

\footnotetext{
${ }^{9}$ VAR representation stands for the same meaning as equation (5) in Asche et al. (1999), equation (3) in Asche et al. (2004), equation (4) in Vinuya (2007). Here I point out one error on p. 251 in Vinuya (2007), $i$ should be from 1 to $k-1$, not 1 to $k$ as showed in equation (4) and (5) on page 251.

${ }^{10}$ See equation (6) in Asche et al. (1999); equation (4) in Dawson and Dey (2002); equation (4) in Asche et al. (2004); equation (2) in Nielsen (2005); equation (5) in Vinuya (2007).

${ }^{11} r$ can be identified by the maximum eigenvalue test and the trace test (Johansen, 1995).
} 
From the 1990 s to the early $21^{\text {st }}$ century, numerous applications for testing the LOP by using Johansen cointegration techniques covering various commodities (Gordon and Hannesson, 1996; Asche et al., 1999; Asche et al., 2004; Nielsen, 2005).

In these studies, the LOP test turns into a test for if the columns of $\beta$ matrix sum to zero. For example, for four price series, $r=N-1=3, \beta$ is a $3 \times 4$ matrix represented as:

$$
\beta=\left[\begin{array}{ccc}
1 & 1 & 1 \\
-\beta_{1} & 0 & 0 \\
0 & -\beta_{2} & 0 \\
0 & 0 & -\beta_{3}
\end{array}\right]
$$

When $N=2, P_{t}=\left[P_{t}^{A}, P_{t}^{B}\right]^{\prime}$ with two price series both are $I(1), r=1$, giving the cointegrating vector, $\beta=\left[\beta_{A}, \beta_{B}\right]$ and the adjustment vector $\alpha=\left[\alpha_{A}, \alpha_{B}\right]^{\prime},{ }^{12}$

$$
\left[\begin{array}{l}
\Delta P_{t}^{A} \\
\Delta P_{t}^{B}
\end{array}\right]=\left[\begin{array}{l}
\mu_{A} \\
\mu_{B}
\end{array}\right]+\sum_{i=1}^{k-1}\left[\begin{array}{ll}
\Gamma_{i, 11} & \Gamma_{i, 12} \\
\Gamma_{i, 21} & \Gamma_{i, 22}
\end{array}\right]\left[\begin{array}{c}
\Delta P_{t-i}^{A} \\
\Delta P_{t-i}^{B}
\end{array}\right]+\left[\begin{array}{c}
\alpha_{A} \\
\alpha_{B}
\end{array}\right]\left[\beta_{A} \beta_{B}\right]\left[\begin{array}{c}
P_{t-k}^{A} \\
P_{t-k}^{B}
\end{array}\right]+\left[\begin{array}{c}
\varepsilon_{t}^{A} \\
\varepsilon_{t}^{B}
\end{array}\right]
$$

The LOP is tested as a long-run concept by imposing the null hypothesis restriction $\beta_{A}=1$ and $\beta_{B}=-1(\beta=[1,-1])$ using a likelihood ratio (LR) statistic since the matrix $\beta$ contains long-run parameters. This test is then equivalent to the test of the LOP based on equation (4). If the null cannot be rejected, the markets are perfectly integrated, while if the null is rejected, imperfect market integration is implied.

However, Baffes (1991) points out that cointegration alone is not sufficient to conclude that the LOP holds. He demonstrates that the linear relationship between prices should have a slope of one, or equivalently, that the price spreads are stationary. The practical importance of the Johansen test is as a pre-test for other econometric tests not just as a test in its own right (Baulch, 1997b). Cointegration based on the LOP is with criticisms. First, the main critique is that cointegration is neither necessary nor is it a sufficient condition for market integration (Barret, 1996; McNew and Fackler, 1997; Miljkovic, 1999; Miljkovic and Rodney, 2001). They claim that integrated markets might not be cointegrated if transport costs (as well as other costs not explicitly included in the LOP equation) are nonstationary; Second, when supply and demand shocks are cointegrated across markets that are spatially separated, price series might display cointegrated relationship even though markets are not integrated with the absence of trade flow; And third, a constant long-run margin between markets could be

\footnotetext{
${ }^{12}$ See equation (5) in Dawson and Dey (2002), they include a dummy $D$ as a vector of other deterministic components, such as seasonality and outliers. Nielsen (2005) includes a trend $t$ and a dummy $D$ in equation (4).
} 
caused by the monopolist and other sources of inefficiencies (Dercon and van Campenhout, 1999).

\subsection{Parity bounds model}

The above analysis based on prices tells us little or nothing about the actual role played by trade costs and trade behavior. Indeed, under some commonly occurring conditions (such as when trade is discontinuous), they prove untrustworthy. As showed in Figure 2, if a shock happened in market $\mathrm{B}$, trade flows will be affected. Distortions in arbitrage (such as policy intervention, unpredicted outbreak) may trigger non-linearities; bidirectional or reversed trade direction when $\mathrm{P}_{\mathrm{t}}^{\mathrm{B}}<\mathrm{P}_{\mathrm{t}}^{\mathrm{A}}$, trade direction changes from $\mathrm{A}$ to $\mathrm{B}$ to $\mathrm{B}$ to $\mathrm{A}^{13}$, or trade costs are nonstationary (Barrett and Li, 2002). At these break points, the slope of the relation between prices is zero ( $\beta_{1}$ in equation (3)), whereas at other times it is roughly one. The greater the trade costs between markets, the more suspect the findings of linear cointegration regressions. Omission of trade costs would lead to estimated $\beta_{1}$ biased toward zero (Kinnucan and Zhang, 2015).

Figure 2: Graphical Depiction of Trade between A and B

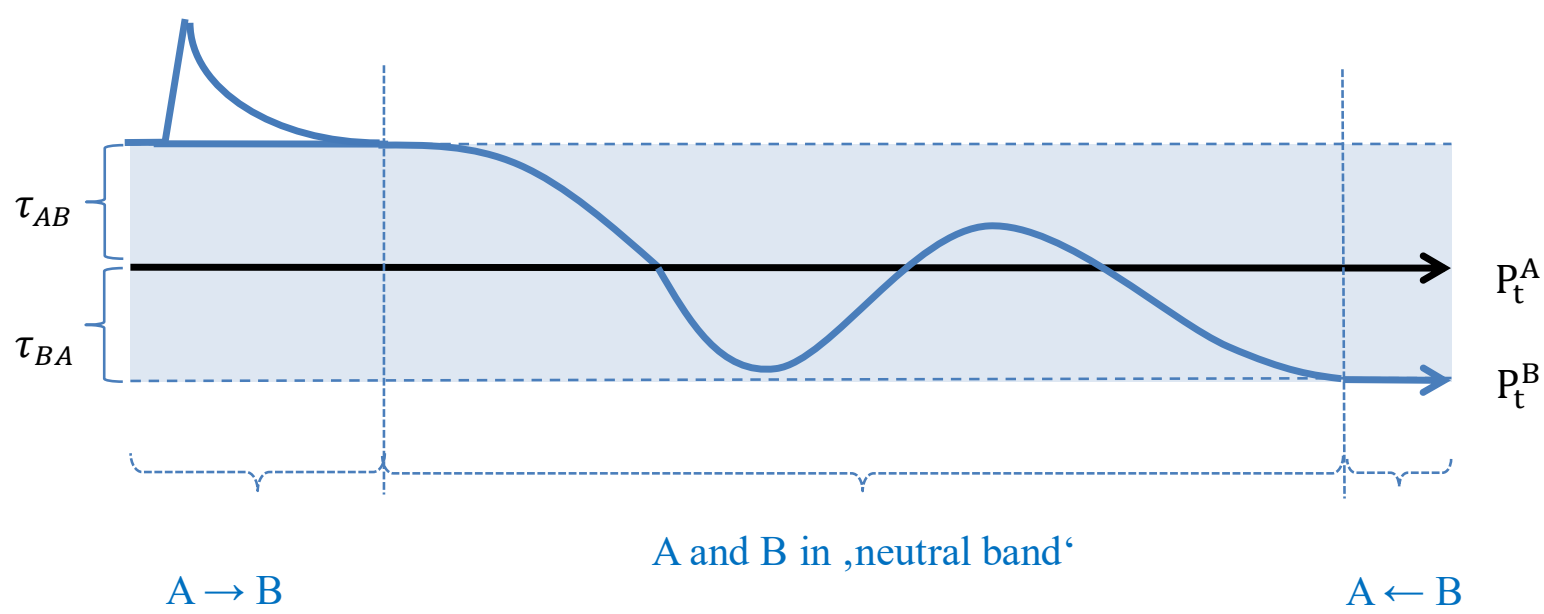

Source: own expression based on von Cramon-Taubadel's (2019) lecture notes.

If time-series data were accessible on trade costs and trade flows in addition to nominal commodity prices, issues from conventional tests could be precluded (Baulch, 1997b). Parity bounds model (PBM, also called switching regime models) provides estimates determined based on this information. The extent of spatial price efficiency could be measured by how

\footnotetext{
${ }^{13}$ If there is a new equilibrium where commodity is traded from B to A instead A to B, there has no work being done to test if the LOP still holds in this case, or when trade is bidirectional both from A to B and from B to A, then the work for testing the LOP could be more complicated.
} 
often violations of the LOP occur by introducing trade costs for the same commodity trade between different locations continuously. The efficiency of spatial arbitrage can be tested by repetitively calculating whether trade takes place whenever price differences between two markets were no less than trade costs if accurate information on trade costs at each time point is available (Baulch, 1997b).

PBM was proposed first by Spiller and Huang (1986), then carried forward by Sexton et al. (1991), Baulch (1997b), and others by combining stochastic frontier and switching regression models. Sexton et al. (1991) extend Spiller and Huang's (1986) model and define three regimes: (a) efficient arbitrage (i.e., the LOP, Regime 1), (b) relative glut (Regime 2), and (c) relative shortage (Regime 3) that exhaust the possible arbitrage conditions between the producing location and any ending market in an application of U.S. celery. They find the probability of binding arbitrage does increase substantially with the adoption of lags related to the physical trade of the commodity from California to faraway markets. Baulch (1997b) estimates PBM to compare observed price differences against exogenously predicted crossmarket transport costs, thereby estimates the three probabilities for three regimes that - rents to arbitrage are zero (regime 1), positive (regime 2), or negative (regime 3) with of $\lambda_{1}^{\prime}$, $\lambda_{2}^{\prime}, 1-\lambda_{1}^{\prime}-\lambda_{2}^{\prime}$ separately as shown in Table $1 ; \tau_{t}^{B A}$ is the trade costs from $A$ to $B$ at time $t$. The LOP holds when efficient arbitrage occurs between two markets, the price difference is equal to the trade cost (rents to arbitrage are zero) with the probability of $\lambda_{1}^{\prime}$ in regime 1.

Table 1. Description of three regimes

\begin{tabular}{cccc}
\hline$R_{t}^{B A}$ & $P_{t}^{B}-P_{t}^{A}-\tau_{t}^{B A}$ & $P_{t}^{B}-P_{t}^{A}-\tau_{t}^{B A}$ & $P_{t}^{B}-P_{t}^{A}-\tau_{t}^{B A}$ \\
& $=0$ & $>0$ & $<0$ \\
\hline Continuous trade & $\lambda_{1}^{\prime}$ (Regime 1) & $\lambda_{2}^{\prime}$ (Regime 2) & $1-\lambda_{1}^{\prime}-\lambda_{2}^{\prime}$ (Regime 3) \\
\hline
\end{tabular}
Note: $P_{t}^{A}=$ Price in A market, $P_{t}^{B}=$ Price in B market, $\mathrm{R}=\mathrm{Rent}, \tau=$ Trade Costs . Source: own representation, based on Baulch (1997b).

$\mathrm{Hu}$ and Brorsen (2017) extend Baulch's (1997b) PBM to determine the price efficiency of spatially separated urea markets of New Orleans-Middle East. Park et al. (2002) estimate a PBM of interregional grain (maize and rice) trade for four sub-periods (1988-89, 1990-91, 1992-93, and 1994-95) to characterize how multiple aspects (arbitrage, trade costs, autarky rate) of market performance change during their research period which is exactly the years with economic transition in China. 
However, the regime models in some studies (Sexton et al., 1991; Hu and Brorsen, 2017) still rely on prices, Baulch (1997b) and Park et al. (2002) add information on trade costs. They fail to disentangle equilibrium and integration. Price differentials no more than trade costs are defined as "integration" even when no flows of a commodity or no transmission of price shocks occur between two markets. Conversely, markets are classified as "segmented" whenever price differentials are larger than trade costs, despite whether there are observed trade flows (Barrett and $\mathrm{Li}, 2002$ ). Trade flow data convey additional information about market integration beyond that offered by observable price and trade cost data (Barrett and $\mathrm{Li}$, 2002). Barrett and $\mathrm{Li}$ (2002) augment the switching regime models by estimating a mixture distribution model with a combination of price, trade cost, and physical trade flow data based on maximum likelihood and a corroborating nonparametric test. So they distinguish between market integration and competitive market equilibrium by defining six regimes instead of three under trade and no trade situations.

Table 2. Description of six regimes

\begin{tabular}{cccc}
\hline$R_{t}^{B A}$ & $P_{t}^{B}-P_{t}^{A}-\tau_{t}^{B A}$ & $P_{t}^{B}-P_{t}^{A}-\tau_{t}^{B A}$ & $P_{t}^{B}-P_{t}^{A}-\tau_{t}^{B A}$ \\
& $=0$ & $>0$ & $<0$ \\
\hline Trade & $\lambda_{1}$ (Regime 1) & $\lambda_{3}$ (Regime 2) & $\lambda_{5}$ (Regime 3) \\
No trade & $\lambda_{2}$ (Regime 4) & $\lambda_{4}$ (Regime 5) & $\lambda_{6}$ (Regime 6)
\end{tabular}

Source: own representation, based on Barrett and Li (2002).

Two categories of trade $\operatorname{costs} \tau_{t}^{B A}$ and three categories of spatial arbitrage $R_{t}^{B A}$ (zero, positive, or negative) yield six regimes defining four possible market conditions: ${ }^{14}$

- Perfect integration (regime 1 and 2 with the probability of $\lambda_{1}+\lambda_{2}$ );

- Segmented equilibrium (regime 6 with the probability of $\lambda_{6}$ );

- Imperfect integration (regime 3 and 5 with the probability of $\lambda_{3}+\lambda_{5}$ );

- Segmented disequilibrium (regime 4 with the probability of $\lambda_{4}$ ).

\footnotetext{
${ }^{14}$ i) In Regime 1 and 2, trade takes place and opportunities for spatial arbitrage are exhausted, the markets are integrated and in spatial equilibrium; ii) in Regime 6, returns to spatial arbitrage are negative and, thus, no trade takes place, the markets are in spatial equilibrium but not integrated; iii) In Regime 3 and 5, trade takes place but does not exhaust opportunities for spatial arbitrage, the markets are integrated but not in spatial equilibrium; and iv) In regime 4, trade does not take place despite the fact that there are opportunities for spatial arbitrage, the markets are neither integrated nor in spatial equilibrium.
} 
Following Barrett and Li (2002), Hillen (2019) estimates an extended PBM by using detailed, transaction-based data on trade flows and trade costs of Italian and Swiss tomato markets. She finds that though seasonal tariff rate quotas lead to inefficiencies and create rents for importers, they are effective in the protection of domestic tomato production against competing for tomota imports.

PBM is expressive but seems to take an extremely stringent view of the LOP. PBM assumes successive trade flows and focuses on either veiled direction of trade flows or, holding the direction constant of trade flows, the sign, and magnitude of summed transactions costs and arbitrage profits, but not actual trade flow patterns (Sexton et al., 1991; Baulch, 1997b; Hu and Brorsen, 2017). An interesting example is given by von Cramon-Taubadel and Goodwin (2021), a discernable commodity flow between two vendors offering a fresh product for sale in the same farmers' market is unlikely to be observed, even though these traders are part of a well-integrated market.

Three limitations of the PBM are drawn by Baulch (1997b): (a) PBM is not dynamic, i.e. only offer static comparisons between prices because only contemporaneous spreads are used. Lagged price adjustments presumed by the Granger causality and Ravallion's (1986) model are hard to be considered fully in PBM; (b) Inaccurate transactions costs would lead to a wide transaction costs band or problems with the convergence of the maximum likelihood procedure; (c) Reasons of the violations of the spatial arbitrage conditions are not clear even they indicate the lack of market integration. Policy implications could be misleading if follow directly from the results of PBM.

\section{Empirical evidence from the LOP tests}

\subsection{Evidence from previous literature}

The conclusion of the empirical evidence from the LOP test results is elusive. The above tests are interpreted as tests that are conditional on assumptions regarding trade linkages but not so much as tests of equilibrium conditions. For example, Dawson and Dey (2002) conclude the LOP holds between prices that are cointegrated and the spatial market integration is perfect so that a price change in one market is a response in all other markets. But most conclusions drawn after testing are neither clear nor consistent to different extents expressing the LOP 
- fails - "the LOP fails uniformly, perfect commodity arbitrage is rejected" (Richardson, 1978); "the LOP, fails, as a long-run relationship, and that deviations from the longrun pattern are not temporary but permanent" (Ardeni, 1989).

- $\quad$ is in force, are nearly perfect substitutes for each other (Nielsen, 2005).

- conditionally fails or holds in an ambiguous statement - "weak evidence for a longrun international market" (Gordon and Hannesson, 1996); or "cannot be rejected as a maintained hypothesis in most cases" (Baffes, 1991); "appears valid in about half combinations considered" (Zanias, 1993); "performs poorly, if trade costs exist and trade does not occur in every period" (Baulch,1997b).

- holds - fail to be rejected" (Goodwin, 1990) or "appears quite strong” (Officer, 1986; Goodwin et al., 1990a, 1990b); "holds for international markets" (Asche et al., 1999; Dragan, 1999); “is in support under integration” (Asche et al., 2004; Vinuya, 2007);

There is mixed empirical evidence using the same dataset but different model specification. For example, comparing the study of Ardeni (1989) to Baffes (1991), the former one finds the LOP holds at least in the long run while the latter one finds that the LOP indeed holds for markets considered. Asche et al. (2004) find that even one cointegration vector exists, the prices could still not follow the LOP with a rejection of the hypothesis at either $1 \%$ or $5 \%$ significant levels.

Since the procedure of PBM for testing the LOP is different from the procedures by using causality (static or dynamic or both) or cointegration models, the interpretation of the results is also different,

- "Nearly all cases departed from the efficient arbitrage condition with significant probability" (Sexton et al., 1991). Constant perfect market integration with $100 \%$ probability $\left(\lambda_{1}+\lambda_{2}=1\right)$ never happens;

- The LOP holds in a certain time - "the LOP does not hold $23 \%$ of the time" (Hu and Brorsen, 2017); Exporters in North America make positive marginal arbitrage profits 30 to $37 \%$ of the time into Japan (Barrett and Li, 2002);

- Rice markets in the Philippines are integrated almost $100 \%$ of the time within a single period (Baulch, 1997b).

There is also mixed expression using the same model specification (e.g. switching regime model). Sexton et al. (1991) interpret the LOP holds with the probability of $\lambda_{1}^{\prime}$ and does not 
hold with the probability of $1-\lambda_{1}^{\prime}$, Baulch (1997b) and Hu and Brorsen (2017) interpret the probabilities summed of regime 1 up with regime $2,\left(\lambda_{1}^{\prime}+\lambda_{2}^{\prime}\right)$ as the probability of market integration and the LOP and the probability of $1-\lambda_{1}^{\prime}-\lambda_{2}^{\prime}$ as not holding, that is why Sexton et al. (1991) conclude almost all cases significantly departed from the efficient arbitrage condition, because $\lambda_{1}^{\prime}$ is quite small if we make this condition so strict with only equaling the transport costs.

We could see previous research using different test procedures interpret their results differently, and different conclusions are sometimes drawn from the same dataset depending on the empirical methods used. Although differences in the data and methodologies employed accord one work not straightforward comparable to another, what brings about is a fuzzy image in which evidence and expressions are not clear.

\subsection{More about the LOP}

Instead of testing the LOP, a theoretical benchmark is driven for the strong version of the LOP in this section and will be applied in Chapters III and IV.

If arbitrage condition holds with price differences being trade costs between market $A$ and $B$ where equation (1) is taken with an equality sign, the spatial equilibrium condition can be written as

$$
P_{t}^{A}=P_{t}^{B}+\tau_{A B}
$$

The elasticity of price transmission between two markets that satisfy this condition, $\eta_{A B}^{P T}$, is defined as

$$
\eta_{A B}^{P T}=\frac{\partial P_{t}^{B}}{\partial P_{t}^{A}} \cdot \frac{P_{t}^{A}}{P_{t}^{B}}=1-\frac{\tau_{A B}}{P_{t}^{A}}
$$

The higher the trade costs $\tau_{A B}$, the lower the elasticity of price transmission between them. Assume that commodity trade costs are a function of the distance between two markets:

$$
\tau_{A B}=f\left(d_{A B}\right)
$$

$\tau_{A B}$ is an increasing function of the distance between $A$ and $B$. Where $d_{A B}$ is the distance between markets $A$ and $B$, and with $\frac{\partial f\left(d_{A B}\right)}{\partial d_{A B}}>0$. 
Combining equations (14) and (15), we expect that the elasticity of price transmission between two markets is a decreasing function of the distance between them. Hence, we expect that estimated elasticity of price transmission in empirical work $\left(\beta_{1}\right.$ in equation (3)) which is an estimate of the elasticity $\eta_{A B}^{P T}$, will be a decreasing function of the distance between markets $A$ and $B, \frac{\partial\left(\eta_{A B}^{P T}\right)}{\partial d_{A B}}<0$.

Moving commodities in space can be viewed as a special case of the processing that takes place in Gardner's (1975) model, in which a commodity at an export market $B$ is 'processed' into a product at an import market $A$ by combining it in fixed proportions with a transportation input. ${ }^{15}$

$$
S_{A}=1-\frac{\tau_{A B}}{\tau_{A B}+P_{t}^{B}}
$$

In this case, the elasticity of input substitution between the export commodity (on market $B$ ) and the transportation input equals 0 , the supply of the transportation input will typically be price elastic, and the cost-share of the transportation input in the price of the product at the import location $A$ will typically be low. Under these conditions, the elasticity of price transmission will tend towards the cost share of the commodity in the export location $B$ in the price of the product in the import location $A$.

The benchmark of estimated elasticity of price transmission as a function of $d_{A B}$, which is regarded as a "theoretical benchmark", defines for any given $d_{A B}$ the maximum elasticity of price transmission, and thus the minimum value of $\tau_{A B}$ that can be attained.

\section{Additional issues: the role of transport costs and trade flow}

Trade costs are most often mentioned by economists for the inconsistent LOP testing results. Most of the above studies state that violations of the strong form of the LOP may indicate an existence of transactions costs or lack of a stable trade relationship (or both). Unfortunately, it is universally admitted that time-series data on trade costs (an obvious component is transport costs) are unusually available to economists and, even when they are, such data are rarely of the same periodicity as the agricultural commodity price data which are available with high frequency (Baulch, 1997b).

\footnotetext{
${ }^{15} S_{\mathrm{a}}$ in Gardner's (1975, p. 404) notation, $E_{P_{B} \bar{P}_{A}}=\frac{S_{A}\left(\sigma+e_{t}\right)}{e_{t}+S_{A} \sigma-S_{\tau} \eta}$, see also Kinnucan and Zhang (2015).
} 
In the body of tests, no transport costs are involved at all in the very early causality models (Isard, 1977; Ravallion, 1986; Officer, 1986; Jabara and Schwartz, 1987; Giovannini, 1988) to currently popular cointegration models (Ardeni, 1989; Asche et al., 1999; Asche et al., 2004; Nielsen, 2005; Vinuya, 2007). Dragen and Paul (2001) argue that a study like Asche et al. (1999) does not analyze market integration but rather conduct a study on market efficiency using price data alone with no trade costs and trade flow data involved. Generally such study will not draw a force-fitting inference of the LOP. So studies that employ empirical techniques such as cointegration could not confirm or disconfirm the LOP (McNew and Fackler, 1997; Dragen, 1999; Dragen and Paul, 2001).

In some studies, trade costs are estimated based on inter-market price differentials (Faminow and Benson, 1990), treated as a proportion of commodity price (Ravallion, 1986; Goodwin, 1990), or interpreted as the estimated constant (Asche et al., 2004). Per-unit transportation charge, freight rates are got attention as a direct measure of transport in some studies costs (e.g., Goodwin et al., 1990a, 1990b). Ravallion (1986) and Dawson and Dey (2002) get consistent results by focusing on rice markets in Bangladesh but for different periods (Richardson (1978), from 1972 to 1975; Dawson and Dey (2002), from 1992 to 1997). Ravallion (1986) finds the average price differentials accord roughly with distances, and Dawson and Dey (2002) show that transport costs vary with geographic distance directly. While Baffes (1991) does find the freight rates are stationary and cointegrated with price differences on testing the LOP for seven commodities among four countries. Goodwin et al. (1990b) employ nonparametric tests (Frenkel and Levich, 1975) that incorporate estimating the band of transactions costs and provide additional evidence demonstrating the LOP in an expectations-augmented version of the LOP. Given the importance of oil prices (e.g., diesel fuel, petrol) as a component of transport costs, Dillon and Barrett (2015) present that worldwide fuel prices do have considerable effects on maize prices mainly through transport costs rather than prices of maize themselves.

Another issue is about trade flow and the direction change of trade flow: estimating price relationships with data (often wholesale and retail prices) that are assumed in one-direction trade, and evidence of co-movement and dynamic interactions are often found. But, as pointed out by von Cramon-Taubadel and Goodwin (2021), the relationship between dynamic interplays and the underlying arbitrage conditions at the specific transaction level are 
complex. ${ }^{16}$ The existed literature has been to take no notice of this issue and only concerns the price of an exported market to the price of one of the imported markets.

\section{Concluding remarks}

As conveyed in the quote by Marshall (1890) at the beginning of this chapter, and concluded by von Cramon-Taubadel and Goodwin (2021) by quoting "In a single market, all of these price structures are interrelated and simultaneously determined through transfer costs..." (Bressler and King, 1970), yes, the LOP lives well in the spatial sense. Increasingly complicated econometric techniques have been developed for testing the LOP covering a diverse set of commodities since the 1970s, from causality tests with static models for price levels to dynamic models for price lag levels since the 1980s by considering that the price adjustment could take time.

The LOP has probably been more thoroughly violated by empirical evidence than any other economic law (Williamson, 1986; Miljkovic, 1999). It is often violated, as its assumptions are extremely strict. With most cases characterized by heterogeneous commodities, a low competition degree, complicated trade-in space and time, and (often) highly policy regulations, its empirical expression remains controversial. The market should be explicitly understood when any interpretations are given in the question.

The LOP has little meaning if we effectively assume that it always holds, and any empirical violations are caused by using the wrong empirical test, or missing data. We could assume the more perfect a market is, the more adherence to the LOP for all parts of the market at the same time. So if we regard the LOP as an equilibrium condition, then what we could focus on is how far or how large the deviation from the LOP is for the same commodity in specific markets, rather than just conclude it holds or not, or directly conclude it is a "failure" or is elusively stated after implementing the intuitively appealing testing procedure.

Even when a value closes one is found, temporary deviations from the LOP arise, which we ascribe to transport costs and other impediments to arbitrage in the short-run (Protopapadakis

\footnotetext{
${ }^{16}$ As one simple case with one shock happening, the price relationship changes from $P_{t}^{A}>P_{t}^{B}$ to $P_{t}^{A}<P_{t}^{B}$, redirecting the trade flow from A to B to B to A as showed in Figure 2.
} 
and Stoll, 1983). ${ }^{17}$ A fundamental tendency of the LOP would hold in the long run despite the existence of short-run deviations.

The mechanisms that govern price transmission and its economic impacts could be understood thoroughly with more available new data which are the spark for new methods (Lloyd, 2017). If we had data on every price and cost that is relevant, at some sufficiently high observation frequency we should be able to see that the LOP is violated. If we observe frequently enough, we should sometimes see shocks disturb the equilibrium, even if it is only for a brief moment.

To bridge the gap, advanced procedures should be proposed to benchmark the LOP as a reference in the model. In part of this research, by conducting cointegration analysis coupled with stochastic frontier models, an explicit attempt would be made at benchmarking the strong version of the LOP. The main innovation is that we explicitly account for the effects of distance and transport costs on the expected elasticity of price transmission. The result is of particular importance because it makes the LOP a benchmark and it directs the level of deviations from the LOP rather than assume its existence before the price to be used is selected. The results also give us additional evidence regarding the direct link between distances (transport costs) and the LOP and the elasticity of price transmission in the long run.

\footnotetext{
${ }^{17}$ Note value one. For international trade analysis, it is the estimated coefficient of exchange rate, see for example (Protopapadakis and Stoll (1983, p.1435). For commodities at the same currency, it is the estimated elasticity of price transmission between markets (e.g. $\beta_{1}$ in equation (3)).
} 


\section{Appendix of Chapter II}

\section{Table A.1: Summary of some typical literature about the Law of One Price}

\begin{tabular}{|c|c|c|c|}
\hline Authors & Location Product & Method of analysis & Conclusion \\
\hline Isard (1977) & International & Correlation & Closely substantial and persistent effects \\
\hline Richardson (1978) & US/Canada AC & Causality-Static & Fails uniformly \\
\hline Ravallion (1986) & Bangladesh Rice & Causality-Dynamic & $\begin{array}{l}\text { Significant departures from short- and long- } \\
\text { run }\end{array}$ \\
\hline Liliane and Michel (1981) & $\mathrm{AC}$ & Causality-Static & Holds for primary products \\
\hline Protopapadakis and Stoll (1983) & International AC & Causality- Static & Holds for most commodities \\
\hline Officer (1986) & International ( 22 countries) & Nonlinear & Received strong support \\
\hline Protopapadakis and Stoll (1986) & International AC & Causality-Dynamic & Holds in the long-run, not in the short-run \\
\hline Jabara and Schwartz (1987) & Japan/US AC & Causality-Static & Significant deviations in some instances \\
\hline Smith (1988) & $\begin{array}{l}\text { US/Canada/Australia/Argentina } \\
\text { AC }\end{array}$ & Causality-Static & Does hold, to an approximation \\
\hline Giovannini (1988) & Japan Domestic and export & Causality-Static & \\
\hline Ardeni (1989) & International* & Engle and Granger & As a long-run relationship, fails \\
\hline Faminow and Benson (1990) & Canada Hogs & Causality-Dynamic & The pricing system disintegrated \\
\hline Goodwin (1990) & International Natural rubber & REM & Fail to reject the LOP \\
\hline
\end{tabular}




\begin{tabular}{|c|c|c|c|}
\hline Goodwin et al. (1990a) & US/Rotterdam $17 \mathrm{AC}$ & REM & Stronger support for the LOP \\
\hline Goodwin et al. (1990b) & US/Rotterdam 17 AC & REM+Nonparametric & The LOP appears quite strong \\
\hline Baffes (1991) & International* & Engle and Granger & In most cases, cannot be rejected \\
\hline Sexton et al. (1991) & US Celery & PBM & $\begin{array}{l}\text { Nearly all cases departed with a significant } \\
\text { probability }\end{array}$ \\
\hline Goodwin (1992) & International wheat & Multivariate Johansen & Adjusted for freight rates, is fully supported \\
\hline Zanias (1993) & European Community AC & Engle and Granger & $\begin{array}{l}\text { appears valid in half the combinations } \\
\text { considered }\end{array}$ \\
\hline Gordon and Hannesson (1996) & European and US Cod Fish & EG + Johansen & Weak evidence \\
\hline Baulch (1997b) & Philippines Rice & PBM & Violations of the spatial arbitrage \\
\hline Baulch (1997a) & - & Review & \\
\hline Asche et al. (1999) & International Salmon & Johansen (1988) & The LOP holds for an international \\
\hline Dragan (1999) & - & Review & \\
\hline Fackler and Goodwin (2001) & - & Review & \\
\hline Dawson and Dey(2002) & Bangladesh rice & Johansen (1988) & Rice markets are perfectly integrated \\
\hline Park et al. (2002) & China's grain markets & PBM & $\begin{array}{l}\text { The extent of market integration varies over } \\
\text { the years }\end{array}$ \\
\hline Asche et al. (2004) & France Whitefish & Johansen + LOP & Well-integrated, the LOP holds \\
\hline Conforti (2004) & $\mathrm{AC}$ & & \\
\hline
\end{tabular}




\begin{tabular}{llll}
\hline Nielsen (2005) & European Whitefish & Johansen + LOP & Rejected \\
Rapsomanikis et al (2006) & Food and cash crop markets & Review + case studies & An ambiguous concept \\
Vinuya (2007) & International Shrimp & Johansen + LOP & Integrated, in support of the LOP \\
$\begin{array}{l}\text { Emmanouilides and Fousekis (2012) } \\
\text { Dillon and Barrett (2015) }\end{array}$ & EU pork & Strong + weak & Valid for all market pairs \\
$\begin{array}{l}\text { Hu and Brorsen (2017) } \\
\text { von Cramon-Taubadel and Goodwin } \\
(2021)\end{array}$ & Maize in east Africa & Engle and Granger & The LOP does not hold across the border \\
\end{tabular}

Note: AC-agricultural commodities; REM-rational expectation models; EG-Engle and Granger. 


\title{
III Estimating Dynamic Market Efficiency Frontiers
}

Authors: Yali Mu and Stephan von Cramon-Taubadel

\begin{abstract}
Past studies have used standard regression techniques to explain variation in estimated measures of the strength and speed of price transmission. We propose an alternative method for benchmarking the magnitude and speed of restoring market efficiency that combines cointegration analysis coupled with frontier estimation methods. The use of frontier methods provides a convenient way of accounting for sampling error in estimated measures of price transmission. We illustrate the proposed method using price data from 30 provincial pork markets in China from 2000 to 2017. As expected, the frontier magnitude and speed of restoring market efficiency both fall with increasing distance between two markets. We find significant province effects in the magnitude of market efficiency. Provinces located farther to the south and west display lower levels of market efficiencies than those located in the northeast and central regions of China.
\end{abstract}

Keywords: Spatial price transmission, market efficiency, VECM, stochastic frontier benchmark

\section{Introduction}

A vast literature on spatial price transmission for agricultural commodities has accumulated over the last six decades. Harriss (1979) cites dozens of studies from the 1960s and 1970s based on the analysis of correlation coefficients between prices. Ardeni (1989) was the first in agricultural economics to use the cointegration methods that dominate the literature today. Cointegration methods, specifically error correction models (ECMs), make it possible to simultaneously estimate both the long-run equilibrium relationship between prices at different locations and the error correction mechanism that restores this equilibrium relationship whenever it is disturbed by shocks. Over time, increasingly sophisticated ECMs have been used to account for different types of non-linearity or regime dependence in price transmission. These include asymmetric ECMs (von Cramon-Taubadel, 1998); ECMs that include threshold effects in long-run equilibrium relationships (threshold cointegration - 
Gonzalo and Pitarakis, 2006) as well as in error correction (threshold autoregression Abdulai, 2000; threshold ECMs - Goodwin and Piggott, 2001; Greb et al., 2013); nonparametric ECMs (Serra et al., 2006; Guney et al. 2019); Markov-switching ECMs (Brümmer et al., 2009); and other forms of ECM with time-varying error correction (such as state space models - Adämmer and Bohl, 2015, 2018; Vollmer et al. 2020). All of these methods are motivated by efforts to account for the fact that the relationship between two prices in space will not necessarily be constant over time due to phenomena such as changes in trade costs, policies and the direction of trade (von Cramon-Taubadel and Goodwin, 2021). Cointegration methods can produce misleading results if one fails to account for these sources of nonlinearity in equilibrium relationships between prices (Barrett, 1996; McNew, 1996; McNew and Fackler, 1997).

Ultimately, researchers who employ these methods aim to draw conclusions about market integration and efficiency. As Barrett (2001) points out, economists typically define integration in terms of the Law of One Price (LOP); if the LOP holds between two markets, then they are integrated, and vice versa. However, this definition is not intuitively appealing to non-economists, who typically define integration in terms of trade; if trade takes place between two markets, then they are integrated, and vice versa. To improve communication between researchers and public and private decision makers, and to heighten researchers' awareness of the important assumptions that underlie price transmission and market integration analysis, Barrett (2001, p. 20) therefore argues that economists should distinguish "between flow-based notions of integration and price-based notions of efficiency based on economic concepts of equilibrium" such as the LOP. Drawing on spatial equilibrium theory (Enke, 1951; Samuelson, 1952; Takayama and Judge, 1972), Barrett and Li (2002) identify four combinations of integration and equilibrium that can hold between two markets:

I. Perfect integration, in which trade takes place and opportunities for spatial arbitrage are exhausted - in this case the markets are integrated and in spatial equilibrium;

II. $\quad$ Segmented equilibrium, in which returns to spatial arbitrage are negative and, thus, no trade takes place - in this case the markets are not integrated but nevertheless in spatial equilibrium;

III. Imperfect integration, in which trade takes place but does not exhaust opportunities for spatial arbitrage - in this case the markets are integrated but not in spatial equilibrium; and

IV. $\quad$ Segmented disequilibrium, in which no trade takes place despite opportunities for 
spatial arbitrage- in this case the markets are neither integrated nor in spatial equilibrium.

If, following Barrett (2001), we consider market efficiency to be synonymous with equilibrium, then conditions i) and ii) above are efficient, while conditions iii) and iv) are not. In the former two, there are no unrealized potential Pareto improvements; in the latter two there are.

These conclusions are based on a static concept of efficiency - given a set of demand and supply conditions on two (or more) markets in space, and trade costs between them, they are either in equilibrium and therefore efficient, or not. ${ }^{1}$ Market efficiency, however, also has two additional dynamic dimensions. First, trade costs vary over time and space due to technology (e.g. the introduction of refrigeration; Goodwin et al., 2002), infrastructure (e.g. improved road and rail systems; Donaldson, 2018; Zant, 2018) and institutions (e.g. differences in tariff levels or the administrative costs of customs procedures). Consider two otherwise identical pairs of markets: $A$ and $B$, and $C$ and $D$. $A$ and $B$ are connected by a paved highway, $C$ and $D$ by a dirt track. Even if each pair is in spatial equilibrium and can therefore be considered efficient, comparison of the two pairs will reveal that lower trade costs lead to more trade and a higher level of aggregate welfare in $A$ and $B$ than in $C$ and $D$. Hence, we can conclude that $A$ and $B$ are more efficient than $C$ and $D$. Indeed, if trade costs between $C$ and $D$ are prohibitively high, they will be in segmented equilibrium (condition II above), and realise no welfare gains from trade. In the following we refer to this as the relative magnitude of efficiency, and in section 2 below we demonstrate that it can be measured using the long-run elasticity of price transmission between two markets.

Second, since moving agricultural products between markets takes time, trade and prices cannot adjust instantaneously to shocks that disturb equilibrium (Ravallion, 1986). ${ }^{2}$ Furthermore, even where unit trade costs between pairs of markets are identical, differences in technology, infrastructure and institutions might lead to differences in the volumes of trade that can flow between them per unit of time. If it is possible to move twice as many tons of a

\footnotetext{
${ }^{1}$ These conclusions are also based on the assumption that supply and demand on the markets in question accurately reflect preferences and economic costs. If prices on market $A$ follow a speculative bubble, or if they are distorted by the exercise of market power or an externality, then economic efficiency on neighbouring market $B$ will not necessarily be increased by equilibrium with $A ; B$ might be better off in segmented disequilibrium with respect to $A$.

${ }^{2}$ No price adjustment is truly instantaneous, even on financial markets with very rapid trade. However, if an adjustment begins and ends within the interval between observations of the available price data, it will appear instantaneous. This highlights the importance of working with data of sufficient frequency.
} 
product per unit of time between $A$ and $B$ as between $C$ and $D$, all other things being equal, then when both pairs are subjected to a given shock, $A$ and $B$ can be expected to return to equilibrium, and thus efficiency, more rapidly following the shock than $C$ and $D$. In the following we refer to this as the relative speed of restoring efficiency, and in section 2 below measure it using the so-called adjustment parameters from a bivariate vector error correction model (VECM) of the prices on two markets.

These two dimensions of efficiency - the magnitude of the gains from trade that can be realised in equilibrium, and the speed with which equilibrium and thus efficiency is restored following shocks - will typically be interrelated. For example, streamlining customs procedures between two countries can increase per period volumes of trade between them, leading to more rapid restoration of spatial equilibrium following a shock. But it might also reduce trade costs by reducing processing fees and/or the scope for discretionary behavior and the extraction of bribes by customs officials, and thus increase total trade volumes and gains from trade. Similarly, widening a canal can both lower trade costs per ton of product and increase the number of tons that can be shipped per unit time.

Both of these dimensions of efficiency, magnitude and speed, draw attention to the fact that market efficiency is a relative concept. Even if tests enable us to conclude that two markets are in spatial equilibrium and therefore efficient in a static sense ${ }^{3}$, it is only by comparing them with other pairs of markets that we can determine whether there is scope for increasing efficiency by lowering trade costs and/or increasing the rates at which price signals are transmitted between them. Hence, to assess the efficiency of a pair of markets we need benchmarks derived from the observation and analysis of other pairs.

The magnitude and speed dimensions of market efficiency have important implications for policy. If we observe that it takes a certain number of weeks for prices on markets $A$ and $B$ to return to their long-run equilibrium following a shock, but several weeks longer on otherwise identical markets $C$ and $D$, the obvious question is 'why?' Perhaps the roads between $C$ and $D$ are of worse quality than those between $A$ and $B$; perhaps market participants in $A$ and $B$ have access to better market information than participants in $C$ and $D$; perhaps a series of informal checkpoints on the route from $C$ and $D$ is impeding trade flows. If both pairs of markets are separated by international borders, then perhaps $C$ and $D$ are lagging $A$ and $B$ in the

\footnotetext{
${ }^{3}$ Barrett (1996), Fackler and Goodwin (2001) and McNew and Fackler (1997) discuss the many challenges that complicate such tests.
} 
implementation of trade facilitation measures. Each of these causes suggests possible policy responses such as improving roads, establishing market information systems, eliminating informal checkpoints, or facilitating trade. Establishing empirical benchmarks and comparing dynamic market efficiency can help identify sources of impedance, design appropriate policy responses, and predict the benefits that these responses can generate.

Several studies have taken first stabs at benchmarking market efficiency. All employ variations of a two-step procedure. In the first step, measures of the strength or speed of price transmission are estimated using the cointegration methods discussed above. In the second step, regression analysis with these estimates as dependent variables is used to explain variations in the strength or speed of price transmission.

- Kouyaté et al. (2016) estimate ECMs of price transmission between pairs of rice markets in Western Africa in their first step. In their second-step regressions show that distance, common borders and common languages affect the likelihood of finding cointegration between individual pairs.

- Kouyaté and von Cramon-Taubadel (2016) do not estimate own first-step measures of price transmission, but rather extract estimates for 1,189 pairs of cereal market from 57 published studies. In their second-step regressions they find that geographic distance and international borders affect the strength and speed of price transmission.

- Svanidze and Götz (2019a) use ECMs to estimate long-run elasticities of price transmission between wheat markets in Russia, and between corn markets in the US. In the second step of their analysis they compare the effects of factors such as geographic distance between markets, export volumes and production levels on elasticities of price transmission in Russia and the US.

- Svanidze and Götz (2019b) also estimate price transmission parameters for Russian wheat and US corn markets in their first step. They do not carry out a second-step regression analysis, but instead compare boxplots of different estimated parameters for Russian wheat and US corn. They consider the US corn market to be a benchmark that reflects "the maximum level of spatial market efficiency obtainable in an empirical context" and conclude "that the integration of regional grain markets within Russia is relatively low compared to the USA" (Svandize and Götz, 2019b, p. 66).

In this paper we propose a modification to the benchmarking procedure outlined above. Rather than using standard regression techniques in the second step to explain variation in 
estimated measures of the strength and speed of price transmission, we estimate stochastic frontiers. Stochastic frontier methods have two advantages over the approaches employed to date. First, estimating a stochastic frontier establishes a within-sample benchmark for market efficiency against which performance can be measured. Svanidze and Götz's (2019a, 2019b) comparisons of Russian wheat and US corn markets, and Kouyaté and von CramonTaubadel's (2016) meta-analysis of published price transmission coefficients generate interesting insights. However, they are based on comparison of boxplots and standard regression techniques that focus on explaining variation around mean measures of price transmission. Frontier analysis instead identifies the strongest and most rapid examples of price transmission that can be attained in a given setting, and attempts to explain why price transmission between markets is sometimes closer to or farther from this benchmark. In typical applications of stochastic frontier methods, production functions are estimated, and an individual observation's distance from the frontier function is considered to be a measure of its production inefficiency. In our application, the frontier represents the strongest or most rapid price transmission that is attainable between pairs of markets, and an individual market pair's distance from that frontier is considered to be a measure of its market inefficiency.

Second, stochastic frontier methods provide a straightforward and intuitively appealing means of accounting for the fact that the measures of price transmission generated in the first step of the benchmarking procedure are estimates. Because they are estimates, some of the observed variation in these measures is due to sampling error, i.e. the difference between the true value of the parameter in question and the value estimated with the available sample of price data. If this sampling error is not constant across observations, the resulting heteroscedasticity can lead to inefficient estimation and misleading inference in the second step (Lewis and Linzer, 2005). Intuitively, some of the first-step measures of price transmission are estimated more precisely than others and should therefore have a correspondingly greater influence on the results of the second-step of the procedure. Svanidze and Götz (2019a) employ bootstrapping techniques to address this issue; the other studies mentioned above ignore it. The stochastic frontier approach decomposes deviations from the frontier into two components; inefficiency and measurement error. As explained in section 2 below, we incorporate the standard errors of the first-step estimates of the strength and speed of price transmission directly into the measurement error component of our second-step estimation of the market efficiency frontier.

We illustrate our proposed method using monthly data on pork prices on 30 provincial markets in China from 2000 to 2017. In the first step we use standard ECM methods to 
estimate elasticities of price transmission as well as adjustment parameters that measure the speed of transmission between individual markets. In the second step we estimate frontiers for the elasticities and adjustment speeds using stochastic frontier techniques and covariates such as the geographic distance between the markets in question.

The rest of this paper is structured as follows. In section 2 we outline the methods and the data that we use. In sections 3 and 4 we present and discuss results, respectively. Section 5 closes with conclusions and implications for future research.

\section{Methods, specification and data}

\subsection{Methods}

The first step of our procedure is similar to that employed in the earlier studies outlined above (e.g. Svanidze and Götz, 2019a); we use the Johansen (1991; 1995) method to estimate the following bivariate VECM for pairs of pork prices in China:

$\left[\begin{array}{l}\Delta \ln p_{i, t} \\ \Delta \ln p_{j, t}\end{array}\right]=\left[\begin{array}{l}\varphi_{i} \\ \varphi_{j}\end{array}\right]+\left[\begin{array}{l}\alpha_{i} \\ \alpha_{j}\end{array}\right]\left[\ln p_{i, t-1}-\beta_{i j, 0}-\beta_{i j, 1} \ln p_{j, t-1}\right]+\sum_{k=1}^{l}\left[\begin{array}{cc}\delta_{i k} & \rho_{i k} \\ \delta_{j k} & \rho_{j k}\end{array}\right]\left[\begin{array}{l}\Delta \ln p_{i, t-k} \\ \Delta \ln p_{j, t-k}\end{array}\right]+\left[\begin{array}{l}\varepsilon_{i, t} \\ \varepsilon_{j, t}\end{array}\right]$

In equation (1), $i, j=\{1,2, \ldots, 30\}$ index provinces in China. Estimation is carried out for the 435 unique pairs of provinces for which $i>j$. The index $t=\{1,2, \ldots, 216\}$ counts monthly price observations from January 2000 to December 2017. Since both prices are in logarithms, the coefficient $\beta_{i j, 1}$ in the long-run equilibrium relationship

$$
\ln p_{i, t}=\beta_{i j, 0}+\beta_{i j, 1} \ln p_{j, t}+\epsilon_{t}
$$

is an estimate of the elasticity of price transmission from market $j$ to market $i$. We normalise the long-run equilibrium relationship in equation (2) (and thus the error correction term $\left[\ln p_{i, t-1}-\beta_{i j, 0}-\beta_{i j, 1} \ln p_{j, t-1}\right]$ on the RHS of equation (1)) on the higher of the two prices, so that $\beta_{i j, 1}$ is expected to be less than or equal to 1 . The adjustment parameters $\left(\hat{\alpha}_{i}, \hat{\alpha}_{j}\right)$ in equation (1) measure how $\ln p_{i}$ and $\ln p_{j}$ change in period $t$ in response to any disequilibrium $\left(\ln p_{i, t-1}-\beta_{i j, 0}-\beta_{i j, 1} \ln p_{j, t-1} \neq 0\right)$ in the previous period $t-1$. The lag-length $l$ in equation (1) is chosen using the Schwarz Bayesian Information Criteria (SBIC: Lütkepohl, 1985; Lütkepohl 2005, pp. 156-157).

This first-step estimation generates 435 estimates of the elasticity of price transmission $\left(\hat{\beta}_{i j, 1}\right)$ and an equal number of estimated pairs of adjustment parameters $\left(\hat{\alpha}_{i}, \hat{\alpha}_{j}\right)$. As explained in the 
following, we consider the estimated $\hat{\beta}_{i j, 1}$ to be measures of the relative magnitude of market efficiency defined above, and we use the estimated adjustment parameters $\left(\hat{\alpha}_{i}, \hat{\alpha}_{j}\right)$ to measures of the relative speed of restoring market efficiency.

First consider the estimated elasticities of price transmission $\left(\hat{\beta}_{i j, 1}\right)$ and the magnitude of market efficiency. The spatial equilibrium condition can be written as

$$
p_{i}=p_{j}+\tau_{i j}
$$

where $\tau_{i j}$ represents the trade costs from market $j$ to market $i$. The elasticity of price transmission between two markets that satisfy this condition, $\eta_{i j}^{P T}$, is defined as

$$
\eta_{i j}^{P T}=\frac{\partial p_{i}}{\partial p_{j}} * \frac{p_{j}}{p_{i}}=\frac{p_{i}-\tau_{i j}}{p_{i}}=1-\frac{\tau_{i j}}{p_{i}}
$$

which can be interpreted as the cost share of the product in the lower-price location $j$ in the price of the product in the higher-price location $i{ }^{4}$ The higher the trade costs $\tau_{i j}$, the lower the elasticity of price transmission between them. We assume that commodity trade costs are a function of the distance between two markets:

$$
\tau_{i j}=f\left(d_{i j}\right)
$$

where $d_{i j}$ is the distance between markets $i$ and $j$, and with $\frac{\partial f\left(d_{i j}\right)}{\partial d_{i j}}>0$.

Combining equations (4) and (5), we expect that the elasticity of price transmission between two markets is a decreasing function of the distance between them. Hence, we expect that $\hat{\beta}_{i j, 1}$, which is an estimate of the elasticity $\eta_{i j}^{P T}$, will be a decreasing function of the distance between markets $i$ and $j$. The stochastic frontier for $\hat{\beta}_{i j, 1}$ as a function of $d_{i j}$, which we label $\beta_{i j, 1}^{*}$, defines for any given $d_{i j}$ the maximum elasticity of price transmission, and thus the minimum value of $\tau_{i j}$ that can be attained in the setting under consideration (such as pork markets in China). We therefore interpret deviations from the frontier $\beta_{i j, 1}^{*}$ as deviations from

\footnotetext{
${ }^{4}$ Note the analogy to Gardner's (1975) model of vertical price transmission. Moving a product in space can be viewed as a special case of the processing that takes place in Gardner's model, in which a product at an export location is 'processed' into a product at an import location by combining it in fixed proportions with a transportation input. In this case, the elasticity of input substitution between the export product and the transportation input equals 0 , the supply of the transportation input will typically be price elastic, and the cost share of the transportation input in the price of the product at the import location will typically be low. Under these conditions the elasticity of price transmission will tend towards the cost share of the product in the export location in the price of the product in the import location $\left(S_{a}\right.$ in Gardner's notation, see also Kinnucan and Zhang, 2015).
} 
the maximum attainable magnitude of market efficiency. For example, $\hat{\beta}_{i j, 1}$ for a specific pair of markets $i$ and $j$ separated by distance $d_{i j}$ might lie below the frontier $\beta_{i j, 1}^{*}$ at $d_{i j}$ because $\tau_{i j}$ between the two markets is higher than it could be based on the evidence provided by the full set of $\hat{\beta}_{i j, 1}$ for all available market pairs.

Next consider the estimated adjustment parameters $\left(\hat{\alpha}_{i}, \hat{\alpha}_{j}\right)$ and the speed of restoring market efficiency. In equation (1), $\alpha_{i}$ is expected to be less than zero and $\alpha_{j}$ is expected to be greater than zero to ensure error correction, i.e. to ensure that prices tend to return to equilibrium following a shock. We therefore calculate $\hat{\alpha}_{i j}=\hat{\alpha}_{j}-\hat{\alpha}_{i}$ as a measure of the total speed of price transmission between markets $i$ and $j . \hat{\alpha}_{i j}$, which is expected to lie between 0 and 1 , measures the proportion of any disequilibrium that is corrected per period. We assume that the speed of price transmission between two markets is, like the elasticity of price transmission, a decreasing function of the distance between them:

$$
\hat{\alpha}_{i j}=g\left(d_{i j}\right)
$$

with $\frac{\partial g\left(d_{i j}\right)}{\partial d_{i j}}<0$.

The stochastic frontier for $\hat{\alpha}_{i j}$ as a function of $d_{i j}$, which we label $\alpha_{i j}^{*}$, defines for any given $d_{i j}$ the maximum speed of price transmission that can be attained in the setting under consideration, and we interpret deviations from this frontier as deviations from the maximum attainable speed of restoring market efficiency.

In the second step of our procedure we estimate stochastic frontier models for $\hat{\beta}_{i j, 1}$ and $\hat{\alpha}_{i j}$. For the magnitude of market efficiency we estimate

$$
\hat{\beta}_{i j, 1}=X_{k} \gamma+\left(v_{i j}-u_{i j}\right)
$$

where $X_{k}$ is a vector of variables that are expected to influence the magnitude of market efficiency, such as the distance $d_{i j}$ between the markets in question, and $\gamma$ is a vector of parameters to be estimated. Similarly, for the speed of restoring market efficiency we estimate

$$
\hat{\alpha}_{i j}=Y_{k} \delta+\left(\varrho_{i j}-\omega_{i j}\right)
$$

where $Y_{k}$ is a vector of variables that are expected to influence the speed of market efficiency, and $\delta$ is a vector of parameters to be estimated. The two-sided error terms $v_{i j}$ and $\varrho_{i j}$ 


$$
v_{i j} \sim N\left(0, \sigma_{v_{i j}}^{2}\right) \text { and } \varrho_{i j} \sim N\left(0, \sigma_{\varrho_{i j}}^{2}\right)
$$

capture random factors such as measurement error. Since the dependent variables $\hat{\beta}_{i j, 1}$ and $\hat{\alpha}_{i j}$ are estimated, $v_{i j}$ and $\varrho_{i j}$ are heteroscedastic. Failure to account for this will lead to inconsistent estimation of the models in equation (7a) and (7b) and invalid inference (Hadri, 1999). We therefore model this heteroscedasticity as

$$
\sigma_{v_{i j}}^{2}=\exp \left(V_{i j} \zeta\right) \text { and } \sigma_{\varrho_{i j}}^{2}=\exp \left(W_{i j} \xi\right)
$$

In equation (9), $V_{i j}$ and $W_{i j}$ are vectors that include an intercept term and the estimated standard errors $\left(\hat{\sigma}_{\widehat{\beta}_{i j, 1}}\right.$ and $\hat{\sigma}_{\widehat{\alpha}_{i j}}$, respectively) of the estimated $\hat{\beta}_{i j, 1}$ and $\hat{\alpha}_{i j} \cdot \zeta$ and $\xi$ are vectors of parameters to be estimated. While the estimated standard errors $\hat{\sigma}_{\widehat{\beta}_{i j, 1}}$ of the $\hat{\beta}_{i j, 1}$ are a direct by-product of the estimation of the VECM in equation (1) in the first step of our procedure, we need to calculate the estimated standard errors $\hat{\sigma}_{\widehat{\alpha}_{i j}}$ of the $\hat{\alpha}_{i j}$ using: ${ }^{5}$

$$
\hat{\sigma}_{\widehat{\alpha}_{i j}}=\sqrt{\hat{\sigma}_{\widehat{\alpha}_{i}}^{2}+\hat{\sigma}_{\hat{\alpha}_{j}}^{2}-2 \widehat{\operatorname{cov}}\left(\hat{\alpha}_{i}, \hat{\alpha}_{j}\right)}
$$

The one-sided error terms $u_{i j}$ and $\omega_{i j}$

$$
u_{i j} \sim N^{+}\left(0, \sigma_{u}^{2}\right) \text { and } \omega_{i j} \sim N^{+}\left(0, \sigma_{\omega}^{2}\right)
$$

are assumed to be uncorrelated with $v_{i j}$ and $\varrho_{i j}$, respectively. $u_{i j}=0\left(\omega_{i j}=0\right)$ indicates that the market pair $i, j$ attains the frontier magnitude (speed) of market efficiency, and $u_{i j}>0$ $\left(\omega_{i j}>0\right)$ correspondingly measures inefficiency.

\subsection{Specification}

In our empirical application the markets $i$ and $j$ are provinces in China. As mentioned above, we include the distance $d_{i j}$ between markets $i$ and $j$ in the vectors $X_{\mathrm{k}}$ and $Y_{\mathrm{k}}$ in the frontier models (7a) and (7b), respectively. We expect that the frontier magnitude and speed of restoring market efficiency will both fall as $d_{i j}$ increases.

\footnotetext{
${ }^{5}$ Stata command 'estat vce' (Stata, 2020) generates a complete variance-covariance matrix for the estimated parameters of a VECM including the estimate of $\operatorname{cov}\left(\hat{\alpha}_{i}, \hat{\alpha}_{j}\right)$ that is required in equation (10).
} 
In addition, we include a dummy variable $B_{i j}$ that equals 1 if markets $i$ and $j$ share a common border. If borders between provinces in China impede pork trade in any manner, then all other things being equal we would expect higher magnitudes and speeds of market efficiency to be attained between markets that share a common border. Ideally we would also include a variable that measures the volume of pork trade between markets $i$ and $j$ in the frontier models (7a) and (7b). It is conceivable that especially the speed of price transmission between two markets could be a positive function of the volume of trade between them. However, data on intra-Chinese pork trade are not available.

As explained above, we include the estimated standard errors of $\hat{\beta}_{i j, 1}$ and $\hat{\alpha}_{i j}\left(\hat{\sigma}_{\widehat{\beta}_{i j, 1}}\right.$ and $\left.\hat{\sigma}_{\widehat{\alpha}_{i j}}\right)$ in the vectors $V_{i j}$ and $W_{i j}$ to account for heteroscedasticity in the error terms $v_{i j}$ and $\varrho_{i j}$, respectively. We include province dummies in the one-sided inefficiency terms $u_{i j}$ and $\omega_{i j}$ to capture province-specific effects such as differences in the quality of infrastructure or cultural differences (for example, in some provinces a large proportion of the population is Muslim).

\subsection{Data}

We estimate the bivariate VECMs in equation (1) with logarithms of monthly pork prices in Yuan/kg from 30 provinces in China from January 2000 to December 2017 (Ministry of Agriculture of China, 2001-2018). The provincial monthly averages are based on weekly observations monitored by the Ministry of Agriculture of China at hundreds of markets in all provinces of China except Tibet. The price series could be extended up to and including 2020, but the outbreak of African Swine Fever in late 2018 and more recently the Covid-19 pandemic have led to major disruptions on the supply and demand sides of Chinese pork markets that will have affected market integration and would confound our analysis (Ma et al., 2020). Hence, we forego more recent observations to avoid the risk of structural breaks in the price relations that we study. Figure 1 presents several typical pork price series selected from set of 30. We measure $d_{i j}$ as the distance in $1000 \mathrm{~km}$ between province capitals. 
Figure 1 Three typical Chinese pork price series (monthly data from Jan. 2000 to Dec. 2017)

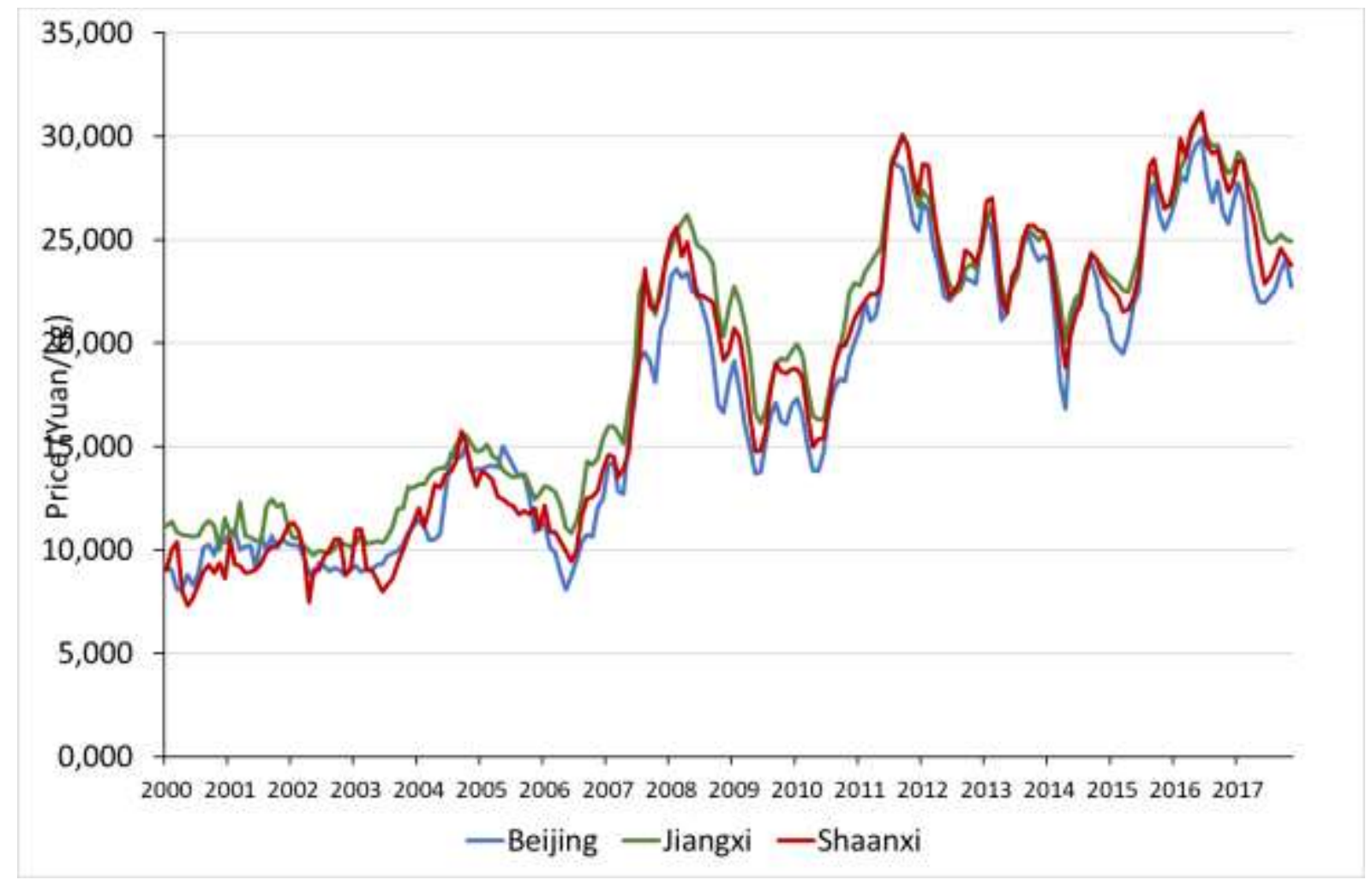

Source: Ministry of Agriculture of China (2001-2018).

\section{Results}

For each of the 30 price series individually the ADF test (Said and Dickey, 1984) fails to reject the null hypothesis that the series is $\mathrm{I}(1)$, but rejects this null hypothesis for first differences of the prices. In addition, the $p$ CADF test, a panel unit root test that combines $\mathrm{p}$ values from covariate ADF tests (Constantini and Lupi, 2013), fails to reject the null hypothesis that all of the series are I(1). Johansen's (1991; 1995) trace test for cointegration indicates that the null of no cointegration is rejected for 423 price pairs at the $1 \%$ level of significance, and for another 11 price pairs at the 5\% level; only in one of the 435 price pairs is the null hypothesis of no cointegration not rejected at conventional levels of significance. ${ }^{6}$

First step: We estimated the 435 bivariate VECMs using Johansen's $(1991,1995)$ maximum likelihood method. In 385 of 435 cases (89\%) the SBIC criterion selects the lag-length $l=2$; in the remaining cases $l=1(3 \%)$ or $l=3(8 \%)$. Figure 2 presents the distribution of the 435 estimated elasticities of long-run price transmission $\left(\hat{\beta}_{i j, 1}\right)$ and descriptive statistics; similarly,

\footnotetext{
${ }^{6}$ Results of the ADF, $p$ CADF and Johansen test are in Appendix.
} 
Figure 3 presents the distribution of the estimated speeds of price transmission $\left(\hat{\alpha}_{i j}\right)$. In Figure 2 we see that more than half of the estimated elasticities of price transmission are greater than 0.9. The results depicted in Figure 3 reveal that the median speed of price transmission is roughly 0.3 , which indicates that for half of the 435 market pairs at least $30 \%$ of any deviation from long-run equilibrium is corrected within one month. For the great majority of market pairs, between 15 and $50 \%$ of any deviation is corrected within one month.

Figure 2: Distribution of the estimated price transmission elasticities $\left(\widehat{\boldsymbol{\beta}}_{i j, 1}\right)$

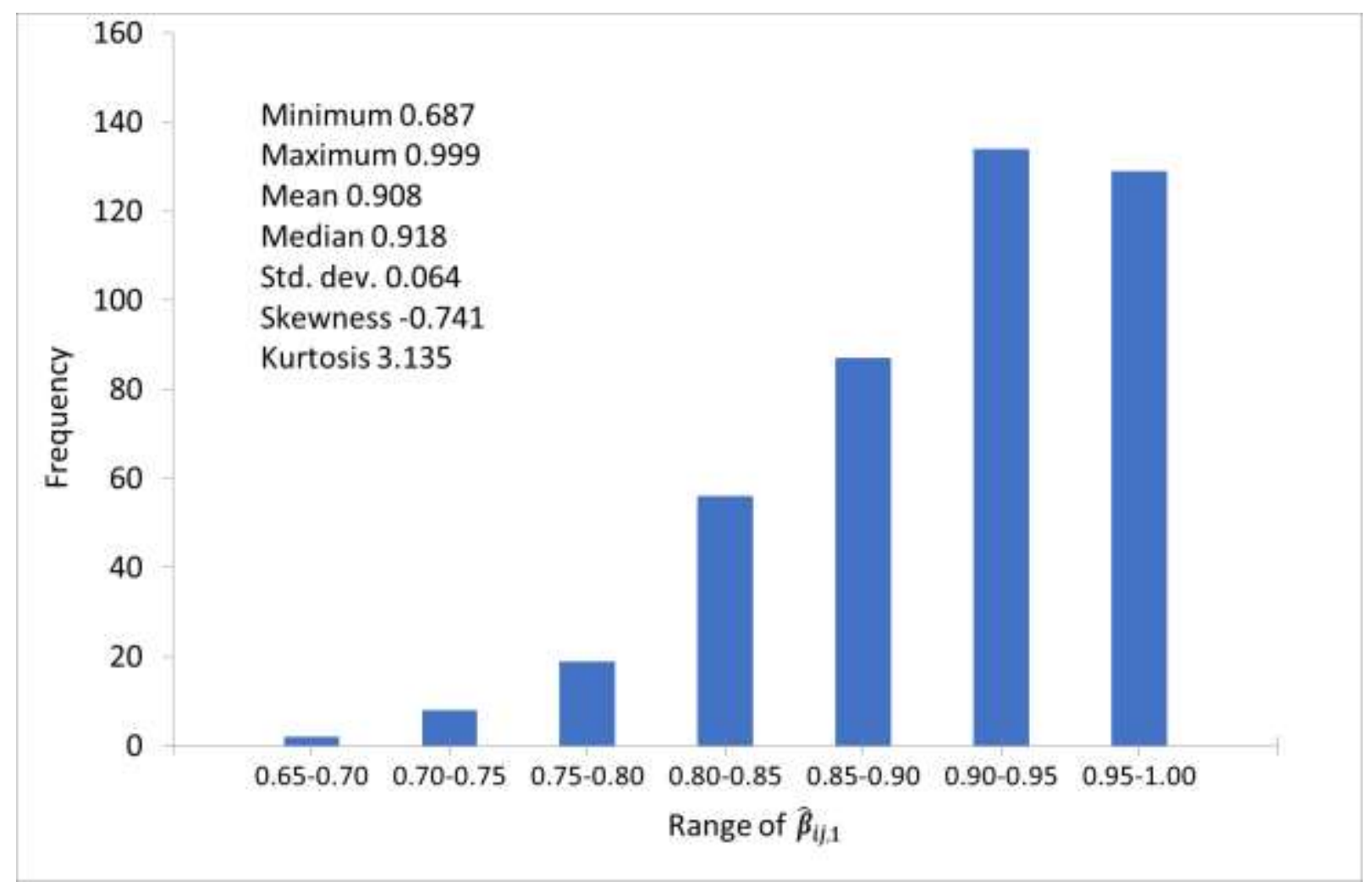

Source: Own calculations using Ministry of Agriculture of China (2001-2018). 
Figure 3: Distribution of the estimated speeds of price transmission $\left(\widehat{\alpha}_{i j}\right)$

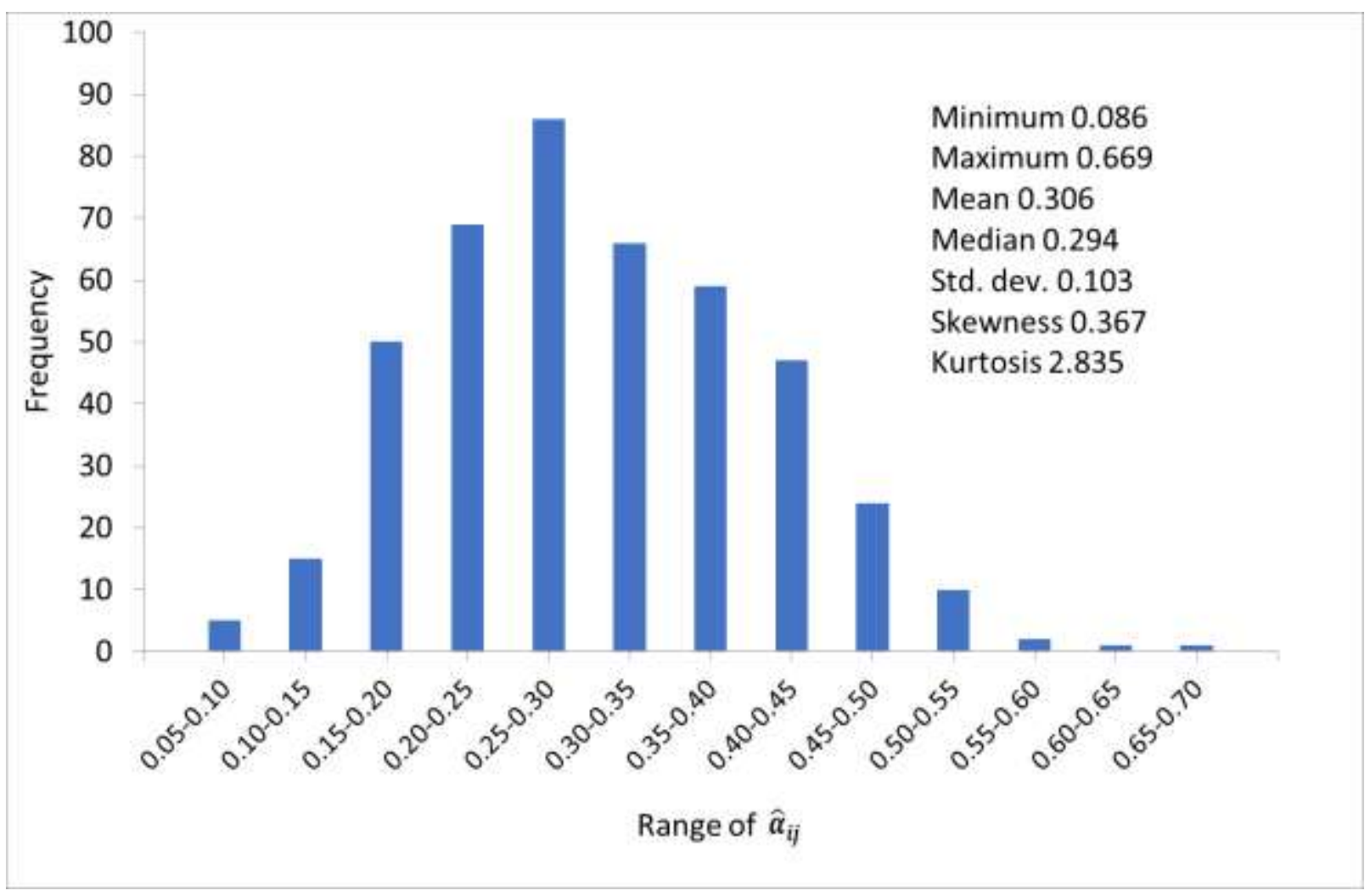

Source: Own calculations using Ministry of Agriculture of China (2001-2018).

Second step: Table 1 presents the estimation results of the frontier model for the magnitude of market efficiency (equation (7a), dependent variable $\hat{\beta}_{i j, 1}$ ). According to these results, the frontier $\hat{\beta}_{i j, 1}$ falls by 0.015 per $1000 \mathrm{~km}$ of distance between two markets. Sharing a common border has unexpected negative but insignificant effect on the magnitude of market efficiency, and omitting the common border dummy variable has no notable effects on the remaining results.

As expected, the estimated standard errors of the estimates of $\hat{\beta}_{i j, 1}$ from the first step of the analysis $\left(\hat{\sigma}_{\widehat{\beta}_{i j, 1}}\right)$ have a significant positive influence on the variance of the random error $v_{i j}$ $\left(\sigma_{v_{i j}}^{2}\right)$. Furthermore, there are significant province effects in the variance $\sigma_{u_{i j}}^{2}$ of the one-sided inefficiency term $u_{i j}$. We have omitted the dummy for the province Heilongjiang in the estimation; all other province dummies have positive effects on the variance of the inefficiency term (increasing from the top to the bottom of the list in Table 1). This indicates that the variance of the inefficiency term is higher for market pairs that include these other provinces. In some cases (e.g. Jilin and Liaoning at the top of the list) the estimated additional variance relative to Heilongjiang is small and insignificant; moving down the list it becomes 
larger, and from Jiangsu province onward it is statistically significant at the 5\% level. This ranking of the 30 provinces according to the variance of the inefficiency term $u_{i j}$ is not identical but very similar to the ranking of the provinces according to their average market efficiencies (discussed below); Spearman's correlation coefficient for the two rankings equals 0.9919, and the provinces near the top (bottom) of the list in Table 1 are also the provinces that attain the highest (lowest) average magnitudes of market efficiency.

Table 1 Estimated magnitude of market efficiency frontier (equation (7a), dependent variable $\widehat{\boldsymbol{\beta}}_{i j, 1}$ )

\begin{tabular}{|c|c|c|c|c|c|c|}
\hline $\begin{array}{l}\text { Model } \\
\text { component }\end{array}$ & Variable & Coefficient & $\begin{array}{l}\text { Standard } \\
\text { Error }\end{array}$ & $\begin{array}{l}\mathbf{t}- \\
\text { statistic }\end{array}$ & $\begin{array}{l}95 \% \\
\text { interval }\end{array}$ & confidence \\
\hline $\begin{array}{l}\text { Efficiency } \\
\text { frontier }\left(X_{\mathrm{k}} \gamma\right)\end{array}$ & $\begin{array}{r}\text { Constant } \\
\qquad \begin{array}{r}d_{i j} \\
B_{i j}\end{array}\end{array}$ & $\begin{array}{l}0.992 \\
-0.015 \\
-0.005\end{array}$ & $\begin{array}{l}0.0058 \\
0.0029 \\
0.0053\end{array}$ & $\begin{array}{l}171.23 \\
-5.23 \\
-0.95\end{array}$ & $\begin{array}{l}0.981 \\
-0.021 \\
-0.016\end{array}$ & $\begin{array}{l}1.004 \\
-0.010 \\
0.005\end{array}$ \\
\hline $\begin{array}{l}\text { Random error } \\
\sigma_{v_{i j}}^{2}=\exp \left(V_{i j} \zeta\right)\end{array}$ & $\begin{array}{r}\text { Constant } \\
\hat{\sigma}_{\widehat{\beta}_{i j, 1}}\end{array}$ & $\begin{array}{l}-8.028 \\
21.123\end{array}$ & $\begin{array}{l}0.302 \\
8.844\end{array}$ & $\begin{array}{l}-26.59 \\
2.39\end{array}$ & $\begin{array}{l}-8.620 \\
3.790\end{array}$ & $\begin{array}{l}-7.437 \\
38.462\end{array}$ \\
\hline $\begin{array}{l}\text { Inefficiency term } \\
\qquad \sigma_{u_{i j}}^{2}\end{array}$ & $\begin{array}{l}\text { Constant } \\
\text { Jilin } \\
\text { Liaoning } \\
\text { Tianjin } \\
\text { Beijing } \\
\text { Shandong } \\
\text { Zhejiang } \\
\text { Shanxi } \\
\text { Inner Mongolia } \\
\text { Chongqing } \\
\text { Hunan } \\
\text { Henan } \\
\text { Hebei } \\
\text { Jiangsu } \\
\text { Jiangxi } \\
\text { Hubei } \\
\text { Gansu }\end{array}$ & $\begin{array}{l}-9.241 \\
0.002 \\
0.255 \\
0.536 \\
0.537 \\
0.540 \\
0.620 \\
0.657 \\
0.745 \\
0.788 \\
0.843 \\
0.854 \\
1.040 \\
1.276 \\
1.364 \\
1.802 \\
1.875\end{array}$ & $\begin{array}{l}0.870 \\
0.557 \\
0.530 \\
0.546 \\
0.564 \\
0.542 \\
0.532 \\
0.541 \\
0.542 \\
0.537 \\
0.533 \\
0.541 \\
0.554 \\
0.545 \\
0.543 \\
0.546 \\
0.534\end{array}$ & $\begin{array}{l}-10.62 \\
0.000 \\
0.480 \\
0.980 \\
0.950 \\
1.000 \\
1.170 \\
1.210 \\
1.370 \\
1.470 \\
1.580 \\
1.580 \\
1.880 \\
2.340 \\
2.510 \\
3.300 \\
3.510\end{array}$ & $\begin{array}{l}-10.946 \\
-1.089 \\
-0.783 \\
-0.535 \\
-0.569 \\
-0.522 \\
-0.423 \\
-0.404 \\
-0.318 \\
-0.265 \\
-0.203 \\
-0.206 \\
-0.045 \\
0.207 \\
0.299 \\
0.731 \\
0.829\end{array}$ & $\begin{array}{l}-7.535 \\
1.093 \\
1.293 \\
1.607 \\
1.643 \\
1.602 \\
1.663 \\
1.718 \\
1.808 \\
1.841 \\
1.888 \\
1.914 \\
2.125 \\
2.344 \\
2.429 \\
2.872 \\
2.921\end{array}$ \\
\hline
\end{tabular}




\begin{tabular}{l|l|l|l|l|ll} 
Guangxi & 2.074 & 0.529 & 3.920 & 1.038 & 3.110 \\
Shaanxi & 2.141 & 0.537 & 3.990 & 1.089 & 3.192 \\
Qinghai & 2.154 & 0.535 & 4.030 & 1.105 & 3.202 \\
Xinjiang & 2.178 & 0.548 & 3.970 & 1.103 & 3.252 \\
Sichuan & 2.280 & 0.530 & 4.300 & 1.241 & 3.318 \\
Anhui & 2.359 & 0.543 & 4.350 & 1.295 & 3.423 \\
Hainan & 2.543 & 0.529 & 4.810 & 1.507 & 3.580 \\
Guizhou & 2.949 & 0.523 & 5.640 & 1.924 & 3.975 \\
Fujian & 3.000 & 0.532 & 5.640 & 1.957 & 4.043 \\
Yunnan & 3.044 & 0.518 & 5.880 & 2.029 & 4.058 \\
Guangdong & 3.864 & 0.547 & 7.060 & 2.791 & 4.937 \\
Shanghai & 4.098 & 0.556 & 7.370 & 3.008 & 5.189 \\
Ningxia & 4.101 & 0.549 & 7.470 & 3.024 & 5.177 \\
\hline
\end{tabular}

Source: Own calculations with Stata (2020) 'frontier' command.

Figure 4 presents a scatterplot of the 435 estimates of $\hat{\beta}_{i j, 1}$ against distance $d_{i j}$ as well as the estimated magnitude of market efficiency frontier based on the results in Table 1. In Figure 4 we highlight all of the market pairs that include Heilongjiang (the most efficient province) as well as all of the market pairs that include Ningxia (the least efficient province). It is readily apparent that the individual $\hat{\beta}_{i j, 1}$ are on average farther from the frontier for market pairs that include Ningxia than for market pairs that include Heilongjiang. 
Figure 4 The estimated magnitude of market efficiency frontier and observed $\widehat{\boldsymbol{\beta}}_{i j, 1}$

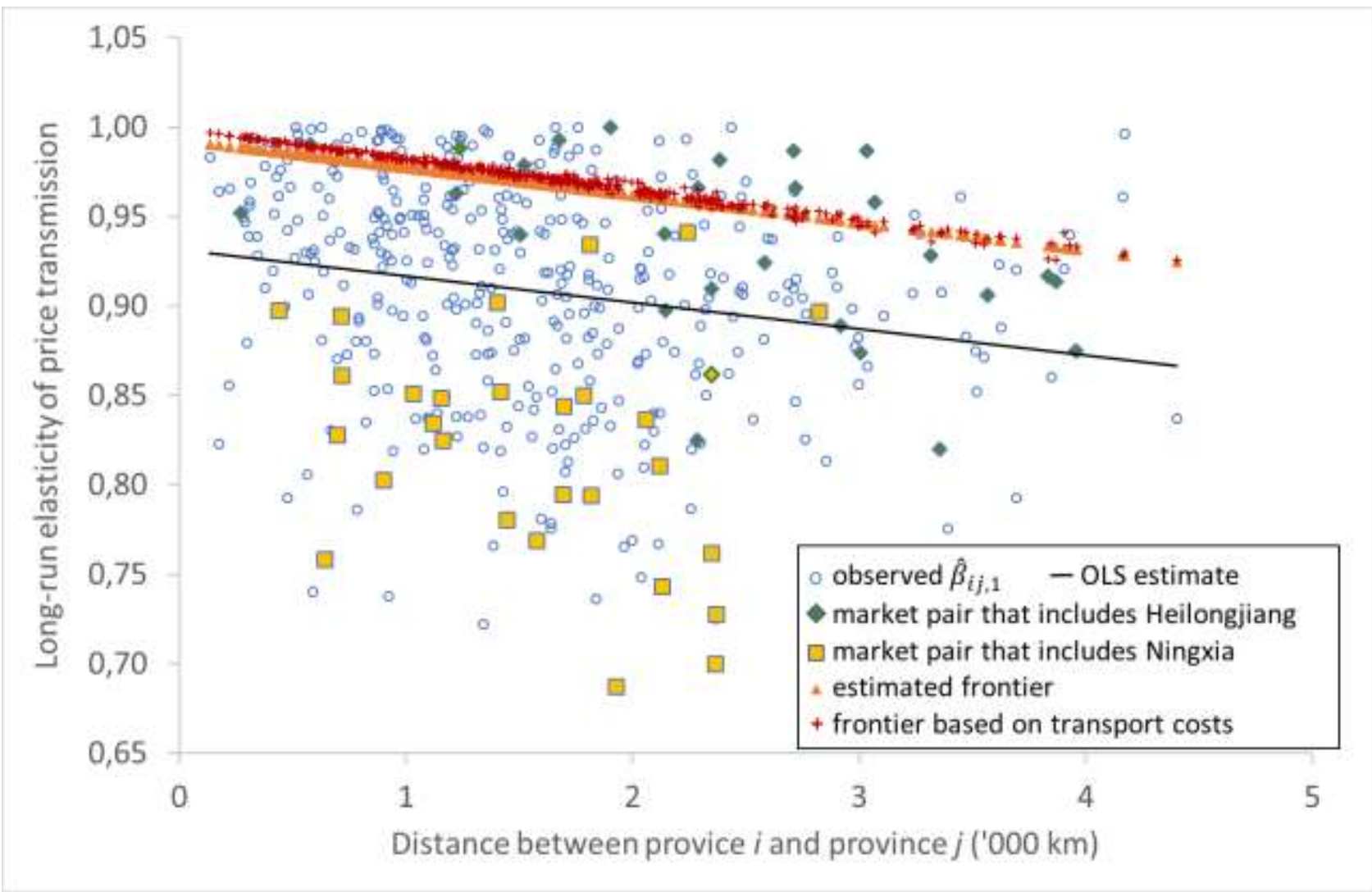

Source: Own calculations using Ministry of Agriculture of China (2001-2018) and Suzhou Dongchen Refrigerated Logistics Company (2019).

Figure 4 also includes a theoretical frontier that we have calculated using equation (4) and estimates of transport costs for pork between different regions of China provided by a Chinese transportation company. ${ }^{7}$ We see that the estimated frontier lies just slightly below the theoretical frontier based on these transport costs. This provides some support for the validity of the estimated frontier and suggests that transport accounts for most of the total costs of pork trade between provinces in China. We also see that the estimated frontier differs considerably from the OLS estimate of $\hat{\beta}_{i j, 1}$ on distance that has been used in past studies (e.g. Kouyaté et al., 2016; Svanidze and Götz, 2019a).

Table 2 presents the estimation results of the frontier model for the speed of restoring market efficiency (equation (7b), dependent variable $\hat{\alpha}_{i j}$ ). According to these results, the frontier of

\footnotetext{
${ }^{7}$ Fixed and variable transport costs for pork between selected pairs of market in China were provided by the Suzhou Dongchen Refrigerated Logistics Company (2019) as showed in Appendix (Figure A.1). Based on these costs and using equation (4) $\left(\eta_{i j}^{P T}=1-\frac{\tau_{i j}}{p_{i}}\right)$ we calculated a theoretical long-run elasticity of price transmission for each market pair as the cost share of pork in the lower-price province $j$ in the price of pork in the higher-price province $i$.
} 
$\hat{\alpha}_{i j}$ falls by 0.014 per $1000 \mathrm{~km}$ of distance between two markets, i.e. the proportion of a deviation from long-run equilibrium that is corrected per month falls by 1.4 percentage points for each additional $1000 \mathrm{~km}$ of distance. Sharing a common border has the expected positive effect on the speed of market efficiency, but this effect is insignificant and omitting the common border dummy has no notable effects on the remaining results.

Table 2 Estimated speed of market efficiency frontier (equation (7b), dependent variable $\left.\widehat{\alpha}_{i j}\right)$

\begin{tabular}{l|l|l|l|l|lc}
\hline $\begin{array}{l}\text { Model } \\
\text { component }\end{array}$ & Variable & Coefficient & $\begin{array}{l}\text { Standard } \\
\text { Error }\end{array}$ & $\begin{array}{l}\text { t- } \\
\text { statistic }\end{array}$ & $\begin{array}{l}\text { 95\% } \\
\text { interval }\end{array}$ & confidence \\
\hline $\begin{array}{l}\text { Efficiency } \\
\text { frontier }\end{array}$ & Constant & 0.336 & 0.0149 & 22.46 & 0.306 & 0.365 \\
$\left(Y_{\mathrm{k}} \delta\right)$ & $d_{i j}$ & -0.014 & 0.0067 & -2.12 & -0.027 & -0.001 \\
\hline Random error & $B_{i j}$ & 0.010 & 0.0150 & 0.69 & -0.019 & 0.040 \\
$\sigma_{\varrho_{i j}^{2}=\exp \left(W_{i j} \xi\right)}$ & $\hat{\sigma}_{\widehat{\alpha}_{i j}}$ & 106.100 & 18.467 & 5.75 & 69.906 & 142.294 \\
\hline \multirow{2}{*}{$\begin{array}{l}\text { Inefficiency term } \\
\sigma_{\omega}^{2}\end{array}$} & Constant & -5.863 & 0.402 & -14.58 & -6.651 & -5.075 \\
\hline
\end{tabular}

Source: Own calculations with Stata (2020) 'frontier' command.

As expected, the estimated standard errors of the estimates of $\hat{\alpha}_{i j}$ from the first step of the analysis $\left(\hat{\sigma}_{\widehat{\alpha}_{i j}}\right)$ have a significant positive influence on the variance of the random error $\varrho_{i j}$ $\left(\sigma_{Q_{i j}}^{2}\right)$. We find that only the dummy for the province Xinjiang in the far West of China has significant effects on the variance $\sigma_{\omega}^{2}$ of the one-sided inefficiency term $\omega_{i j}$. We also find that the estimated inefficiency $\left(\hat{u}_{i j}\right)$ from the frontier model for $\hat{\beta}_{i j, 1}$ has a significant effect on the variance of the inefficiency term $\omega_{i j}$. This result provides some evidence that unobserved factors that reduce the magnitude of market efficiency also reduce the speed of restoring market efficiency.

Figure 5 presents a scatterplot of the 435 estimates of $\hat{\alpha}_{i j}$ against distance $d_{i j}$, as well as the estimated frontier based on the results in Table 2. The market pairs that involve Xinjiang are highlighted. We see that for many market pairs the observed $\hat{\alpha}_{i j}$ lie sometimes well above the estimated frontier. This suggests that a large proportion of the deviations from the frontier can be attributed to random error variance, i.e. uncertainty about the first-step estimates of $\hat{\alpha}_{i j}$. 
This is reflected in the large value (106.1) of the coefficient for the estimated standard error of $\hat{\alpha}_{i j}\left(\hat{\sigma}_{\widehat{\alpha}_{i j}}\right)$ reported in Table 2 .

Figure 5 highlights the fact that while the estimated effect of distance on the speed of restoring market efficiency is significant, it is small in magnitude. The OLS estimate of the relationship between $\hat{\alpha}_{i j}$ and distance $d_{i j}$ is considerably steeper, but this estimate does not account for the standard errors of the estimated $\hat{\alpha}_{i j}$, and it appears to be influenced by the market pairs that involve the province Xinjiang. Note that in Figure 5 we do not include a theoretical frontier for $\hat{\alpha}_{i j}$ as we did for $\hat{\beta}_{i j, 1}$ in Figure 4 . We derived the theoretical frontier for $\hat{\beta}_{i j, 1}$ from the spatial equilibrium condition (equations (3) and (4)) and calculated it using information on transport costs for pork in China. However, there is no equivalent theoretical foundation for deriving a frontier for $\hat{\alpha}_{i j}$, as the speed of price transmission depends on a complex set of logistic factors such as transport capacities and speeds, and the time it takes to initiate and execute transactions.

Figure 5 The estimated speed of restoring market efficiency frontier and observed $\widehat{\alpha}_{i j}$

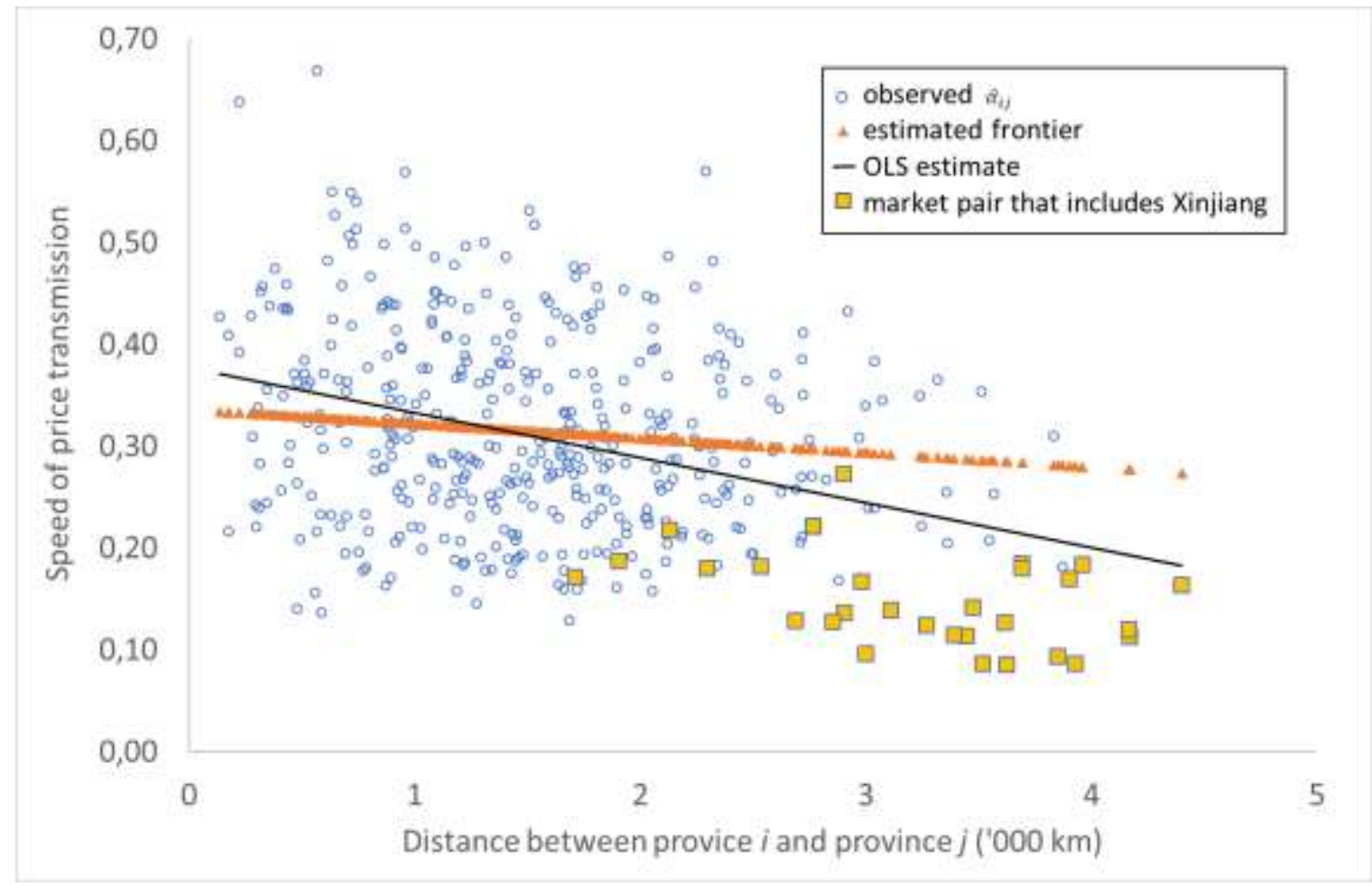

Source: Own calculations using Ministry of Agriculture of China (2001-2018).

\section{Discussion}

The results reported above for the magnitude of market efficiency and for the speed of restoring market efficiency differ from one another in several respects. Figure 6 presents the 
distributions of the estimated inefficiencies for the magnitude of market efficiency (i.e. how far are the observed $\hat{\beta}_{i j, 1}$ from the corresponding frontier estimates $\beta_{i j, 1}^{*}$ ) and for the speed of restoring market efficiency (i.e. how far are the observed $\hat{\alpha}_{i j}$ from the corresponding frontier estimates $\alpha_{i j}^{*}$ ). Consider first the speed of restoring market efficiency. For over one-half of the market pairs deviations from efficiency are corrected by 0.03-0.05 (3 to 5 percentage points) per month less than is attained by the market pairs that define the frontier. However, the distribution is skewed, and the average inefficiency for all market pairs is $5.5 \%$. Detailed results reveal that the average inefficiency for the 29 market pairs that include Xinjiang is 13.9\% compared with $4.9 \%$ for the other 406 market pairs. Hence, market pairs that include Xinjiang are on average 9 percentage points farther from the frontier, which means that on average deviations from long-run equilibrium are corrected by $9 \%$ less per month for market pairs that include Xinjiang than for all other market pairs. Xinjiang is located in the far West of China and it could be that travel and trade restrictions that apply to Xinjiang are slowing price transmission and the restoration of equilibrium between that province and the rest of the country.

\section{Figure 6 Distributions of inefficiency for the magnitude and the speed of market efficiency}

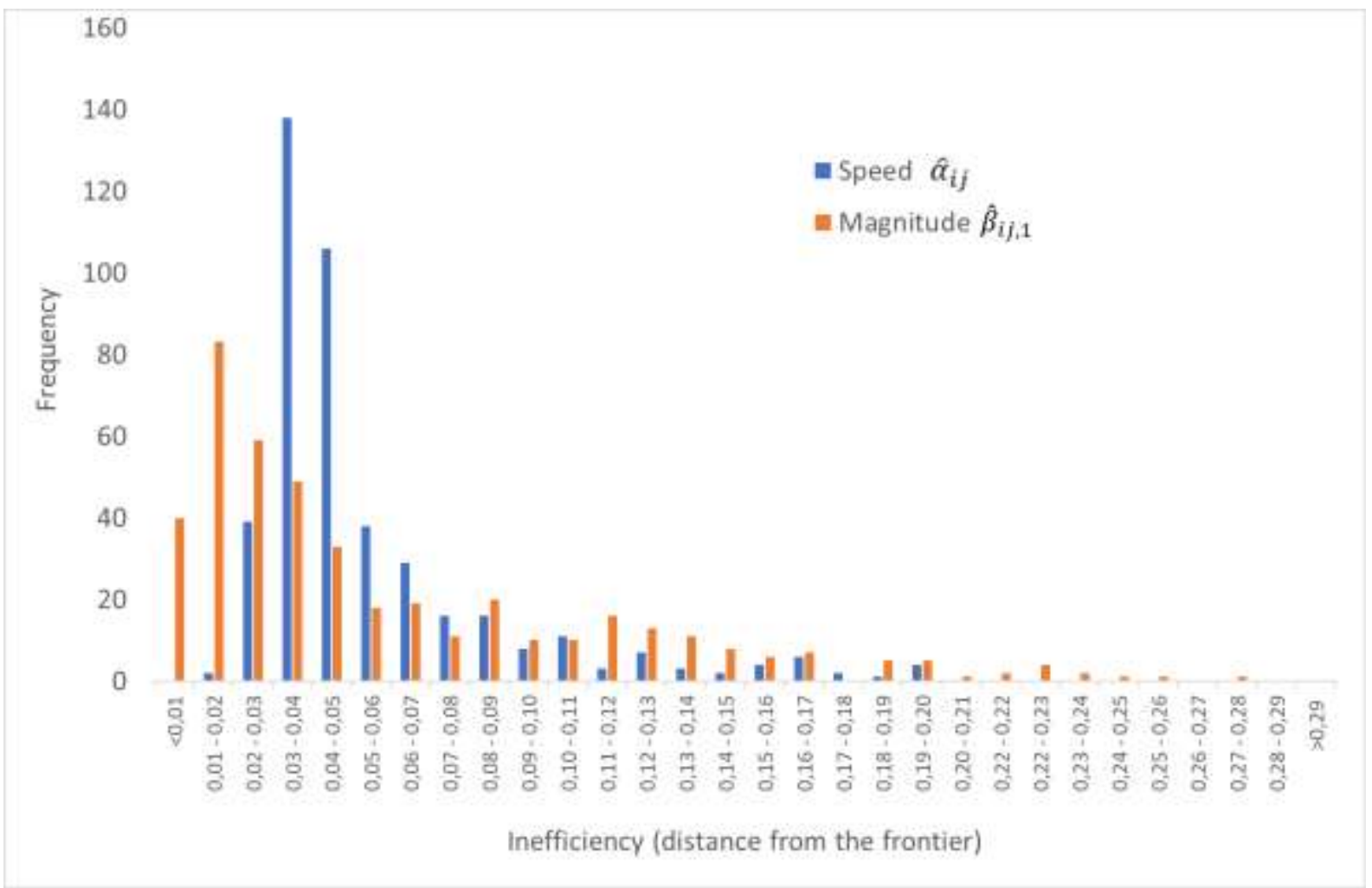

Source: Own calculations using Ministry of Agriculture of China (2001-2018). 
In comparison, the distribution of the inefficiency scores for the magnitude of market efficiency in Figure 6 shows that for many market pairs the long-run elasticity of price transmission is within $0.03(3 \%)$ of the frontier. The average inefficiency is $5.9 \%$. As presented above (Table 1), we find significant province effects in these inefficiency scores.

\section{Figure 7 Regional differences in the magnitude of pork market efficiency in China}

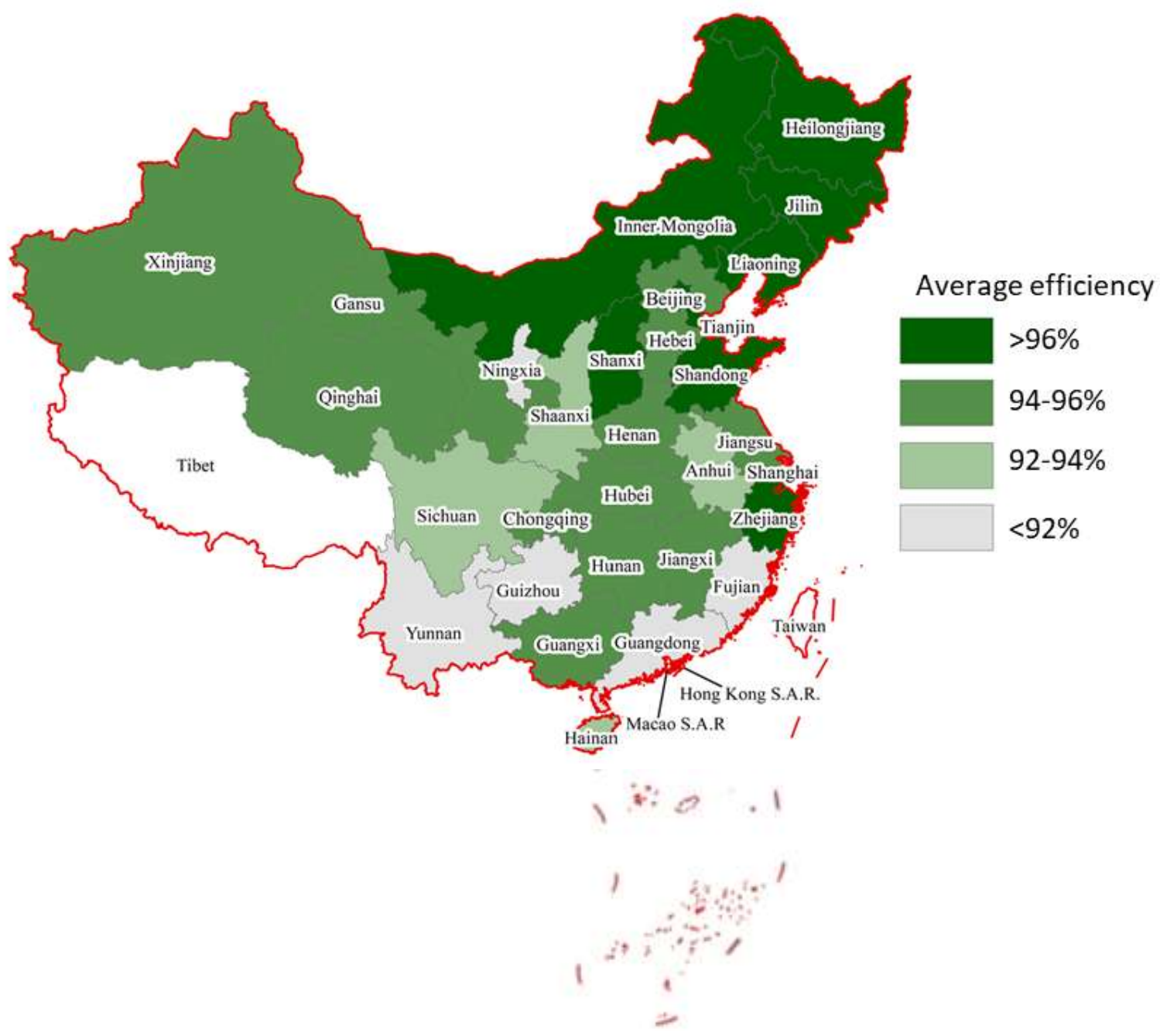

Source: Own calculations.

To illustrate these effects, in Figure 7 each province is shaded according to the average market efficiency of the pairs in which it is included. We see that market pairs involving provinces located in the Northeast of China are characterised by the highest magnitude of market efficiency, and that the magnitude of market efficiency tends to be lower for provinces located farther to the South and West. Provinces with lower levels of market efficiency 
include Shanghai, Guangdong and Fujian; perhaps imports of pork from outside of China are affecting prices in these border provinces. Ningxia in western China also stands out, as do Yunnan and Guizhou; factors such as ethnicity and dietary customs (for example the relatively high proportion of Hui Muslims in Ningxia) and relative remoteness might contribute to these results.

\section{Conclusions and suggestions for future research}

We propose a new method for benchmarking dynamic market efficiency using cointegration analysis coupled with frontier estimation methods. The use of frontier methods allows us to estimate within-sample benchmarks for the magnitude and the speed of restoring market efficiency. It also provides a convenient way of accounting for sampling error in estimated measures of price transmission. An empirical application to the example of pork markets in China demonstrates that the method is feasible and produces plausible results that allow for a richer interpretation than past attempts based on OLS regression.

Several limitations and open questions could be addressed in future research. First, in our application to pork markets in China we are unable to address the question of how physical trade flows affect market efficiency, because data on trade between provinces in China are not available. Physical trade is not a necessary condition for market integration, as information flows can also play a role (Stephens et al., 2012). Nevertheless, it is reasonable to hypothesise that trade flows have an influence. Future research could apply the methods outlined in this paper to settings, for example the EU, in which appropriate trade data are available.

Second, we analyse factors that affect variation in market efficiency within China, but we are not able to identify whether there are factors specific to China as a whole that make its pork markets more or less efficient than pork markets in other countries. The frontier method that we propose could be extended using meta-frontier techniques (Battese et al., 2004; O'Donnell et al., 2008) to simultaneously estimate within- and between-country benchmarks and thus investigate whether there are indications that markets in some countries are systematically more or less efficient than markets in others.

Finally, in our empirical application we assume that the elasticities and adjustment parameters that describe pork price transmission between provinces in China have been constant over the 2000-2017 sample period. China has experienced rapid economic growth and restructuring over this period, which has led to shifts in regional pork supply and demand as well as changes in trade infrastructure. As a result, the elasticities and adjustment parameters that we 
estimate and analyse may have changed over the sample period. To avoid what are likely major structural breaks on Chinese pork markets due to the African Swine Fever outbreak and COVID-19 in China, we carried out our empirical application without data from 2018 onward. But structural breaks and other sources of non-constant parameters may also affect the earlier years that we do analyse. Future applications could use time-varying ECM estimation techniques (Adämmer and Bohl, 2015, 2018) to generate time series of varying error correction parameters for each market pair in the first step. In the second step, panel frontier techniques (e.g. Kumbhakar, 1990) could then be applied to study how the market efficiency frontier has shifted over time, and what factors have influenced the evolution of efficiency in individual regions relative to that frontier. 


\section{Appendix of Chapter III}

Markets analyzed in question are listed as follows:

Table A.1: List of markets in China

\begin{tabular}{lll}
\hline & \multicolumn{2}{c}{ Interprovincial analysis } \\
China
\end{tabular}

\section{Pork prices and Distance}

Pork prices (Yuan/kg) are from the Ministry of Agriculture of China. Source: http://www.moa.gov.cn/

Road distance (1 000 kilometers) between markets $i$ and $j$; calculated as road distance between capitals of provinces. Source: https://map.baidu.com/ 
Table A.2.1: ADF test for prices in levels

\begin{tabular}{|c|c|c|c|c|}
\hline \multirow[b]{2}{*}{ Price level } & \multirow[b]{2}{*}{ Lags } & \multicolumn{3}{|c|}{ Test statistics } \\
\hline & & None & Constant & Const \& trend \\
\hline Beijing & 2 & 0.716 & -1.880 & -3.141 \\
\hline Tianjin & 1 & 0.850 & -1.634 & -2.897 \\
\hline Hebei & 4 & 0.805 & -1.691 & -2.607 \\
\hline Shanxi & 3 & 0.739 & -1.898 & -3.017 \\
\hline Inner Mongolia & 2 & 0.826 & -1.847 & -2.998 \\
\hline Liaoning & 4 & 0.909 & -1.707 & -2.551 \\
\hline Jilin & 4 & 0.940 & -1.979 & -2.876 \\
\hline Heilongjiang & 3 & 0.631 & -1.747 & -3.187 \\
\hline Shanghai & 2 & 0.762 & -1.320 & -2.878 \\
\hline Jiangsu & 3 & 0.894 & -1.591 & -2.957 \\
\hline Zhejiang & 2 & 0.941 & -1.447 & -2.930 \\
\hline Anhui & 2 & 0.637 & -1.641 & -3.237 \\
\hline Fujian & 2 & 0.749 & -1.299 & -3.038 \\
\hline Jiangxi & 2 & 0.769 & -1.505 & -2.929 \\
\hline Shandong & 4 & 0.955 & -1.479 & -2.686 \\
\hline Henan & 2 & 0.726 & -1.568 & -2.787 \\
\hline Hubei & 3 & 0.861 & -1.408 & -2.500 \\
\hline Hunan & 3 & 0.853 & -1.438 & -2.621 \\
\hline Guangdong & 2 & 0.866 & -1.177 & -2.727 \\
\hline Guangxi & 3 & 0.820 & -1.395 & -2.284 \\
\hline Hainan & 1 & 0.996 & -0.714 & -2.928 \\
\hline Chongqing & 2 & 0.620 & -1.739 & -3.295 \\
\hline Sichuan & 3 & 0.884 & -1.509 & -2.714 \\
\hline Guizhou & 3 & 1.024 & -1.358 & -2.651 \\
\hline Yunnan & 2 & 0.962 & -1.330 & -2.622 \\
\hline Shaanxi & 2 & 0.505 & -1.501 & -3.269 \\
\hline Gansu & 2 & 0.928 & -1.824 & -3.029 \\
\hline Qinghai & 1 & 0.799 & -1.487 & -2.691 \\
\hline Ningxia & 1 & 0.720 & -1.863 & -3.124 \\
\hline Xinjiang & 2 & 0.896 & -1.837 & -2.980 \\
\hline
\end{tabular}

Note: a) Number of lags is chosen by SBIC criterion. b) ADF test (no constant, no trend): -2.58 (1\%), -1.95 (5\%), -1.62 $(10 \%)$; ADF test with constant:-3.46 (1\%), -2.88 (5\%), -2.57 (10\%); ADF test with constant and trend: $-3.99(1 \%),-3.43$ $(5 \%),-3.13(10 \%)$. 
Table A.2.2: ADF test for prices in first differences

\begin{tabular}{|c|c|c|c|c|}
\hline \multirow[b]{2}{*}{ Price difference } & \multirow[b]{2}{*}{ Lags } & \multicolumn{3}{|c|}{ Test statistics } \\
\hline & & None & Constant & Const \& trend \\
\hline$\Delta$ Beijing & 1 & -9.784 & -9.832 & -9.831 \\
\hline$\Delta$ Tianjin & 1 & -10.435 & -10.519 & -10.532 \\
\hline$\Delta$ Hebei & 3 & -7.954 & -8.022 & -8.032 \\
\hline$\Delta$ Shanxi & 2 & -8.668 & -8.726 & -8.738 \\
\hline$\Delta$ Inner Mongolia & 1 & -9.128 & -9.197 & -9.208 \\
\hline$\Delta$ Liaoning & 3 & -8.291 & -8.377 & -8.396 \\
\hline$\Delta$ Jilin & 3 & -8.344 & -8.442 & -8.480 \\
\hline$\Delta$ Heilongjiang & 2 & -8.224 & -8.267 & -8.260 \\
\hline$\Delta$ Shanghai & 1 & -9.252 & -9.292 & -9.271 \\
\hline$\Delta$ Jiangsu & 2 & -8.078 & -8.155 & -8.148 \\
\hline$\Delta$ Zhejiang & 1 & -8.626 & -8.706 & -8.695 \\
\hline$\Delta$ Anhui & 1 & -8.798 & -8.832 & -8.817 \\
\hline$\Delta$ Fujian & 1 & -8.910 & -8.952 & -8.931 \\
\hline$\Delta$ Jiangxi & 1 & -8.961 & -9.010 & -8.997 \\
\hline$\Delta$ Shandong & 3 & -7.955 & -8.046 & -8.043 \\
\hline$\Delta$ Henan & 1 & -9.064 & -9.110 & -9.101 \\
\hline$\Delta$ Hubei & 2 & -8.617 & -8.681 & -8.673 \\
\hline$\Delta$ Hunan & 2 & -8.066 & -8.136 & -8.128 \\
\hline$\Delta$ Guangdong & 2 & -7.562 & -7.630 & -7.611 \\
\hline$\Delta$ Guangxi & 2 & -8.461 & -8.519 & -8.512 \\
\hline$\Delta$ Hainan & 1 & -10.137 & -10.188 & -10.176 \\
\hline$\Delta$ Chongqing & 1 & -8.863 & -8.899 & -8.887 \\
\hline$\Delta$ Sichuan & 2 & -7.944 & -8.025 & -8.024 \\
\hline$\Delta$ Guizhou & 2 & -7.571 & -7.681 & -7.679 \\
\hline$\Delta$ Yunnan & 1 & -7.819 & -7.911 & -7.897 \\
\hline$\Delta$ Shaanxi & 1 & -9.870 & -9.885 & -9.864 \\
\hline$\Delta$ Gansu & 1 & -9.145 & -9.230 & -9.236 \\
\hline$\Delta$ Qinghai & 1 & -9.845 & -9.893 & -9.884 \\
\hline$\Delta$ Ningxia & 2 & -10.031 & -10.113 & -10.124 \\
\hline$\Delta X$ injiang & 1 & -9.506 & -9.577 & -9.585 \\
\hline
\end{tabular}

Note: a) Number of lags is chosen by SBIC criterion. b) Critical values for ADF test (no constant, no trend): -2.58 (1\%), $1.95(5 \%),-1.62(10 \%)$; ADF test (with constant): -3.46 (1\%), -2.88 (5\%), -2.57 (10\%); ADF test (with constant and trend): $3.99(1 \%),-3.43(5 \%),-3.13(10 \%)$. c) Critical values for KPSS test with constant: $0.74(1 \%), 0.46(5 \%), 0.35(10 \%)$. 
Table A.3: PCADF test results

\begin{tabular}{|c|c|c|c|c|c|}
\hline \multicolumn{3}{|c|}{ Price level } & \multicolumn{3}{|c|}{ Price difference level } \\
\hline Province & P.value & Lag & $\Delta$ Province & P.value & Lag \\
\hline Beijing & 0.282 & 1 & $\Delta$ Beijing & $1.00 \mathrm{E}-16$ & 0 \\
\hline Tianjin & 0.413 & 0 & $\Delta$ Tianjin & $1.00 \mathrm{E}-16$ & 0 \\
\hline Hebei & 0.456 & 3 & $\Delta$ Hebei & $2.01 \mathrm{E}-15$ & 2 \\
\hline Shanxi & 0.342 & 2 & $\Delta$ Shanxi & $2.15 \mathrm{E}-15$ & 1 \\
\hline Inner Mongolia & 0.192 & 1 & $\Delta$ Inner Mongolia & $1.00 \mathrm{E}-16$ & 0 \\
\hline Liaoning & 0.429 & 3 & $\Delta$ Liaoning & $9.05 \mathrm{E}-15$ & 2 \\
\hline Jilin & 0.380 & 3 & $\Delta$ Jilin & $7.12 \mathrm{E}-15$ & 2 \\
\hline Heilongjiang & 0.307 & 2 & $\Delta$ Heilongjiang & $1.90 \mathrm{E}-15$ & 1 \\
\hline Shanghai & 0.574 & 1 & $\Delta$ Shanghai & $1.00 \mathrm{E}-16$ & 0 \\
\hline Jiangsu & 0.508 & 2 & $\Delta$ Jiangsu & $1.33 \mathrm{E}-14$ & 1 \\
\hline Zhejiang & 0.447 & 1 & $\Delta$ Zhejiang & $3.10 \mathrm{E}-14$ & 0 \\
\hline Anhui & 0.361 & 1 & $\Delta$ Anhui & $1.00 \mathrm{E}-16$ & 0 \\
\hline Fujian & 0.647 & 1 & $\Delta$ Fujian & $1.00 \mathrm{E}-16$ & 0 \\
\hline Jiangxi & 0.486 & 1 & $\Delta$ Jiangxi & $1.00 \mathrm{E}-16$ & 0 \\
\hline Shandong & 0.484 & 3 & $\Delta$ Shandong & $2.14 \mathrm{E}-15$ & 2 \\
\hline Henan & 0.357 & 1 & $\Delta$ Henan & $2.17 \mathrm{E}-14$ & 0 \\
\hline Hubei & 0.515 & 2 & $\Delta$ Hubei & $9.08 \mathrm{E}-15$ & 1 \\
\hline Hunan & 0.549 & 2 & $\Delta$ Hunan & $5.01 \mathrm{E}-14$ & 1 \\
\hline Guangdong & 0.555 & 1 & $\Delta$ Guangdong & $1.70 \mathrm{E}-13$ & 1 \\
\hline Guangxi & 0.570 & 2 & $\Delta$ Guangxi & $1.81 \mathrm{E}-14$ & 1 \\
\hline Hainan & 0.691 & 0 & $\Delta$ Hainan & $1.00 \mathrm{E}-16$ & 0 \\
\hline Chongqing & 0.342 & 1 & $\Delta$ Chongqing & $3.81 \mathrm{E}-15$ & 0 \\
\hline Sichuan & 0.426 & 2 & $\Delta$ Sichuan & $1.92 \mathrm{E}-12$ & 1 \\
\hline Guizhou & 0.624 & 2 & $\Delta$ Guizhou & $1.27 \mathrm{E}-15$ & 1 \\
\hline Yunnan & 0.492 & 1 & $\Delta$ Yunnan & $6.46 \mathrm{E}-12$ & 0 \\
\hline Shaanxi & 0.304 & 1 & $\Delta$ Shaanxi & $1.00 \mathrm{E}-16$ & 0 \\
\hline Gansu & 0.408 & 1 & $\Delta$ Gansu & $1.00 \mathrm{E}-16$ & 0 \\
\hline Qinghai & 0.465 & 0 & $\Delta$ Qinghai & $1.00 \mathrm{E}-16$ & 0 \\
\hline Ningxia & 0.220 & 0 & $\Delta$ Ningxia & $1.00 \mathrm{E}-16$ & 1 \\
\hline Xinjiang & 0.402 & 1 & $\Delta X$ injiang & $1.00 \mathrm{E}-16$ & 0 \\
\hline
\end{tabular}

\begin{tabular}{lll}
\hline & crosscorr $=0$ & crosscorr $=0$ \\
test statistic: & -0.856 & -43.028 \\
p-value: & 0.196 & 0 \\
\hline Note: Choi (2001). & &
\end{tabular}




\section{Table A.4.1 Results of the Johansen trace tests for cointegration $\left(\mathrm{H}_{0}: \mathrm{r}=0\right)$}

Beijing

Tianjin $\quad 40.71$

Hebei $\quad 28.08 \quad 43.78$

$\begin{array}{llll}\text { Shanxi } \quad 27.44 & 39.17 & 45.05\end{array}$

$\begin{array}{lllll}\text { Inner } \quad 34.54 & 49.79 & 39.83 & 37.75\end{array}$

Liaoning $\quad \begin{array}{lllll}29.16 & 43.89 & 42.09 & 31.54 & 59.56\end{array}$

$\begin{array}{lllllll}\text { Jilin } \quad 33.79 & 56.44 & 34.59 & 20.11 & 37.10 & 34.06\end{array}$

$\begin{array}{llllllll}\text { Hei } & 35.95 & 50.57 & 36.92 & 31.83 & 54.21 & 37.81 & 46.65\end{array}$

$\begin{array}{llllllllll}\text { Shanghai } & 25.73 & 27.22 & 30.16 & 36.81 & 28.23 & 34.38 & 32.87 & 28.47\end{array}$

$\begin{array}{llllllllll}\text { Jiangsu } & 24.07 & 37.07 & 33.64 & 53.74 & 22.92 & 31.41 & 35.37 & 29.83 & 27.92\end{array}$

$\begin{array}{llllllllllll}\text { Zhejiang } & 23.28 & 27.83 & 36.61 & 55.62 & 23.94 & 42.10 & 42.79 & 34.38 & 24.25 & 39.94\end{array}$

$\begin{array}{lllllllllllll}\text { Anhui } & 30.26 & 31.01 & 51.09 & 65.86 & 31.03 & 51.55 & 43.10 & 39.05 & 36.17 & 41.62 & 40.81\end{array}$

$\begin{array}{lllllllllllll}\text { Fujian } & 26.35 & 32.53 & 34.70 & 45.09 & 24.57 & 42.10 & 40.84 & 32.96 & 18.65 & 37.90 & 24.28 & 38.88\end{array}$

$\begin{array}{llllllllllllll}\text { Jiangxi } & 26.17 & 34.36 & 45.73 & 48.96 & 31.14 & 52.65 & 44.82 & 41.30 & 32.80 & 34.02 & 33.83 & 49.35 & 22.62\end{array}$

$\begin{array}{llllllllllllllll}\text { Shandong } & 27.92 & 42.53 & 30.42 & 42.52 & 40.64 & 31.52 & 34.16 & 33.73 & 28.00 & 51.97 & 37.49 & 39.88 & 37.89 & 36.40\end{array}$

$\begin{array}{lllllllllllllllll}\text { Henan } & 22.53 & 28.69 & 54.03 & 72.89 & 22.88 & 43.75 & 37.15 & 30.94 & 23.99 & 32.71 & 24.03 & 67.76 & 26.16 & 42.52 & 27.19\end{array}$

$\begin{array}{lllllllllllllllll}\text { Hubei } & 29.86 & 40.77 & 49.47 & 50.85 & 39.24 & 60.70 & 46.95 & 47.93 & 31.43 & 29.37 & 25.84 & 48.43 & 23.25 & 43.44 & 38.07 & 42.53\end{array}$

$\begin{array}{lllllllllllllllllllll}\text { Hunan } & 24.41 & 28.40 & 42.58 & 54.60 & 24.50 & 42.99 & 38.48 & 35.79 & 29.78 & 32.64 & 35.72 & 56.95 & 33.01 & 43.16 & 34.53 & 50.55 & 33.93\end{array}$

$\begin{array}{lllllllllllllllllll}\text { Guangdong } & 21.01 & 30.26 & 33.04 & 41.57 & 22.87 & 40.95 & 38.32 & 35.62 & 19.85 & 33.79 & 21.46 & 37.88 & 33.88 & 25.35 & 33.32 & 23.00 & 25.89 & 32.56\end{array}$

$\begin{array}{lllllllllllllllllllllll}\text { Guangxi } & 21.47 & 32.92 & 33.01 & 34.48 & 23.85 & 35.63 & 34.15 & 32.83 & 24.16 & 25.51 & 22.81 & 40.39 & 22.28 & 34.99 & 24.45 & 30.87 & 27.63 & 44.73 & 22.07\end{array}$

$\begin{array}{lllllllllllllllllllllll}\text { Hainan } & 25.17 & 26.57 & 29.91 & 36.73 & 22.64 & 36.46 & 37.40 & 30.53 & 22.91 & 33.39 & 24.43 & 27.74 & 19.35 & 24.48 & 30.75 & 21.96 & 23.38 & 25.19 & 15.06 & 18.48\end{array}$

$\begin{array}{llllllllllllllllllllll}\text { Chongqing } & 31.86 & 51.46 & 37.59 & 40.02 & 44.08 & 58.21 & 58.39 & 56.15 & 27.59 & 27.97 & 27.74 & 30.83 & 24.97 & 29.58 & 38.59 & 31.97 & 31.60 & 23.62 & 27.13 & 29.95 & 25.20\end{array}$

$\begin{array}{lllllllllllllllllllllllllll}\text { Sichuan } & 22.79 & 34.96 & 30.95 & 37.37 & 32.10 & 55.90 & 47.18 & 51.46 & 21.12 & 22.98 & 22.68 & 29.67 & 18.73 & 26.27 & 31.67 & 26.06 & 18.07 & 20.80 & 21.85 & 23.40 & 20.19 & 42.53\end{array}$

$\begin{array}{llllllllllllllllllllllllllll}\text { Guizhou } & 35.46 & 43.26 & 35.37 & 44.55 & 39.67 & 49.83 & 51.95 & 49.52 & 32.94 & 44.05 & 40.04 & 38.13 & 27.07 & 31.77 & 45.98 & 33.32 & 38.34 & 28.01 & 28.77 & 24.49 & 21.58 & 40.88 & 34.92\end{array}$

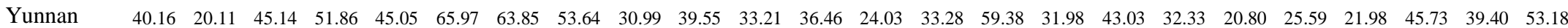

$\begin{array}{llllllllllllllllllllllllllllllll}\text { Shaanxi } & 34.99 & 45.74 & 40.46 & 46.73 & 58.13 & 60.91 & 62.54 & 70.76 & 34.64 & 47.16 & 34.72 & 36.91 & 26.57 & 40.01 & 47.28 & 37.50 & 47.34 & 32.63 & 26.25 & 27.35 & 20.23 & 46.12 & 53.17 & 58.25 & 70.73\end{array}$

$\begin{array}{llllllllllllllllllllllllllll}\text { Gansu } & 39.99 & 52.07 & 46.86 & 43.20 & 44.65 & 65.85 & 54.38 & 54.35 & 35.03 & 30.59 & 23.40 & 40.59 & 29.65 & 40.10 & 50.23 & 28.41 & 42.14 & 28.54 & 31.19 & 30.45 & 24.09 & 35.42 & 37.06 & 44.77 & 40.54 & 41.28\end{array}$

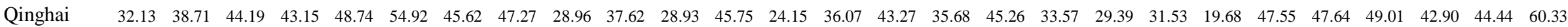

$\begin{array}{lllllllllllllllllllllllllllllllll}\text { Ningxia } & 32.16 & 31.28 & 34.84 & 29.11 & 41.50 & 43.27 & 31.71 & 41.07 & 34.11 & 22.68 & 38.96 & 39.87 & 27.32 & 38.30 & 43.37 & 34.67 & 28.62 & 39.64 & 31.26 & 29.43 & 31.08 & 44.46 & 48.43 & 40.27 & 55.11 & 57.53 & 42.79 & 44.32\end{array}$

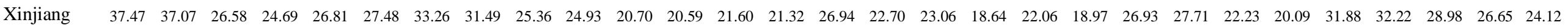


Table A.4.2 Results of the Johansen trace tests for cointegration $\left(\mathrm{H}_{0}: \mathrm{r}=1\right)$

\begin{tabular}{|c|c|c|c|c|c|c|c|c|c|c|c|c|c|c|c|c|c|c|c|c|c|c|c|c|c|c|c|c|c|}
\hline \multicolumn{30}{|l|}{ Beijing } \\
\hline Tianjin & 3.98 & & & & & & & & & & & & & & & & & & & & & & & & & & & & \\
\hline Hebei & 4.49 & 4.13 & & & & & & & & & & & & & & & & & & & & & & & & & & & \\
\hline Shanxi & 5.21 & 4.84 & 4.91 & & & & & & & & & & & & & & & & & & & & & & & & & & \\
\hline Inner & 3.86 & 4.16 & 3.71 & 4.47 & & & & & & & & & & & & & & & & & & & & & & & & & \\
\hline Liaoning & 5.67 & 5.17 & 5.75 & 5.72 & 4.76 & & & & & & & & & & & & & & & & & & & & & & & & \\
\hline Jilin & 5.07 & 5.45 & 4.73 & 3.50 & 3.70 & 5.21 & & & & & & & & & & & & & & & & & & & & & & & \\
\hline Hei & 4.72 & 4.66 & 4.74 & 5.82 & 4.45 & 6.06 & 6.59 & & & & & & & & & & & & & & & & & & & & & & \\
\hline Shanghai & 3.14 & 3.19 & 2.85 & 3.10 & 3.15 & 3.17 & 2.97 & 3.03 & & & & & & & & & & & & & & & & & & & & & \\
\hline Jiangsu & 4.81 & 5.20 & 3.54 & 3.82 & 2.67 & 3.20 & 3.24 & 3.65 & 4.72 & & & & & & & & & & & & & & & & & & & & \\
\hline Zhejiang & 2.97 & 2.91 & 2.62 & 2.35 & 2.74 & 2.45 & 2.34 & 2.44 & 3.48 & 3.50 & & & & & & & & & & & & & & & & & & & \\
\hline Anhui & 3.35 & 3.31 & 3.38 & 3.85 & 3.40 & 4.14 & 3.87 & 3.65 & 3.25 & 4.85 & 3.14 & & & & & & & & & & & & & & & & & & \\
\hline Fujian & 2.10 & 2.23 & 1.94 & 2.32 & 2.34 & 2.34 & 2.12 & 2.14 & 2.38 & 3.50 & 3.26 & 2.44 & & & & & & & & & & & & & & & & & \\
\hline Jiangxi & 2.78 & 2.95 & 2.60 & 2.63 & 3.13 & 2.94 & 2.91 & 2.97 & 3.18 & 4.81 & 3.37 & 2.82 & 2.35 & & & & & & & & & & & & & & & & \\
\hline Shandong & 4.18 & 3.98 & 3.98 & 4.40 & 3.69 & 3.28 & 3.82 & 4.42 & 3.26 & 4.15 & 2.43 & 3.58 & 2.29 & 2.80 & & & & & & & & & & & & & & & \\
\hline Henan & 3.57 & 3.67 & 2.77 & 2.79 & 3.58 & 2.87 & 2.44 & 2.95 & 3.50 & 4.60 & 3.08 & 3.70 & 2.70 & 3.44 & 2.80 & & & & & & & & & & & & & & \\
\hline Hubei & 3.40 & 3.55 & 2.99 & 2.86 & 3.65 & 3.31 & 3.11 & 3.41 & 3.28 & 5.00 & 3.13 & 3.31 & 2.48 & 3.10 & 3.11 & 3.75 & & & & & & & & & & & & & \\
\hline Hunan & 3.12 & 3.33 & 2.82 & 2.56 & 2.68 & 2.71 & 2.70 & 2.97 & 4.10 & 2.94 & 3.58 & 3.48 & 3.31 & 3.87 & 2.87 & 3.62 & 3.90 & & & & & & & & & & & & \\
\hline Guangdong & 2.18 & 2.77 & 2.06 & 2.46 & 2.56 & 2.37 & 2.32 & 2.48 & 2.67 & 3.87 & 3.18 & 2.77 & 2.48 & 2.82 & 2.42 & 2.67 & 2.65 & 3.74 & & & & & & & & & & & \\
\hline Guangxi & 3.26 & 2.41 & 2.71 & 2.11 & 2.27 & 1.79 & 2.65 & 1.86 & 3.80 & 4.34 & 3.39 & 3.29 & 2.95 & 3.33 & 2.89 & 2.60 & 2.72 & 3.76 & 3.00 & & & & & & & & & & \\
\hline Hainan & 1.73 & 2.03 & 1.67 & 1.94 & 1.89 & 2.08 & 2.03 & 2.01 & 1.98 & 2.76 & 2.24 & 1.91 & 1.84 & 2.05 & 1.82 & 1.93 & 1.78 & 2.16 & 1.85 & 1.95 & & & & & & & & & \\
\hline Chongqing & 3.27 & 4.31 & 3.20 & 3.77 & 3.64 & 3.80 & 3.99 & 3.65 & 3.12 & 5.34 & 3.50 & 3.24 & 2.29 & 2.90 & 3.39 & 3.66 & 3.53 & 4.05 & 2.49 & 3.57 & 1.73 & & & & & & & & \\
\hline Sichuan & 3.22 & 3.38 & 2.74 & 2.97 & 3.34 & 3.18 & 3.02 & 3.16 & 3.39 & 4.60 & 3.33 & 3.16 & 2.70 & 3.16 & 3.01 & 3.53 & 3.37 & 3.66 & 2.98 & 3.40 & 1.78 & 3.38 & & & & & & & \\
\hline Guizhou & 3.20 & 3.41 & 3.03 & 3.37 & 3.15 & 3.65 & 3.97 & 3.46 & 3.35 & 5.19 & 3.36 & 2.78 & 2.62 & 3.50 & 3.20 & 3.64 & 3.09 & 3.32 & 3.23 & 3.18 & 2.78 & 3.14 & 3.64 & & & & & & \\
\hline Yunnan & 2.10 & 3.50 & 1.98 & 2.17 & 1.86 & 2.38 & 2.47 & 2.33 & 2.40 & 3.49 & 2.62 & 1.85 & 1.98 & 1.99 & 2.16 & 2.37 & 1.98 & 2.32 & 2.08 & 2.02 & 1.78 & 1.82 & 1.69 & 2.28 & & & & & \\
\hline Shaanxi & 3.45 & 3.39 & 3.62 & 4.56 & 3.48 & 4.70 & 4.62 & 4.10 & 3.07 & 5.18 & 3.25 & 3.13 & 2.34 & 2.86 & 3.55 & 3.77 & 3.39 & 3.51 & 2.54 & 3.38 & 1.58 & 3.14 & 3.15 & 2.77 & 1.94 & & & & \\
\hline Gansu & 3.68 & 3.81 & 3.44 & 3.88 & 3.84 & 4.14 & 4.11 & 3.98 & 3.47 & 2.94 & 3.23 & 3.34 & 2.47 & 3.12 & 4.12 & 3.87 & 3.59 & 3.65 & 2.14 & 2.79 & 2.00 & 3.71 & 3.53 & 3.27 & 2.19 & 3.55 & & & \\
\hline Qinghai & 3.37 & 3.42 & 3.27 & 3.89 & 3.62 & 3.92 & 4.16 & 3.82 & 3.34 & 5.27 & 3.37 & 3.04 & 2.33 & 2.97 & 3.47 & 3.75 & 3.34 & 3.39 & 3.03 & 3.47 & 2.12 & 3.20 & 3.24 & 3.04 & 2.31 & 3.03 & 3.51 & & \\
\hline Ningxia & 4.22 & 4.36 & 4.40 & 3.45 & 4.53 & 5.27 & 3.25 & 5.22 & 3.67 & 2.96 & 3.47 & 3.64 & 2.65 & 3.30 & 4.06 & 4.22 & 3.46 & 3.73 & 3.03 & 2.89 & 2.43 & 3.95 & 3.61 & 3.56 & 2.49 & 3.63 & 4.10 & 3.93 & \\
\hline Xinjiang & 4.15 & 3.77 & 4.51 & 5.76 & 4.02 & 5.88 & 7.17 & 5.87 & 2.57 & 4.33 & 2.85 & 3.22 & 1.93 & 2.81 & 4.09 & 3.60 & 3.47 & 3.12 & 2.17 & 3.21 & 1.80 & 3.84 & 3.46 & 2.11 & 1.97 & 3.45 & 3.52 & 3.09 & 4.35 \\
\hline
\end{tabular}


Note: for Table A.4.1 and A.4.2 a) The first row of provincial names for price series (which are exactly transposed order of provincial names in the first column) are omitted due to limited space. b) Critical values for Johansen trace test statistics with the null of no cointegration $\left(\mathrm{H}_{0}: \mathrm{r}=0\right)$ in Table A.4.1 are $24.60(1 \%), 19.96(5 \%), 17.85(10 \%)$, and the null of cointegration $\left(\mathrm{H}_{0}: \mathrm{r}=1\right)$ in Table A.4.2 are $12.97(1 \%), 9.24(5 \%), 7.52(10 \%)$.

Table A.5: Summary statistics

\begin{tabular}{clllll}
\hline Variable & Obs & Mean & Std. Dev. & Min & Max \\
\hline$\beta_{i j, 1}$ & 435 & 0.908 & 0.064 & 0.687 & 0.999 \\
$\hat{\sigma}_{\widehat{\beta}_{i j, 1}}$ & 435 & 0.027 & 0.012 & 0.008 & 0.089 \\
$\hat{\alpha}_{i}$ & 435 & -0.145 & 0.112 & -0.576 & 0.108 \\
$\hat{\sigma}_{\widehat{\alpha}_{i}}$ & 435 & 0.057 & 0.019 & 0.019 & 0.121 \\
$\hat{\alpha}_{j}$ & 435 & 0.160 & 0.118 & -0.208 & 0.537 \\
$\hat{\sigma}_{\widehat{\alpha}_{j}}$ & 435 & 0.061 & 0.020 & 0.021 & 0.138 \\
$\hat{\alpha}_{i j}$ & 435 & 0.306 & 0.103 & 0.086 & 0.669 \\
$\widehat{\operatorname{cov}}\left(\hat{\alpha}_{i}, \hat{\alpha}_{j}\right)$ & 435 & 0.002 & 0.002 & 0.000 & 0.011 \\
$\hat{\sigma}_{\widehat{\alpha}_{i j}}$ & 435 & 0.054 & 0.011 & 0.026 & 0.086 \\
$d_{i j}$ & 435 & 1.609 & 0.850 & 0.136 & 4.401 \\
$B_{i j}$ & 435 & 0.152 & 0.359 & 0.000 & 1.000 \\
$S_{a}$ & 435 & 0.527 & 0.268 & 0.063 & 1.408 \\
$\tau_{i j}$ & 435 & 0.971 & 0.015 & 0.925 & 0.997 \\
\hline
\end{tabular}

Table A.6: Summary statistics for magnitude of market efficiency frontier

\begin{tabular}{llllll}
\hline Variable & Obs & Mean & Std. Dev. & Min & Max \\
\hline Inefficiency & 435 & 0.944 & 0.050 & 0.760 & 0.994 \\
Efficiency & 435 & 0.059 & 0.055 & 0.006 & 0.275 \\
Frontier & 435 & 0.967 & 0.012 & 0.925 & 0.987 \\
\hline
\end{tabular}

Table A.7: Summary statistics for speed of restoring market efficiency frontier

\begin{tabular}{llllll}
\hline Variable & Obs & Mean & Std. Dev. & Min & Max \\
\hline Inefficiency & 435 & 0.055 & 0.033 & 0.019 & 0.196 \\
Efficiency & 435 & 0.947 & 0.030 & 0.822 & 0.981 \\
Frontier & 435 & 0.315 & 0.014 & 0.273 & 0.344 \\
\hline
\end{tabular}


Table A.8: Provincial inefficiency of magnitude of market efficiency frontier

\begin{tabular}{|c|c|c|c|c|}
\hline Province & Mean & $\begin{array}{l}\text { Std. } \\
\text { Dev. }\end{array}$ & Min & Max \\
\hline Jilin & 0.027 & 0.028 & 0.007 & 0.135 \\
\hline Heilongjiang & 0.026 & 0.030 & 0.006 & 0.119 \\
\hline Liaoning & 0.031 & 0.033 & 0.006 & 0.129 \\
\hline Beijing & 0.036 & 0.034 & 0.008 & 0.137 \\
\hline Tianjin & 0.037 & 0.037 & 0.007 & 0.141 \\
\hline Shandong & 0.037 & 0.037 & 0.008 & 0.137 \\
\hline Inner Mongolia & 0.038 & 0.037 & 0.007 & 0.152 \\
\hline Shanxi & 0.039 & 0.037 & 0.008 & 0.146 \\
\hline Zhejiang & 0.039 & 0.039 & 0.008 & 0.154 \\
\hline Chongqing & 0.041 & 0.039 & 0.006 & 0.146 \\
\hline Hebei & 0.042 & 0.039 & 0.008 & 0.169 \\
\hline Henan & 0.042 & 0.039 & 0.007 & 0.153 \\
\hline Hunan & 0.043 & 0.041 & 0.007 & 0.150 \\
\hline Jiangsu & 0.046 & 0.042 & 0.010 & 0.167 \\
\hline Jiangxi & 0.048 & 0.043 & 0.010 & 0.166 \\
\hline Hubei & 0.054 & 0.046 & 0.012 & 0.187 \\
\hline Gansu & 0.057 & 0.049 & 0.011 & 0.190 \\
\hline Xinjiang & 0.058 & 0.048 & 0.018 & 0.213 \\
\hline Qinghai & 0.058 & 0.051 & 0.010 & 0.222 \\
\hline Guangxi & 0.059 & 0.056 & 0.011 & 0.192 \\
\hline Shaanxi & 0.063 & 0.053 & 0.011 & 0.203 \\
\hline Anhui & 0.065 & 0.048 & 0.010 & 0.198 \\
\hline Sichuan & 0.066 & 0.052 & 0.011 & 0.195 \\
\hline Hainan & 0.073 & 0.058 & 0.020 & 0.234 \\
\hline Fujian & 0.082 & 0.056 & 0.018 & 0.227 \\
\hline Guizhou & 0.087 & 0.064 & 0.013 & 0.239 \\
\hline Yunnan & 0.090 & 0.065 & 0.013 & 0.248 \\
\hline Guangdong & 0.121 & 0.067 & 0.016 & 0.255 \\
\hline Shanghai & 0.133 & 0.063 & 0.016 & 0.275 \\
\hline Ningxia & 0.140 & 0.063 & 0.026 & 0.275 \\
\hline
\end{tabular}


Figure A.1 Transport Cost and Distance

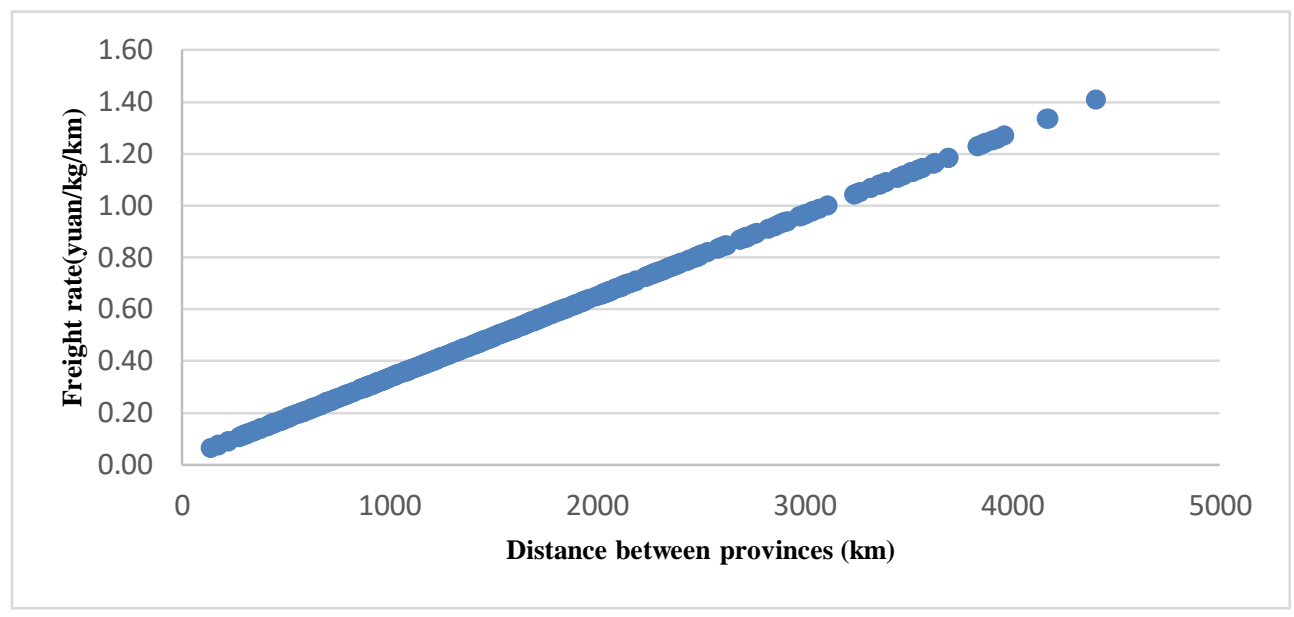

Note: a) The cost is 450 in total if distance is within $50 \mathrm{~km}$. b) Tax is included. c) Total weight of pork for one vehicle is 20 tonnes. Source: Suzhou Dongchen Logistics, Jiangsu province (2019). 


\title{
IV Comparing Market Efficiency Frontiers
}

Author: Yali Mu

\begin{abstract}
In the extensive empirical literature on testing the LOP, most studies find violations of the LOP and conclude that it does not hold. Rather than focusing on the simple acceptance/rejection of the LOP, it is more fruitful to compare actual adherence to this law with benchmarks. This concept is illustrated by analyzing the transmission of hog prices among 30 provinces in China and 23 member states in the EU. Two possible benchmarks are estimated, one for China and one for the EU by combining cointegration analysis with stochastic frontier analysis using monthly hog price data from July 2004 to December 2017. Stochastic frontier techniques make it possible to estimate a 'best practice' frontier for these estimated price transmission elasticities. For most market pairs the estimated elasticity of price transmission is below the empirical frontier - i.e. there is evidence of 'inefficiency' or less than perfect adherence to the LOP on both Chinese hog markets and the EU hog markets. In addition, significant provincial effects (China) and member-state effects (EU) in market efficiency are found. Comparing the two benchmarks, the results show that the empirical frontier estimates of the elasticity of price transmission in the EU are lower than in China. This may reflect higher transport costs and more stringent animal welfare-based restrictions on transporting live hogs in the EU.
\end{abstract}

Keywords: Spatial market integration, LOP, market efficiency, stochastic frontier, benchmark

\section{Introduction}

"All prices for a commodity are related over time, space and product form." (Blank and Schmiesing, 1988, p. 35). Spatial market integration involves linkages among markets separated by distance, which is often stated as the fundamental axiom - the "Law of One Price" (LOP) (von Cramon-Taubadel and Goodwin, 2021). An extensive empirical literature has accumulated to investigate these price linkages (relationship) or to test this "Law" for markets that are separated by space, time and form over the last decades. Studies from the 1960s are based on the analysis of correlation coefficients between prices (Harriss 1979). A shift from static price correlation models (Richardson, 1978) to dynamic models for price lag levels (Ravallion, 1986) generated new development in time series techniques employed on 
commodity market integration analysis. Cointegration methods developed by Engle and Granger (1987), Johansen (1991, 1995) and Pesaran et al. (2001) have been used to account for the nature of price series (purely stationary, purely nonstationay or mixed with stationary and nonstationary) (Getnet et al., 2005; Svanidze and Götz, 2019a). Recent studies are capable of accounting for non-linearity (Emmanouilidis and Fousekis, 2012) and threshold effects (threshold cointegration - Gonzalo and Pitarakis, 2006; non-parametric threshold cointegration - Serra et al., 2006). All of these studies are motivated to account for the fact that the relationship between two prices in space will not necessarily be fully transmitted with $100 \%$ completion over time due to phenomena such as changes in trade costs, government intervention policies, market transparency, and/or liquidity (Svanidze and Götz, 2019a), and changes in the direction of the trade (von Cramon-Taubadel and Goodwin, 2021).

The EU adopted the Single Market Program to complete a large integrated market and to foster dynamic efficiency of all goods and services since the early 1990s. The analysis of price relationships across space allows researchers to assess whether markets are segmented or integrated under the Single Market. At the same time, Chinese policymakers have paid much attention to price fluctuations and have issued some policies to make pork prices stable (Dong et al., 2018). Few studies on hog market analysis in China include spatial market integration analysis (Pan and $\mathrm{Li}, 2019 ; \mathrm{Mu}, 2018$ ), asymmetric price transmission with the pork market (Dong et al., 2018). A few studies have empirically investigated the spatial integration of national EU hog markets. Most of them assess the hog markets by testing the validity of the LOP (weak version or strong version ${ }^{1}$ or both) in small subsets of national markets by employing unit root tests and cointegration analysis under the assumption of linearity (Sanjuán and Gil, 2001; Sosvilla and Gil, 2004; Fousekis, 2007) or threshold cointegration under the assumption of nonlinearity (Serra et.al, 2006; Emmanouilidis and Fousekis, 2012; Emmanouilidis and Proskynitopoulos, 2019). Most find some evidence often of the weak version of the LOP on pork markets.

If we consider market efficiency to be synonymous with the economic concepts of equilibrium such as the LOP by following Barrett (2001), then in this situation opportunities for arbitrage have been exhausted (Fackler and Goodwin, 2001), therefore no unrealized potential Pareto improvements remain and markets are either in perfect integration or

\footnotetext{
${ }^{1}$ As Fackler and Goodwin (2001) note, the weak form of the LOP is the spatial arbitrage condition $\mathrm{P}_{\mathrm{t}}^{\mathrm{A}}-\mathrm{P}_{\mathrm{t}}^{\mathrm{B}} \leq \tau_{\mathrm{AB}}$; the strong form is with the relation in arbitrage condition taken with an equality sign (the presumption being that trade is continuous), $\mathrm{P}_{\mathrm{t}}^{\mathrm{A}}-\mathrm{P}_{\mathrm{t}}^{\mathrm{B}}=\tau_{\mathrm{AB}}$.
} 
segmented equilibrium (Barrett and Li, 2002). Under segmentation, profitability opportunities are not exhausted, thus resulting in efficiency losses (Serra et al., 2006).

Rather than focusing on the simple acceptance or rejection of the perfect integration of the LOP, we maintain that it is more fruitful to compare actual adherence to this law with benchmarks. The ultimate benchmark is the LOP in its strong version: For homogeneous commodities the same price at all locations at all times. However, this is analogous to the concept of frictionless motion in physics, behavior that will never be observed in reality. In the case of agricultural commodity markets, deviations from the strong form of the LOP will be caused by two types of 'friction': First, trade costs (which drive a wedge between equilibrium prices at different locations). Second, trade delays (which, even if trade were costless, would still imply that it takes time for markets to return to equilibrium if one or more of them are shocked).

It is possible to formulate weak forms of the LOP that account for these 'frictions', for example, spatial equilibrium theory (Takayama and Judge, 1971; Barrett and Li, 2002), according to which the price differences for homogeneous commodities at different markets will be less than or equal to the trade costs between these markets. However, in empirical applications, even these weaker benchmarks will not be attained. The problem is that our estimates of trade costs will generally be incomplete because only some trade costs (e.g. fuel costs for transport) are observable, but many others are not (e.g. risk preferences, insurance premiums, market information research, government interventions). Furthermore, some factors are specific for certain agricultural commodities that could not be easily measured (e.g. animal welfare, veterinary crises, farmers' protest).

In the following, we refer to the magnitude of market efficiency as the relative adherence extent to the strong version of the LOP, and in section 3 below we demonstrate that it can be measured using the long-run elasticity of price transmission between two markets. The basic idea is that we estimate the price transmission elasticity between two markets A and B which are spatially separated and compare these estimates with those for an otherwise identical pair of market $\mathrm{C}$ and market D. If we find that the estimated elasticity between $\mathrm{C}$ and $\mathrm{D}$ is lower than between $\mathrm{A}$ and $\mathrm{B}$, then we can conclude that the magnitude of market efficiency between $\mathrm{C}$ and $\mathrm{D}$ is lower than between $\mathrm{A}$ and market $\mathrm{B}$, market $\mathrm{C}$ and $\mathrm{D}$ adhere less to the strong form of the LOP than markets A and B. 
Of course, in reality, we will rarely if ever find otherwise identical pairs of markets for comparison. The magnitudes of market efficiency are not comparable since differences in technology, infrastructure, and institutions of markets might lead to differences in the volumes of trade that can flow between them per unit of time. However, we can use econometric techniques to control for observable and unobservable differences between market pairs. Unless all other things being equal, once benchmarks of market efficiency are established within a country, market efficiency is comparable at the interregional level. Similarly, once a benchmark is established for countries, market efficiency could be compared between countries at the international level.

Several studies do move forward to explain variations in the magnitude or speed of price transmission: Kouyaté and von Cramon-Taubadel (2016) identify geographic distance and international borders influence the magnitude and speed of market efficiency of cereal market by using meta-analysis. Kouyaté et al. (2016) show that distance, common borders, and common languages affect the likelihood of finding cointegration between rice markets in Western Africa; Holst and von Cramon-Taubadel (2013) identify that pig meat market integration of $15 \mathrm{EU}$ members is stronger between new or old EU members, whereas market integration is relatively weaker between new and old members. They also find more rapid price transmission between members both are Euro-zone or sharing common borders; $\mathrm{Mu}$ (2018) estimates the determinants of speed of price transmission and finds that proximity matters for market integration of pork markets in China. Svanidze and Götz (2019a) compare the effects of factors (e.g. geographic distance, export volumes) on elasticities of price transmission for Russia and the US.

In this paper we make two modifications to the literature outlined above, first focusing on the same agricultural commodity in two different economic systems during the same period. It can be expected that the EU hog markets differ a lot from Chinese hog markets even though both of them further increase their production due to structural changes of pig industry and optimal use of natural resources. Both China and the EU have the potential to produce more pigs. The pork production potential requires a spatially efficient hog market that ensures domestic integration between provinces in China and the international integration between member states of the EU. Nevertheless, a survey from supermarkets around the EU conducted by European Commission (2013) shows that imperfect market integration has been persistent over time, and prices for essentially identical commodities even in neighboring or comparable member states are not related so much. While studies for pork market in the EU and China 
show us variations in the degree of spatial integration between members in the EU (Holst and von Cramon-Taubadel, 2013; Emmanouilidis and Proskynitopoulos, 2019) or between provinces in China (Pan and Li, 2019; Mu, 2018) are large.

And second, estimating stochastic frontier to establish within-sample market efficiency frontiers against which performance can be measured, and comparing the established benchmarks by applying the procedure proposed in Chapter III. The stochastic frontier analysis enables us to identify the strongest examples of price transmission that can be attained in the given sets - China and the EU and attempts to explain why integration between markets is sometimes closer to or farther from this benchmark. In our application, the estimated frontier for China represents the strongest price transmission that is attainable between interprovincial pairs, and the estimated frontier for the EU represents the strongest price transmission that is attainable between international pairs, an individual market pair's distance from that frontier is considered to be a measure of their market inefficiency at interprovincial level or international level. Thus we could compare the market efficiency distributions and frontiers of China and the EU.

In this study, the empirical benchmarks of the hog market for both China and the EU could be assessed. Globally, the EU is the largest pork exporter (since 2013), whereas China is the largest pork producer and importer. Domestically, pork is mainly produced and consumed, and heavily traded within both China and the EU. Furthermore, the hog trade within China or the EU is covered by various geographic distances, which is essential for benchmarking market efficiency frontiers for spatially separated regions. The spatial integration of the international or interprovincial hog markets is also very heterogeneous. We aim to compare the spatial magnitude and frontier of hog market efficiency of the Chinese provinces against the EU member states.

We use monthly data on hog prices at the international (23 member states in the EU) and interprovincial (30 provinces in China) levels from July 2004 to December 2017. The basic objective is to further explore the strengths and limitations of the proposed method in Chapter III. The international hog markets in the EU sharing an average distance of $1610 \mathrm{~km}$ (up to $5100 \mathrm{~km}$ ), whereas interprovincial markets are separated by a relatively large average distance of $1890 \mathrm{~km}$ (up to $4400 \mathrm{~km}$ ). In the first step, we estimate the elasticities of price transmission between individual markets. In the second step, we benchmark the elasticities using stochastic frontier techniques and covariates such as the geographic distance and common border 
between the markets in question, and finally, we compare the estimated magnitude and frontier of market efficiency for China to the EU.

The rest of this paper is structured as follows: Section 2 compares China's and the EU's hog markets. In section 3 we outline the methodological framework and model specification. In section 4 we present the data that we use, and in section 5 we discuss empirical results. Conclusions and policy implications are drawn in the last section.

\section{Hog market characteristics of China and the EU}

In this section, the hog market of China is investigated in contrast with the EU by following a comparative approach. Table 1 presents some similarities and differences between the hog market in China and the EU.

Table 1 Characteristics of hog market of China and the EU

\begin{tabular}{lll}
\hline Characteristics & China & EU \\
\hline Primary livestock & Pig & Pig \\
The primary use of pork & Domestic consumption & Consumption and export \\
Average carcass weight & $77.64 \mathrm{~kg}$ & $88.28 \mathrm{~kg}$ \\
Transportation infrastructure & Road, rail, and barge & Road, rail, and barge \\
Pig welfare & Legislation developing & Legislation developed \\
Government intervention & Various intervention & Less intervention \\
Futures market & Since 2021 & Volume futures market \\
\hline
\end{tabular}

Note: Average carcass weight equals to total slaughtered hog weight amount divided by slaughtered heads using data from the Chinese Ministry of Agriculture (2018) and European Commission (2021).

The EU-23 produces approximately 23 million tons of pig meat from more than 249 million slaughtered pigs in $2017^{2}$. There were 144 million pigs in the 23 EU member states. Pigs are abundant in Denmark and the Netherlands while much scarcer in Greece and the UK and Slovenia and Slovakia. The hog industry is more intensive and more vertically integrated with some regions (Emmanouilidis and Fousekis, 2012; Gilbert, M. et al., 2015). The main production area extends from Denmark through northern Germany into the Belgium and Netherlands. To some extent, the location of farms for producing pigs in the EU is connected to easy access to ports where imported animal feed is unloaded (EPRS, 2020).

\footnotetext{
${ }^{2}$ All data quoted in this section for China are from the Ministry of Agriculture of China, and data for the EU are derived from Eurostat and refer to EU-23 in our study sample. More statistics could be found in Table A.4 in Appendix A.5.
} 
Similarly, hog production in China is concentrated in spatially protracted locations due to large and geographic variations (e.g. the natural environment, economic and social structure) ${ }^{3}$. There were 442 million pigs in China in 2017, around 702.02 million pigs were slaughtered in China, the overall pork production was 54.52 million tonnes. Pigs are abundant in Yunnan and Hunan, while much scarcer in Shanghai and Ningxia in 2017. Currently, the main hogproducing regions are located along the Yangtze River Northwards (Xiao et al., 2012). China's "Corn Belt" mainly dominates pork production, accounting for nearly $50 \%$ of total Chinese pork production in $2017 .^{4}$

Pig meat is produced with huge differences in methods and sizes of farms between member states: from small diversified farms keeping just one or two pigs to industrial installations with thousands of pigs, and from extensive organic farming to conventional intensive production. For example, Germany has the largest share of pig meat production (2017) in the EU with advantageous geographical location (easy access to sea ports, close to the members from which feed material is imported with small distances - Denmark and the Netherlands), high per capita pork consumption of pork (about $55 \mathrm{~kg}$ per year in 2017), and farmers' abundant experience (Stępień and Polcyn, 2016). Danish pork market is dominated by a cooperative system of meat processing and distribution. Almost the entire pig production is processed by cooperatives that manage nearly $90 \%$ of the total produced pork. French pig farmers have strongly developed cooperation, they also hold stakes in the slaughterhouses to which they supply their pigs. Overall, the EU pig industry is more intensive and more vertically integrated (Gilbert, M. et al., 2015).

The pork production system in China is still extensive with high densities of raised pigs (Gilbert, M. et al., 2015) from various sized farms (such as large commercial, medium-sized specialized) and small backyards (Tian and Cramon-Taubadel, 2020), moreover, the Chinese pig industry is not highly vertically integrated (Zhang et al., 2019). In 2010, around 450 million heads of pigs were from farms with less than 100 finished pigs, which still accounted for about half of all slaughtered pigs in China.

\footnotetext{
${ }^{3}$ For example, pork production and pork consumption in China is officially divided into six regions: the Yangtze River, North China, Northeast, Southeast, Municipalities and Other regions (Zhang et al., 2005).

${ }^{4}$ Stretching from northeast to southwest across China, the "Corn Belt" includes 11 provinces and is divided into three regions (1) Northeast region: Heilongjiang, Jilin, Liaoning and Inner Mongolia; (2) Yellow river-Huai river-Hai river region: Hebei, Henan, Shandong and Shanxi; and (3) Southwest mountainous region: Shaanxi, Sichuan and Yunnan (China Statistics Yearbook, 2012).
} 
There exist relevant differences in average carcass weights, diet, and shopping place preferences across China and the EU member states. In 2017, the carcass weight produced across China is quite close with an average of $77.64 \mathrm{~kg}$, while the average carcass weight from the EU members varies a lot. The average weight is $88.28 \mathrm{~kg}$. The pig meat carcass weighs heaviest over $120 \mathrm{~kg}$ from Italy while the lightest under $60 \mathrm{~kg}$ from Greece. Although under the certain assumption, diets from the various regions of the world are all converging towards a so-called "Western diet" (Le Mouël and Forslund, 2017, p.14), diets convergence between China and the EU is limited. But animal protein is mainly from pig meat products for both Chinese and EU consumers. Wet markets ${ }^{5}$ and small meat stores widely speed in both rural and urban areas in China that attract traditional consumers shopping for their convenience. For example, survey evidence in Beijing, Guangzhou, and Shanghai in 2014 shows that over $40 \%$ of citizens only buy fresh pork in the local wet market (Xiao, 2016, Maruyama et al., 2016). While in the EU, grocery stores and supermarkets with cold storage facilities are the destinations for most consumers.

The Chinese policy makers have implemented various policies designed to increase pig production and stabilize pork prices including subsidies and support for productive sows, breed improvement, disease control, the construction of large-scale pig farms, incentives for counties to increase the sale of live pigs, and centralized slaughtering policy. The state has implemented direct pork purchase, stockpiling, and market release policies designed to stabilize the market (Dong et al., 2019). ${ }^{6}$ The EU policy makers have intervened less in pig markets relative to the markets of other livestock products (Serra et al., 2006; Emmanouilides and Fousekis, 2012). For example, the unsolved "pork crisis" triggered protests and block pork shipments from Germany and Spain by French pig farmers (USDA, 2015). ${ }^{7}$

China has made supernormal investments in road and rail infrastructure development in both rural and urban areas in the past decades (Newell et al., 2009), which significantly reduce the costs in transporting inputs and acquiring market information. China just launched live pig futures in Dalian (Liaoning province) at the very beginning of 2021 and becomes the secondlargest live pig future trade after the US. The EU farmers and hog buyers have participated

\footnotetext{
${ }^{5}$ Each wet market consists of many individual stalls that offer fresh vegetable and fruit, live fish, and fresh meat and incur few or no menu costs in adjusting prices.

${ }^{6}$ In May 2012, the National Development and Reform Commission issued a "reserve regulation plan to ease the cyclical fluctuation of live pig prices."

${ }^{7}$ Pig farmers in the EU have been complaining for years about low pork prices, leading many to refer to the persistent low EU prices as a "pork crisis".
} 
earlier in hog futures markets since futures exchanges are operated earlier in some EU members (e.g. the Dutch Hog Futures Exchange, Amsterdam, or Hannover Stock Exchange). However, the number of knowledgeable pig farmers and operators at the futures exchanges is few (Meulenberg and Pennings, 2002). Crucial factors such as complex trade logistics, stringent quality-control standards, immature futures contracts for operating futures contracts, and a retail trading community that has wildly distorted markets in other countries will be challenges for China as well (Reuters, 2020). Further developing hog futures markets benefit both China and the EU.

In summary, the Chinese hog market is characterized by a large number of small holders from producers, wet markets to hot meat-preferring consumers with stabilizing prices under government's interventions, while the EU hog market is with more large modern hog producers, supermarkets, and chilled pork-preferring consumers with less intervention from the EU policymakers. Market characteristics other than geographic distance (and its associated transport costs) can also affect price relationships. The causes of incomplete hog price transmission may also encompass the intervention policy from authorities, especially if it is non-transparent (Liefert, 2009) and non-consistent (e.g. different extent of compliance with pig welfare regulations) and intervention by farmers ("pork crisis" in the EU). Imperfect market transparency and information flows of hog markets might also prevent full-price transmission. In any case, price transmission patterns are likely to have been altered by both supply and demand for pig meat changing and policy interventions triggering (Serra et al., 2006).

\section{Methods and specification}

The procedure to benchmark the magnitude of market efficiency is following the proposed method in Chapter III. First, a pairwise approach to estimate price transmission elasticity is similar to that employed in the earlier studies outlined above (e.g. Getnet et al., 2005; Svanidze and Götz, 2019a). In the second step, we estimate stochastic market efficiency frontiers of the estimated magnitude of market efficiency. 


\subsection{Measurement and determinants of market efficiency}

The first step of our procedure is similar to that employed in Chapter III, we estimate equation (1) to get the elasticity of price transmission $\left(\beta_{i j, 1}\right)$ from market $j$ to market $i$ in the long-run equilibrium relationship: ${ }^{8}$

$$
\ln p_{i, t}=\beta_{i j, 0}+\beta_{i j, 1} \ln p_{j, t}+\epsilon_{t}
$$

$i, j=\{1,2, \ldots, 30\}$ index provinces in China; $i, j=\{1,2, \ldots, 23\}$ index member states in the EU. Estimation is carried out for the 435 pairs of provinces in China and 253 pairs of member states in the EU for which $i>j$. The index $t=\{1,2, \ldots, 162\}$ counts monthly price observations from July 2004 to December 2017.

435 and 253 estimates of the elasticity of price transmission $\left(\hat{\beta}_{i j, 1}\right)$ are generated from the first-step estimation for China and the EU, respectively. We consider the estimated $\hat{\beta}_{i j, 1}$ to be measures of the relative magnitude of market efficiency defined above.

In the second step of our procedure, we estimate stochastic frontier models for $\hat{\beta}_{i j, 1}$ :

$$
\hat{\beta}_{i j, 1}=X_{k} \gamma+\left(v_{i j}-u_{i j}\right)
$$

where $X_{k}$ is a vector of variables that are expected to influence $\hat{\beta}_{i j, 1}$, such as the distance $d_{i j}$ and common border $B_{i j}$ between the markets, and $\gamma$ is a vector of parameters to be estimated.

We consider $\hat{\beta}_{i j, 1}$ as the magnitude of market efficiency following Chapter III. The strong form of the LOP noted by Fackler and Goodwin (2001) can be written as:

$$
p_{i}=p_{j}+\tau_{i j}
$$

where $\tau_{i j}$ represents the trade costs from market $j$ to market $i$. The elasticity of price transmission between two markets that satisfy this condition, $\eta_{i j}^{P T}$, is defined as

$$
\eta_{i j}^{P T}=\frac{\partial p_{i}}{\partial p_{j}} * \frac{p_{j}}{p_{i}}=\frac{p_{i}-\tau_{i j}}{p_{i}}=1-\frac{\tau_{i j}}{p_{i}}
$$

which could be interpreted as the cost-share of the commodity in the lower-price market $j$ in the price of the commodity in the higher-price market $i .^{9}$ The higher the trade $\operatorname{costs} \tau_{i j}$, the

\footnotetext{
${ }^{8}$ All prices are in natural logarithms, We normalise the long-run equilibrium relationship in equation (1) on the higher of the two prices, so that $\beta_{i j, 1}$ is expected to be less than or equal to 1 .
} 
lower the elasticity of price transmission between them. We assume that commodity trade costs are a function of the distance between two markets: $\tau_{i j}=f\left(d_{i j}\right)$, where $d_{i j}$ is the distance between markets $i$ and $j$, and with $\frac{\partial f\left(d_{i j}\right)}{\partial d_{i j}}>0$.

First, consider markets within a country (within China or the EU), combining equations (3) and (4), we expect that the magnitude of market efficiency between two markets is a decreasing function of the distance between them. Hence, we expect that $\hat{\beta}_{i j, 1}$, which is an estimate of the elasticity $\eta_{i j}^{P T}$, will decrease with the increasing distance between markets $i$ and $j$. The stochastic frontier for $\hat{\beta}_{i j, 1}$ as a function of $d_{i j}$, which we label $\beta_{i j, 1}^{*}$, defines for any given $d_{i j}$ the maximum elasticity of price transmission, and thus the minimum value of $\tau_{i j}$ that can be attained in the setting under consideration (such as hog markets in China or the EU).

Second, consider markets between countries (between China and the EU), transport costs are different due to regulations (animal welfare), interruption during shipment ("hog crisis"), etc. In this case, the cost share of transport in the EU is higher, correspondingly, the elasticity of price transmission is lower in general, so we would expect the magnitude of market efficiency in the EU is lower than in China. And the estimated frontier $\beta_{i j, 1}^{*}$ of the EU might lie below the frontier of China.

\subsection{Model specification}

In the empirical application, markets $i$ and $j$ are provinces in China and member states in the EU. Before estimating, we first do the ADF test (Said and Dickey, 1984) to check the nature of price series (stationary or nonstationary). Then Johansen cointegration test (Johansen, 1988) and the bounds testing approach (Pesaran et al., 2001) are used to check the existence of the long-run equilibrium for all the unique hog price pairs for both China and the EU.

The selection of the appropriate econometric model to estimate the elasticity of price transmission depends on the previously tested characteristics of the price series (in Appendix A.3), resulting in three cases as talked about in detail in Appendix A.4.

As mentioned above, distance $d_{i j}$ between markets, $i$ and $j$ is included in the vectors $X_{k}$ in the frontier models (4). It is expected that the frontier magnitude will fall in both China and the

\footnotetext{
${ }^{9}$ The same as footnote 24 in Chapter III ( $\mathrm{S}_{\mathrm{a}}$ in Gardner's notation).
} 
EU as $d_{i j}$ increases. The stochastic frontier for $\hat{\beta}_{i j, 1}$ as a function of $d_{i j}$, which we label $\beta_{i j, 1}^{*}$, defines for any given $d_{i j}$ the maximum elasticity of price transmission, and thus the minimum value of transport cost that can be attained in the setting under consideration (such as hog markets in China and the EU). We, therefore, interpret deviations from the frontier $\beta_{i j, 1}^{*}$ as deviations from the maximum attainable market efficiency. For example, $\hat{\beta}_{i j, 1}$ for a specific pair of markets $i$ and $j$ separated by distance $d_{i j}$ might lie below the frontier $\beta_{i j, 1}^{*}$ at $d_{i j}$ because transport cost between the two markets is higher than it could be based on the evidence provided by the full set of $\hat{\beta}_{i j, 1}$ for all available market pairs.

In addition, a dummy variable $B_{i j}$ in included which equals 1 if markets $i$ and $j$ share a common border (interprovincial for China and international for the EU). If borders between provinces in China or the EU impede trade flow or information flow in any manner, then all other things being equal, a higher market efficiency frontier is expected to be attained between markets that share a common border.

$v_{i j}$ in equation (2) are two-sided error terms, $v_{i j} \sim N\left(0, \sigma_{v_{i j}}^{2}\right)$ capture random factors such as measurement error. Since the dependent variables $\hat{\beta}_{i j, 1}$ are estimated, $v_{i j}$ are heteroscedastic. Therefore we model heteroscedasticity as $\sigma_{v_{i j}}^{2}=\exp \left(V_{i j} \zeta\right) . V_{i j}$ are vectors that include a constant term and the estimated standard errors $\left(\hat{\sigma}_{\widehat{\beta}_{i j, 1}}\right)$ of the estimated $\hat{\beta}_{i j, 1} \cdot \zeta$ is a parameter vector to be estimated. While the estimated standard errors $\hat{\sigma}_{\widehat{\beta}_{i j, 1}}$ of the $\hat{\beta}_{i j, 1}$ are directly attainable by-products from the estimation of equation (1).

The one-sided error terms $u_{i j}$ are assumed to be half normal distributed $\left(u_{i j} \sim N^{+}\left(0, \sigma_{u}^{2}\right)\right)$ and uncorrelated with $v_{i j}$. The market pair $i, j$ attains the market efficiency frontier with no inefficiency if $u_{i j}=0$, and correspondingly there is inefficiency if $u_{i j}>0 . \sigma_{u_{i j}}^{2}=\exp \left(Z_{i j} \lambda\right)$, vectors $Z_{i j}$ are province dummies in the one-sided inefficiency terms $u_{i j}$ to capture provincespecific effects (such as differences in the quality of infrastructure, cultural and religious differences) for China, and member state dummies to capture state-specific effects for the EU that explain inefficiency. $\lambda$ are parameters to be estimated. 


\section{Data}

\subsection{Price series data}

To look into the integration of Chinese and EU primary hog markets more thoroughly, the market efficiency analysis is conducted for the hog producing regions of China at the interprovincial level and the EU at the international level from July 2004 to December 2017. Monthly prices of the hog (Yuan/ $\mathrm{kg}$ ) for 30 provinces in China are used at the interprovincial level. Tibet is excluded because of missing data. Correspondingly, monthly hog prices (Euro/kg) for $23 \mathrm{EU}$ member states are employed at the international level. Two isolated members owing very small size (Malta and Cyprus) and two recently joined (after the beginning of our study period) members (Bulgaria in 2007 and Croatia in 2013) are excluded. The United Kingdom is included since the study period is before Brexit (official date: January 31, 2020). Table 2 describes the price series and sources for the data used in this study, names and capitals of the analyzed markets is presented in detail in Appendix A.1, while several typical hog price series selected from a set of 30 in China and a set of 23 in the EU are plotted in Figure A.1 and Figure A.2 Appendix A.2. Thus, we analyze 435 provincial hog price pairs for China and 253 member-state hog price pairs for the EU, respectively.

Table 2: Database underlying the market efficiency analysis

\begin{tabular}{llll}
\hline Hog markets & Price pairs & Price frequency & Source \\
\hline $\begin{array}{l}\text { Interprovincial } \\
\text { China (30 provinces) }\end{array}$ & 435 & Monthly (162 obs.) & Min. of Ag. (2018) \\
$\begin{array}{l}\text { International } \\
\text { EU (23 members) }\end{array}$ & 253 & Monthly (162 obs.) & European Commission (2021) \\
\hline
\end{tabular}

\subsection{Measure of market efficiency frontier}

In the second step, stochastic frontier models are estimated for the magnitude of market efficiency $\left(\hat{\beta}_{i j, 1}\right)$ for each market pair between July 2004 and December 2017. Distribution of the estimated $\hat{\beta}_{i j, 1}$ for China and the EU, hog markets are provided in Figure 2 in the following section 5 . The statistical description of estimated $\hat{\beta}_{i j, 1}$ for each interprovincial price pair in China and international price pair in the EU are reported in Table 5 in section 6.1. 
Distance $\left(d_{i j}\right.$ in $1000 \mathrm{~km}$ between provincial capitals in China or between member-state capitals in the EU), common borders are measured as determinants of the frontier of market efficiency. 29 province dummies for China and 22 states dummies for EU are introduced separately to consider the differences (culture, religion) between provinces in China and between member states in the EU. A detailed description of all variables and their source is described in Appendix A.5, whereas key descriptive statistics of these variables for interprovincial and international analysis are summarized in Table 5 in section 6.1.

\section{Results}

At the interprovincial level, for each of the 30 hog price series of Chinese provinces individually the ADF test (Said and Dickey, 1984) fails to reject the null hypothesis that the series is $\mathrm{I}(1)$, but rejects this null hypothesis for the first differences of the hog prices. While at the international level, the hog price series of the $23 \mathrm{EU}$ member states are mixes of I(1) and I(0) (Appendix B). So linear cointegration by using Johansen's (1991; 1995) trace test of the price pairs are involved in the whole set for our analysis first. In response for pairs with $\mathrm{I}(1)$ and $\mathrm{I}(0)$ or both $\mathrm{I}(0)$ pairs in the international analysis, then we use the bounds testing approach by using Pesaran and Shin (1998) and Pesaran et al. (2001). Cointegration test results are presented in detail in Appendix A.4.

First step: Figure 2 presents the distribution of the 435 estimated elasticities of the long-run price transmission $\left(\hat{\beta}_{i j, 1}\right)$ for China and the 253 estimated elasticities for the EU. The estimates range between zero and one and the magnitude of $\hat{\beta}_{i j, 1}$ is higher than 0.6 for all the Chinese cases. However, over one-third of the 253 estimated $\hat{\beta}_{i j, 1}$ is lower than 0.6 for all the EU cases, indicating a higher incidence of a lower magnitude of market efficiency in the EU compared to China. More than a half of the 435 estimated $\hat{\beta}_{i j, 1}$ for China are greater than 0.9; while only 52 of the 253 estimated $\hat{\beta}_{i j, 1}$ for the EU are greater than 0.9. 
Figure 2: Distribution of $\widehat{\boldsymbol{\beta}}_{i j, 1}$ for China and the EU

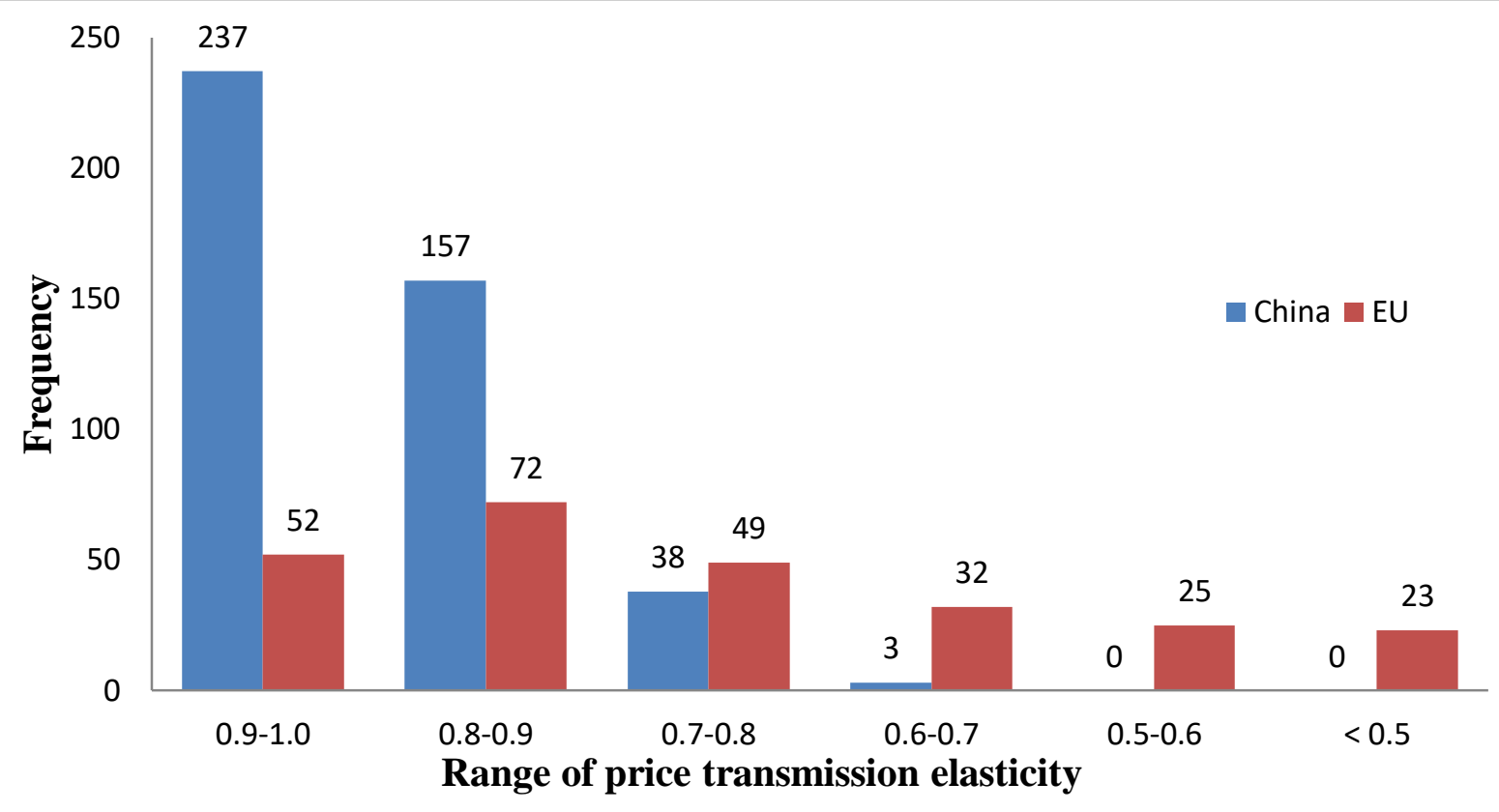

Source: Own calculations using Chinese Ministry of Agriculture (2018) and European Commission (2021).

Second step: Tables 3 and 4 present the estimation results of the frontier model for the magnitude of market efficiency (equation (4), the dependent variable $\hat{\beta}_{i j, 1}$ ) for China and the EU respectively. According to these results, the frontier of $\hat{\beta}_{i j, 1}$ falls by $1 \%$ per $1000 \mathrm{~km}$ of distance between two provinces in China and $3.3 \%$ per $1000 \mathrm{~km}$ of the distance between two member states in the EU. The difference in the influence of distance on $\hat{\beta}_{i j, 1}$ in China and the EU at the two levels of market efficiency analysis provides further evidence of the dissimilarity in the underlying fundamental mechanism of market efficiency. Sharing a common border has expected a positive but insignificant effect on the magnitude of market efficiency. The estimated frontier for China is above the estimated frontier for the EU, while the influence of distance increases three times in the EU at the international level compared to China at the interprovincial level. 
Table 3: Estimated magnitude of market efficiency frontier of China (Heilongjiang omitted, 30 provinces)

\begin{tabular}{|c|c|c|c|c|c|c|}
\hline $\begin{array}{c}\text { Model } \\
\text { component }\end{array}$ & Variable & Coefficient & $\begin{array}{l}\text { Standard } \\
\text { Error }\end{array}$ & $\begin{array}{c}\mathrm{t}- \\
\text { Statistic }\end{array}$ & \multicolumn{2}{|c|}{$\begin{array}{c}95 \% \text { confidence } \\
\text { interval }\end{array}$} \\
\hline \multirow{3}{*}{$\begin{array}{c}\text { Efficiency } \\
\text { frontier } \\
\left(X_{i t} \gamma\right)\end{array}$} & Constant & 0.994 & 0.005 & 188.36 & 0.984 & 1.004 \\
\hline & $d_{i j}$ & -0.010 & 0.003 & -3.3 & -0.016 & -0.004 \\
\hline & $B_{i j}$ & 0.004 & 0.005 & 0.81 & -0.006 & 0.014 \\
\hline \multirow{2}{*}{$\begin{array}{c}\text { Random error } \\
\sigma_{v_{i j}}^{2}=\exp \left(V_{i j} \zeta\right)\end{array}$} & Constant & -8.644 & 0.469 & -18.43 & -9.563 & -7.725 \\
\hline & $\hat{\sigma}_{\widehat{\beta}_{i j, 1}}$ & 14.879 & 9.263 & 1.61 & -3.276 & 33.035 \\
\hline \multirow{30}{*}{$\begin{array}{l}\text { Inefficiency term } \\
\sigma_{u_{i j}}^{2}=\exp \left(Z_{i j} \lambda\right)\end{array}$} & Constant & -8.207 & 0.645 & -12.73 & -9.471 & -6.944 \\
\hline & Tianjin & 0.186 & 0.428 & 0.43 & -0.653 & 1.025 \\
\hline & Shandong & 0.238 & 0.428 & 0.56 & -0.602 & 1.078 \\
\hline & Hebei & 0.280 & 0.422 & 0.66 & -0.546 & 1.107 \\
\hline & Jiangsu & 0.329 & 0.422 & 0.78 & -0.497 & 1.156 \\
\hline & Henan & 0.359 & 0.428 & 0.84 & -0.480 & 1.198 \\
\hline & Guangxi & 0.378 & 0.413 & 0.92 & -0.430 & 1.187 \\
\hline & Shanxi & 0.419 & 0.423 & 0.99 & -0.409 & 1.247 \\
\hline & Hubei & 0.478 & 0.423 & 1.13 & -0.352 & 1.308 \\
\hline & Liaoning & 0.501 & 0.412 & 1.21 & -0.307 & 1.308 \\
\hline & Ningxia & 0.537 & 0.421 & 1.28 & -0.288 & 1.362 \\
\hline & Inner & 0.543 & 0.421 & 1.29 & -0.281 & 1.368 \\
\hline & Hunan & 0.573 & 0.425 & 1.35 & -0.260 & 1.406 \\
\hline & Jilin & 0.577 & 0.413 & 1.4 & -0.233 & 1.387 \\
\hline & Shaanxi & 0.771 & 0.418 & 1.84 & -0.048 & 1.591 \\
\hline & Qinghai & 1.171 & 0.444 & 2.64 & 0.302 & 2.041 \\
\hline & Anhui & 1.294 & 0.438 & 2.96 & 0.436 & 2.152 \\
\hline & Xinjiang & 1.663 & 0.480 & 3.46 & 0.722 & 2.605 \\
\hline & Guizhou & 2.068 & 0.419 & 4.94 & 1.248 & 2.889 \\
\hline & Jiangxi & 2.199 & 0.441 & 4.99 & 1.335 & 3.063 \\
\hline & Zhejiang & 2.289 & 0.442 & 5.18 & 1.422 & 3.156 \\
\hline & Gansu & 2.434 & 0.424 & 5.74 & 1.603 & 3.266 \\
\hline & Beijing & 2.483 & 0.452 & 5.49 & 1.597 & 3.369 \\
\hline & Yunnan & 2.904 & 0.425 & 6.83 & 2.071 & 3.737 \\
\hline & Hainan & 3.008 & 0.434 & 6.92 & 2.156 & 3.859 \\
\hline & Fujian & 3.056 & 0.446 & 6.85 & 2.181 & 3.931 \\
\hline & Shanghai & 3.058 & 0.452 & 6.76 & 2.171 & 3.944 \\
\hline & Chongqing & 3.182 & 0.436 & 7.3 & 2.327 & 4.036 \\
\hline & Sichuan & 3.336 & 0.437 & 7.64 & 2.480 & 4.193 \\
\hline & Guangdong & 3.613 & 0.450 & 8.03 & 2.731 & 4.494 \\
\hline
\end{tabular}


Table 4: Estimated magnitude of market efficiency frontier of EU (Hungary omitted, 23 members)

\begin{tabular}{c|c|c|c|c|cc}
\hline $\begin{array}{c}\text { Model } \\
\text { component }\end{array}$ & Variable & Coefficient & $\begin{array}{c}\text { Standard } \\
\text { Error }\end{array}$ & $\begin{array}{c}\text { t- } \\
\text { statistic }\end{array}$ & \multicolumn{2}{|c}{$\begin{array}{c}\text { 95\% confidence } \\
\text { interval }\end{array}$} \\
\hline Efficiency & Constant & 0.921 & 0.023 & 39.43 & 0.875 & 0.967 \\
frontier & $d_{i j}$ & -0.033 & 0.011 & -2.95 & -0.055 & -0.011 \\
$\left(X_{i t} \gamma\right)$ & $B_{i j}$ & 0.019 & 0.020 & 0.94 & -0.021 & 0.058 \\
\hline Random error & Constant & -5.593 & 0.245 & -22.8 & -6.074 & -5.112 \\
$\sigma_{v_{i j}}^{2}=\exp \left(V_{i j} \zeta\right)$ & $\hat{\sigma}_{\widehat{\beta}_{i j, 1}}$ & 7.762 & 1.478 & 5.25 & 4.866 & 10.659 \\
\hline \multirow{3}{*}{} & Constant & -7.678 & 1.222 & -6.28 & -10.073 & -5.282 \\
& Slovakia & 0.113 & 1.175 & 0.1 & -2.191 & 2.416 \\
& Czechia & 0.195 & 0.992 & 0.2 & -1.750 & 2.139 \\
& Spain & 0.299 & 1.042 & 0.29 & -1.744 & 2.342 \\
& Austria & 0.400 & 0.755 & 0.53 & -1.079 & 1.880 \\
& Italy & 0.484 & 0.994 & 0.49 & -1.465 & 2.432 \\
& Estonia & 0.558 & 0.914 & 0.61 & -1.233 & 2.350 \\
& Netherlands & 0.771 & 0.726 & 1.06 & -0.652 & 2.194 \\
& Latvia & 0.776 & 0.749 & 1.04 & -0.691 & 2.243 \\
& Lithuania & 0.874 & 0.748 & 1.17 & -0.592 & 2.340 \\
$\sigma_{u_{i j}}^{2}=\exp \left(Z_{i j} \lambda\right)$ & Germany & 0.875 & 0.772 & 1.13 & -0.638 & 2.387 \\
& Ireland & 0.880 & 0.827 & 1.06 & -0.740 & 2.500 \\
& France & 0.947 & 0.801 & 1.18 & -0.623 & 2.516 \\
& Denmark & 1.183 & 0.850 & 1.39 & -0.482 & 2.849 \\
& Luxembourg & 1.251 & 0.753 & 1.66 & -0.225 & 2.727 \\
& Finland & 1.268 & 1.070 & 1.19 & -0.829 & 3.365 \\
& Belgium & 1.527 & 0.738 & 2.07 & 0.080 & 2.973 \\
& Slovenia & 1.819 & 0.772 & 2.36 & 0.306 & 3.333 \\
& Portugal & 2.316 & 0.795 & 2.91 & 0.758 & 3.873 \\
& Poland & 2.988 & 0.758 & 3.94 & 1.503 & 4.474 \\
& Greece & 3.379 & 0.796 & 4.25 & 1.819 & 4.939 \\
& Sweden & 3.863 & 0.784 & 4.93 & 2.327 & 5.398 \\
& 5.298 & 0.864 & 6.13 & 3.603 & 6.992 \\
\hline \multirow{3}{*}{${ }^{*}$} & & & & &
\end{tabular}

Source: Own estimations.

Figure 3 presents a scatterplot of the 688 estimates of $\hat{\beta}_{i j, 1}$ (435 estimates for China and 253 estimates for the EU) against distance $d_{i j}$ as well as the estimated market efficiency frontiers based on the results in Table 3 for China and Table 4 for the EU. We see the estimated frontiers for both China and the EU differ considerably from the OLS estimates.

In Figure 3 we highlight all of the market pairs that include Heilongjiang (the most efficient province) as well as all of the market pairs that include Guangdong (the least efficient province). In comparison, we highlight all of the market pairs that include Hungary (the most efficient member) as well as all of the market pairs that include Sweden (the least efficient member) in the EU. It is readily apparent that the individual $\hat{\beta}_{i j, 1}$ are on average farther from 
the frontier for market pairs that include Guangdong than for market pairs that include Heilongjiang in China; similarly, the individual $\hat{\beta}_{i j, 1}$ are on average farther from the frontier for market pairs that include Sweden than for market pairs that include Hungary in the EU.

As expected, the estimated standard errors of the estimates of $\hat{\beta}_{i j, 1}$ from the first step of the analysis $\left(\widehat{\sigma}_{\widehat{\beta}_{i j, 1}}\right)$ have a significant positive influence on the variance of the random error $v_{i j}$ $\left(\sigma_{v_{i j}}^{2}\right)$. Furthermore, there are significant provincial effects and member-state effects in the variance $\sigma_{u_{i j}}^{2}$ of the one-sided inefficiency term $u_{i j}$. We have omitted the dummy for the province Heilongjiang in the estimation for China and Hungary in the estimation for the EU; all other province dummies and member state dummies have positive effects on the variance of the inefficiency term (increasing from the top to the bottom of the list in Table 3 and Table 4). This indicates that the variance of the inefficiency term is higher for market pairs that include these other provinces or these other member states. In some cases (e.g. Tianjin and Shandong at the top of the list of Table 3; Slovakia and Czechia at the top of the list of Table 4) the estimated additional variance relative to Heilongjiang or Hungary is small and insignificant; moving down the list it becomes larger, and from Shaanxi province onward it is statistically significant at the 5\% level for China; and from Belgium onward it is statistically significant at the $5 \%$ level for the EU. The provinces near the top (bottom) of the list in Table 3 and the member states near the top (bottom) of the list in Table 4 are also the provinces and members that attain the highest (lowest) average magnitudes of market efficiency. 
Figure 3: Estimated $\widehat{\boldsymbol{\beta}}_{i j, 1}$ and market efficiency frontier in China and the EU

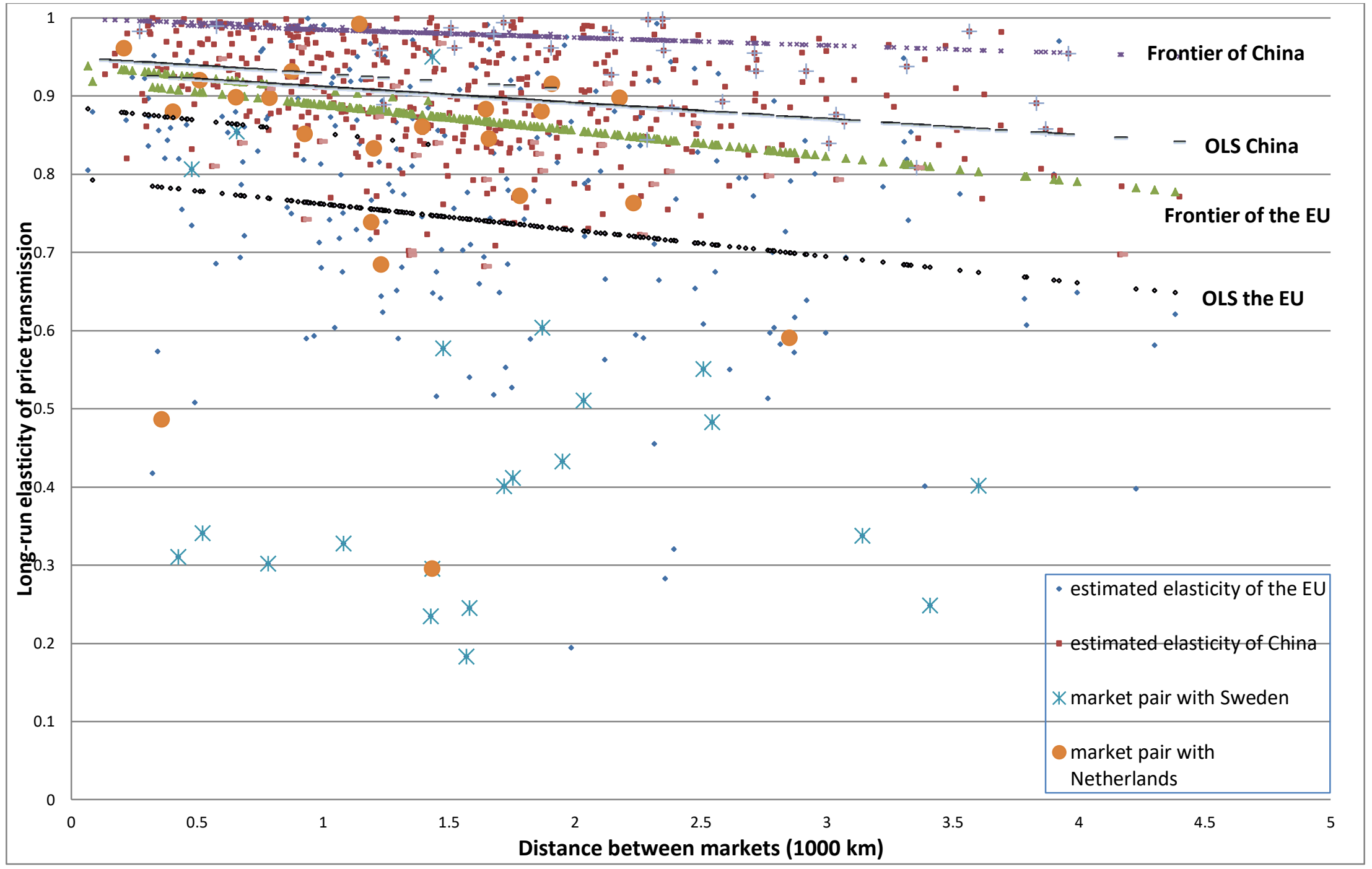

Source: Own estimations using Chinese Ministry of Agriculture (2018) and European Commission (2021). 


\section{Discussion and policy implications}

Market efficiency for both China and the EU are benchmarked and compared by following the proposed two-step procedure in Chapter III: first price transmission elasticities, in the long run, are obtained as the magnitude of market efficiency by utilizing method based on the stationary or nonstationary nature of price series; then coupled with frontier estimation methods that accounting for sampling errors in the estimates of the magnitude of market efficiency, we estimate factors distance and common border that could determine the market efficiency frontier as well as regional effects in inefficiency terms. The use of frontier methods allows us to estimate within-sample benchmarks for the magnitude of market efficiency at the interprovincial level in China and the international level in the EU.

\subsection{Discussion of results}

The results reported above for the market efficiency frontier for China differ from the one for the EU in several respects. Figure 4 presents the distributions of the estimated inefficiencies for the magnitude of market efficiency (i.e. how far are the observed $\hat{\beta}_{i j, 1}$ from the corresponding frontier estimates $\beta_{i j, 1}^{*}$ ) for both China and the EU.

The distribution of the inefficiency scores for the magnitude of market efficiency for China in Figure 4 shows that for many market pairs the long-run elasticity of price transmission is within $0.05(5 \%)$ of the frontier. In comparison, the distribution of the inefficiency scores for the magnitude of market efficiency for the EU shows that for many market pairs the long-run elasticity of price transmission is within $0.1(10 \%)$ of the frontier. The average inefficiency is $8 \%$ in China and $11 \%$ in the EU, as presented in Table 5. Significant provincial effects and memberstate effects in these inefficiency scores are found. 
Figure 4: Distributions of inefficiency for the magnitude of market efficiency for China and the EU

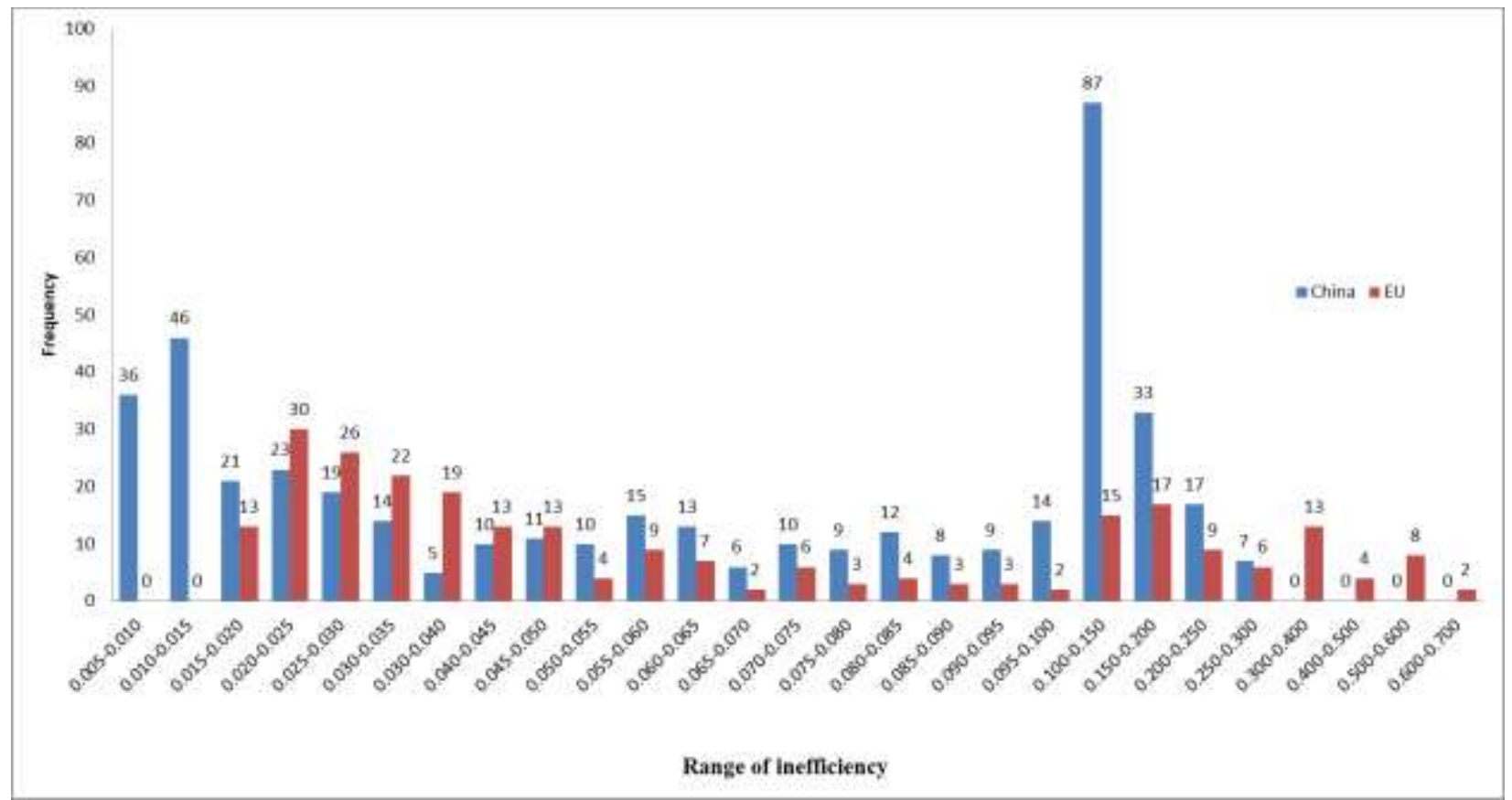

Source: Own calculations using Chinese Ministry of Agriculture (2018) and European Commission (2021).

Table 5: Summary statistics

\begin{tabular}{cccccc}
\hline variable & $\begin{array}{c}\text { No. of market } \\
\text { pairs }\end{array}$ & Mean & $\begin{array}{c}\text { Standard } \\
\text { deviation }\end{array}$ & Minimum & Maximum \\
\hline \multicolumn{5}{c}{ Interprovincial analysis-China } \\
$\hat{\beta}_{i j, 1}$ & 435 & 0.88 & 0.08 & 0.61 & 0.99 \\
$\beta_{i j, 1}^{*}$ & 435 & 0.98 & 0.01 & 0.95 & 0.99 \\
$u_{i j}$ & 435 & 0.08 & 0.06 & 0.01 & 0.29 \\
& \multicolumn{5}{c}{ Interregional analysis-EU } \\
$\hat{\beta}_{i j, 1}$ & 253 & 0.75 & 0.18 & 0.18 & 0.99 \\
$\beta_{i j, 1}^{*}$ & 253 & 0.87 & 0.03 & 0.78 & 0.94 \\
$u_{i j}$ & 253 & 0.11 & 0.13 & 0.02 & 0.68 \\
\hline
\end{tabular}

Source: Own estimations.

To illustrate these effects, in Figures 5 (a) and (b) each province and member state is shaded according to the average market efficiency of the pairs in which it is included.

Figure 5(a): Provincial differences in the magnitude of hog market efficiency in China 


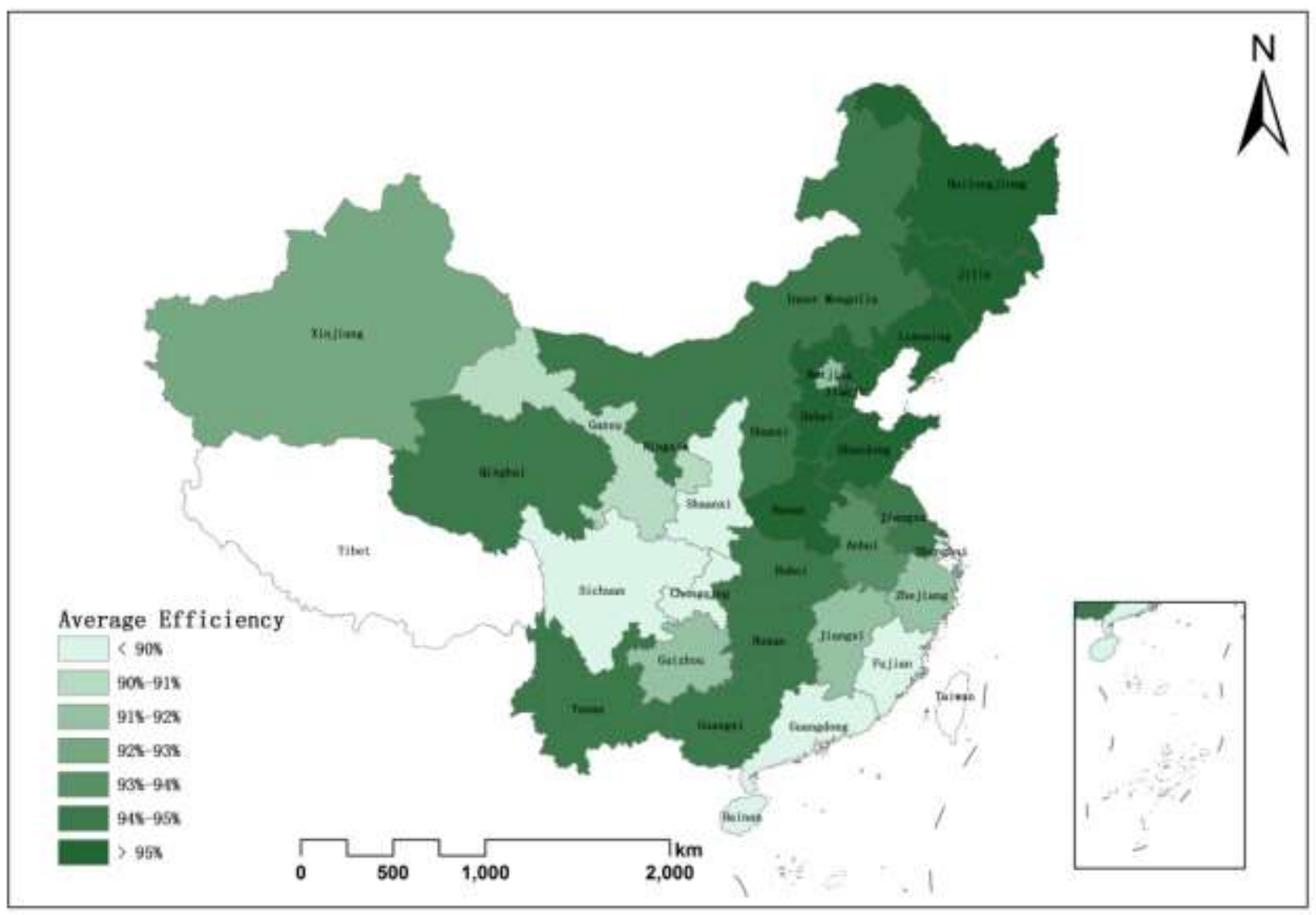

Source: Own expression.

Consider first the magnitude of market efficiency for China. We see that market pairs involving provinces located in Central China are characterized by the highest magnitude of market efficiency and that the magnitude of market efficiency tends to be lower for provinces located farther to the South and West. Provinces with the lowest level of market efficiency are Guangdong, Shanghai, and Fujian. Perhaps imports (to Shanghai) and exports (from Guangdong and Fujian to Hong Kong) are affecting prices in these provinces. Pork product consumption preferences could also be one reason. The coastal regions such as Shanghai, Guangdong are richer, pork consumed in these regions is, therefore, prone to be different from central regions (Zhang et al., 2019). Sichuan and Chongqing in Southwest of China also stand out, this finding is in line with Pan and Li (2019) relative remoteness might contribute to these results. 
Figure 5(b): National differences in the magnitude of hog market efficiency in the EU

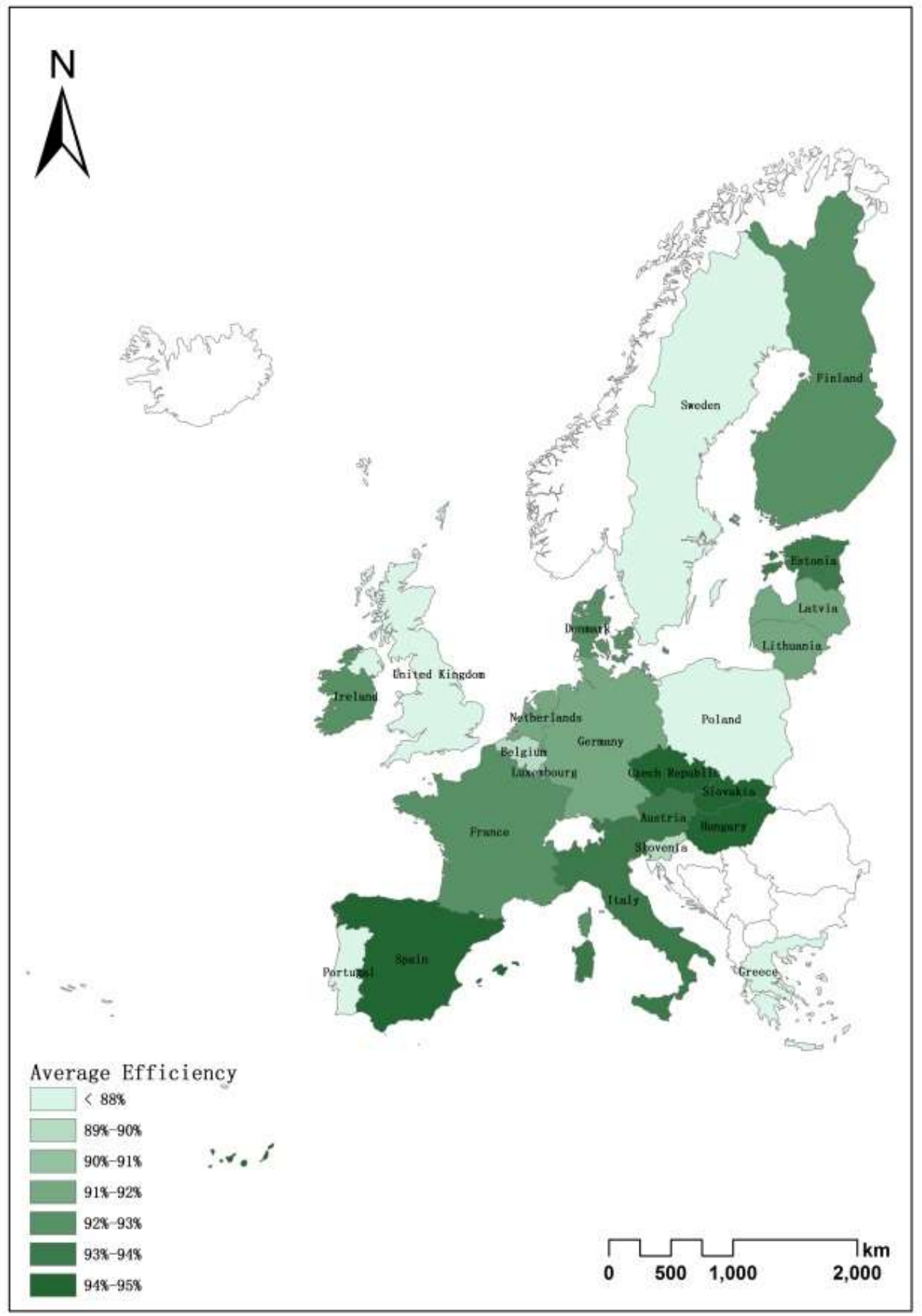

Source: Own expression. 
In comparison, we see that market pairs involving members located in the central EU are characterized by the highest magnitude of market efficiency, this finding is in line with Emmanouilides and Proskynitopoulos (2019), indicating that markets with high values of interaction strengths and appear to be spatially located in central Europe and to be contiguous. And that the magnitude of market efficiency tends to be lower for members located farther to the North. Members with lower levels of market efficiency include Sweden, UK, and Greece. UK and Greece are relatively remote. As also indicated by Emmanouilides and Proskynitopoulos (2019), markets spatially located to the periphery of Europe have smaller closeness centralities (Sweden, UK, and Greece are among their list). As a net importer, Swedish hog prices are relatively higher than other EU members. The retail sector focuses very much on national sourcing so that Swedish meat can get a price premium. This finding is in line with Serra, et al. (2006) as they indicate that in the importing country, pig prices include larger transaction costs than in the exporting country. Pig welfare rules above the EU standards and average carcass weight below the average carcass weight in the EU might also be reasons for higher hog prices in Sweden since a higher weight of hog is reducing the slaughter costs per $\mathrm{kg}$ of the carcass (USDA, 2020).

It is evident from our results that distance is significantly influencing the magnitude of spatial market efficiency. The influence of distance is considerably higher at the international level (the EU) than at the interprovincial level (China).

First, consider the role of transportation cost. If we treat the estimated market efficiency frontiers as the benchmark of the LOP (at least slightly below the strong form) for hog markets in China and the EU, ceteris paribus, the elasticity of price transmission will tend towards the cost share of the product in the export location in the price of the product in the import location ( $S_{a}$ in Gardner's (1975) notation). In our case, $S_{a}$ is smaller in the EU than in China, correspondingly the transportation cost share $\left(1-S_{a}\right)$ is higher in the EU than in China. Trade barriers might be smaller across interprovincial borders than international borders, which makes international trade more costly.

Policy interventions for hog markets and animal welfare regulations during hog transport might play some roles as well. The Chinese policymakers have implemented various policies designed to make pork prices stable (Dong et al., 2019). Market monitoring activities by the Chinese 
central government are generally high and consistent. While the EU officials have intervened less in pig markets (Serra et al., 2006). That is why the magnitude of market efficiency is more heterogeneous for the EU. Distance accounts for variable trade costs related to trade, playing a major role in the spatial market integration especially when animal welfare-based restrictions are associated (administrate costs, upgrading vehicle costs, etc.).

The transport costs, especially over longer distances, are quite a bit higher for hogs in the EU than in China. Transport costs are perhaps even a bit non-linear (Barrett and Li, 2002; Serra et al., 2006) for hogs - beyond a certain threshold they become very high (rest time is scheduled for pigs during long journeys, (European Commission, 2005)). Arbitraging between member states sharing extremely long-distance (e.g. Finland and Portugal, $4385 \mathrm{~km}$ ) is essentially impossible, it has to take place in steps. Similarly, this is also true for very long distances (e.g. Xinjiang and Hainan, $4401 \mathrm{~km}$ ) in China even if animal welfare regulations in China are not as strict as the EU.

\subsection{Policy implications}

Since distance shapes the hog market efficiency frontier in both China and the EU significantly, both China and the EU have experienced rapid economic growth and restructuring over the study period, and will further process transformation deeply for sure beyond. Nevertheless, underdeveloped infrastructure (e.g. road, rail), may restrict the distance (inefficiency) to the potential maximum market efficiency, infrastructure available for transportation and trade during our study period is not sufficient for shifting China and the EU's hog market efficiency up. From our study, we find significant provincial effects and member-state effects in market integration. Substantial development in the hog market and transportation infrastructure should be invested by both Chinese and EU officials especially in the "bottleneck" regions (the least efficient markets).

Unlike grain trade, animal or animal product trade is under stricter restrictions, increasing information flows will make distance play a minor role so that "information costs" could be decreased. Further developing the hog futures market and information services in China and the EU could foster more spread of information thus improve the efficiency of the hog market in both China and the EU. 
Alternatively, Chinese and the EU officials as well could support the restructuring of feed (e.g. corn) supply chain intensified in the hog production regions, if animals or animal products are in transit under stricter regulations (animal welfare) and conditions (cold chain storage on truck) than grain especially the cost of transport starts to get large over too long distances (animals injured, stressed, etc.), which could reduce the interprovincial hog transportation size in China and international hog transportation in the EU. For example, China's swine production in the Northeast probably be affected by increased corn production as larger companies seek to expand, Southwest China is a region with major expansion potential (USDA, 2016). 


\section{Appendix of Chapter IV}

\section{Appendix A.1: Markets analyzed in question}

Markets analyzed in question are listed as follows:

- 30 Provinces for hog markets of China at the inter-provincial level (Appendix of Chapter III).

- 23 Member states for hog markets of the EU at the interregional level.

Table A.1: List of selected markets in the EU

\begin{tabular}{ll}
\hline \multicolumn{2}{c}{$\begin{array}{c}\text { International analysis } \\
\text { EU }\end{array}$} \\
\hline Member state & Capital \\
\hline Belgium & Brussels \\
Czechia & Prague \\
Denmark & Copenhagen \\
Germany & Berlin \\
Estonia & Tallinn \\
Ireland & Dublin \\
Greece & Athens \\
Spain & Madrid \\
France & Paris \\
Italy & Rome \\
Latvia & Riga \\
Lithuania & Vilnius \\
Luxembourg & Luxembourg \\
Hungary & Budapest \\
Netherlands & Amsterdam \\
Austria & Vienna \\
Poland & Warsaw \\
Portugal & Lisbon \\
Slovenia & Ljubljana \\
Slovakia & Bratislava \\
Finland & Helsinki \\
Sweden & Stockholm \\
United Kingdom & London \\
\hline & \\
&
\end{tabular}




\section{Appendix A.2: Hog piece series selected from a set of China and the EU}

Figure A.1(a): Four hog price series of China (monthly data from Jul. 2004 to Dec. 2017)

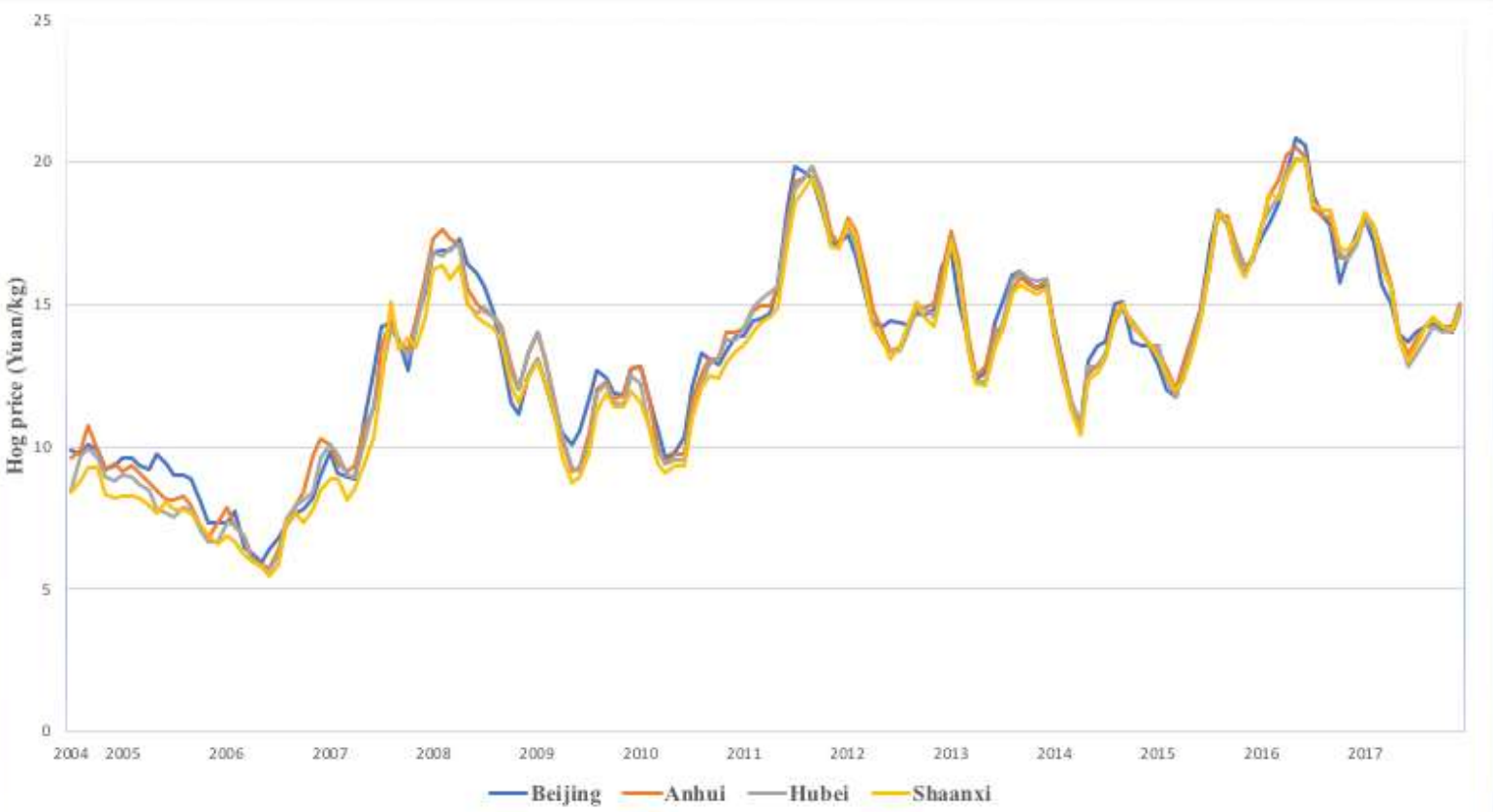

Source: Chinese Ministry of Agriculture (2018).

Figure A.1(b): Four hog price series of the EU (monthly data from Jul. 2004 to Dec. 2017)

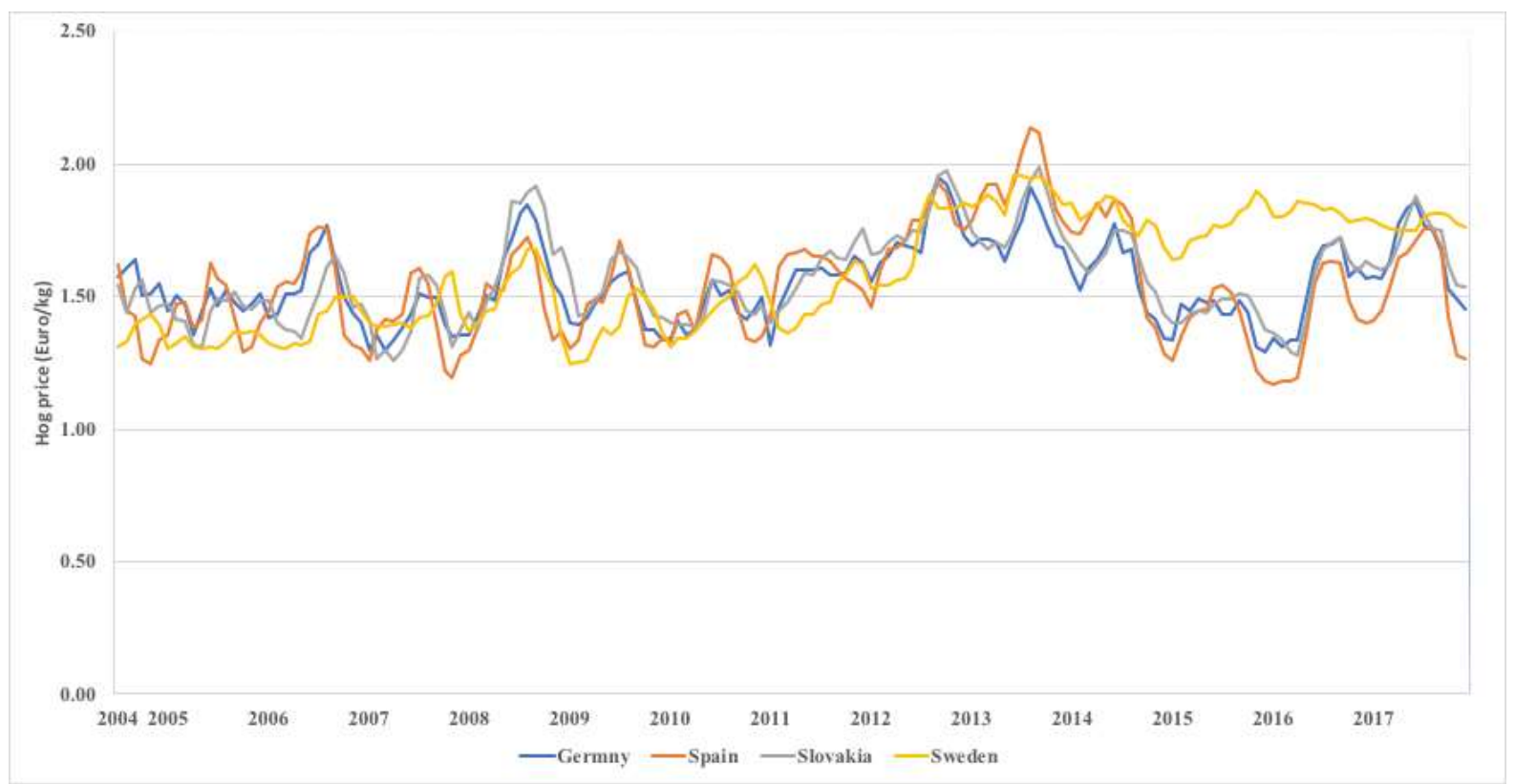

Source: European Commission (2021). 


\section{Appendix A.3: ADF test}

For each of the hog price series of 30 Chinese provinces individually the ADF test (Said and Dickey, 1984) fails to reject the null hypothesis that the series is I(1), but rejects this hypothesis for first differences. However, ADF test results show that 5 hog price series (Czechia, Estonia, Greece, Slovakia, and Finland) are I(0), the other 18 hog price series I(1) for the 23 EU member states.

Table A.2: ADF test for prices in levels and first differences

\begin{tabular}{|c|c|c|c|c|c|}
\hline Price series & Lag & T-statistic & $\Delta$ Price series & Lag & T-statistic \\
\hline \multicolumn{6}{|c|}{ China (intraregional analysis) } \\
\hline Beijing & 3 & -2.437 & $\Delta$ Beijing & 2 & $-8.076^{* * *}$ \\
\hline Tianjin & 2 & -2.677 & $\Delta$ Tiajin & 1 & $-8.727^{* * *}$ \\
\hline Hebei & 4 & -2.401 & $\Delta$ Hebei & 3 & $-6.787^{* * *}$ \\
\hline Shanxi & 3 & -2.349 & $\Delta$ Shanxi & 2 & $-7.904^{* * *}$ \\
\hline Inner Mongolia & 2 & -2.650 & $\Delta$ Inner Mongolia & 1 & $-6.897^{* * *}$ \\
\hline Liaoning & 3 & -2.534 & $\Delta$ Liaoning & 2 & $-7.803^{* * *}$ \\
\hline Jilin & 3 & -2.595 & $\Delta$ Jilin & 2 & $-7.817^{* * *}$ \\
\hline Heilongjinag & 3 & -2.983 & $\Delta$ Heilongjiang & 2 & $-6.968^{* * *}$ \\
\hline Shanghai & 2 & -3.029 & $\Delta$ Shanghai & 2 & $-7.999^{* * *}$ \\
\hline Jiangsu & 3 & -2.915 & $\Delta$ Jiangsu & 2 & $-6.959^{* * *}$ \\
\hline Zhejiang & 3 & -2.874 & $\Delta$ Zhejiang & 2 & $-7.377^{* * *}$ \\
\hline Anhui & 3 & -2.743 & $\Delta$ Anhui & 2 & $-7.291^{* * *}$ \\
\hline Fujian & 2 & -2.972 & $\Delta$ Fujian & 2 & $-8.113^{* * *}$ \\
\hline Jiangxi & 3 & -2.667 & $\Delta$ Jiangxi & 2 & $-7.267^{* * *}$ \\
\hline Shandong & 3 & -2.423 & $\Delta$ Shandong & 2 & $-8.193^{* * *}$ \\
\hline Henan & 3 & -2.581 & $\Delta$ Henan & 2 & $-7.650^{* * *}$ \\
\hline Hubei & 3 & -2.621 & $\Delta$ Hubei & 2 & $-7.323^{* * *}$ \\
\hline Hunan & 3 & -2.606 & $\Delta$ Hunan & 2 & $-7.257^{* * *}$ \\
\hline Guangdong & 3 & -2.704 & $\Delta$ Guangdong & 2 & $-7.010^{* * *}$ \\
\hline Guangxi & 2 & -2.709 & $\Delta$ Guangxi & 1 & $-7.554^{* * *}$ \\
\hline Hainan & 2 & -2.772 & $\Delta$ Hainan & 1 & $-8.014^{* * *}$ \\
\hline Chongqing & 2 & -2.916 & $\Delta$ Chongqing & 1 & $-7.729^{* * *}$ \\
\hline Sichuan & 2 & -2.863 & $\Delta$ Sichuan & 1 & $-7.360^{* * *}$ \\
\hline Guizhou & 3 & -2.159 & $\Delta$ Guizhou & 2 & $-7.224^{* * *}$ \\
\hline Yunnan & 2 & -2.466 & $\Delta$ Yunnan & 2 & $-6.133^{* * *}$ \\
\hline Shaanxi & 3 & -2.697 & $\Delta$ Shaanxi & 2 & $-7.216^{* * *}$ \\
\hline Gansu & 2 & -2.787 & $\Delta$ Gansu & 2 & $-7.651^{* * *}$ \\
\hline Qinghai & 1 & -2.382 & $\Delta$ Qinghai & 1 & $-8.216^{* * *}$ \\
\hline Ningxia & 2 & -3.118 & $\Delta$ Ningxia & 1 & $-7.685^{* * *}$ \\
\hline Xinjiang & 2 & -2.548 & $\Delta$ Xinjiang & 1 & $-7.278^{* * *}$ \\
\hline \multicolumn{6}{|c|}{ EU (interregional analysis) } \\
\hline Belgium & 2 & $-4.137^{* * *}$ & $\Delta$ Belgium & 1 & $-7.453^{* * *}$ \\
\hline Czechia & 5 & -3.059 & $\Delta$ Czechia & 1 & $-7.811^{* * *}$ \\
\hline Denmark & 2 & $-4.030^{* * *}$ & $\Delta$ Denmark & 1 & $-7.051^{* * *}$ \\
\hline
\end{tabular}




\begin{tabular}{llllll}
\hline Germany & 2 & $-4.434^{* * *}$ & $\Delta$ Germany & 1 & $-7.815^{* * * *}$ \\
Estonia & 2 & $-2.877^{* * *}$ & $\Delta$ Estonia & 1 & $-6.664^{* * *}$ \\
Ireland & 2 & $-3.920^{* *}$ & $\Delta$ Ireland & 1 & $-6.674^{* * *}$ \\
Greece & 1 & $-3.951^{* * *}$ & $\Delta$ Greece & 1 & $-7.872^{* * *}$ \\
Spain & 5 & -3.076 & $\Delta$ Spain & 2 & $-7.012^{* * *}$ \\
France & 2 & $-4.308^{* * *}$ & $\Delta$ France & 1 & $-8.401^{* * * *}$ \\
Italy & 1 & $-3.903^{* *}$ & $\Delta$ Italy & 1 & $-7.751^{* * *}$ \\
Latvia & 2 & $-3.987^{* *}$ & $\Delta$ Latvia & 1 & $-8.353^{* * *}$ \\
Lithuania & 2 & $-3.860^{* *}$ & $\Delta$ Lithuania & 1 & $-8.340^{* * *}$ \\
Luxembourg & 2 & $-4.376^{* * *}$ & $\Delta$ Luxembourg & 1 & $-7.612^{* * *}$ \\
Hungary & 2 & $-4.434^{* * *}$ & $\Delta$ Hungary & 1 & $-7.930^{* * *}$ \\
Netherlands & 1 & $-3.726^{* *}$ & $\Delta$ Netherlands & 1 & $-7.602^{* * *}$ \\
Austria & 2 & $-4.418^{* * *}$ & $\Delta$ Austria & 1 & $-7.985^{* * *}$ \\
Poland & 2 & $-4.365^{* * *}$ & $\Delta$ Poland & 1 & $-7.581^{* * *}$ \\
Portugal & 5 & $-4.075^{* * *}$ & $\Delta$ Portugal & 2 & $-7.240^{* * *}$ \\
Slovenia & 2 & $-4.969^{* * *}$ & $\Delta$ Slovenia & 1 & $-7.760^{* * *}$ \\
Slovakia & 5 & -2.905 & $\Delta$ Slovakia & 1 & $-7.832^{* * *}$ \\
Finland & 2 & $-1.741^{* * *}$ & $\Delta$ Finland & 1 & $-6.621^{* * *}$ \\
Sweden & 2 & $-3.819^{* *}$ & $\Delta$ Sweden & 2 & $-7.175^{* * *}$ \\
UK & 3 & $-3.269^{*}$ & $\Delta$ UK & 2 & $-7.131^{* * *}$ \\
\hline Note ADF test (Said and & $1984)$, & lag length selection is based on Schwarz Information Criterion. The deterministic
\end{tabular}

Note: ADF test (Said and Dickey, 1984), lag length selection is based on Schwarz Information Criterion. The deterministic component is a constant and linear trend. ${ }^{*} \mathrm{p}<0.10,{ }^{* *} \mathrm{p}<0.05,{ }^{* * *} \mathrm{p}<0.01$.

\section{Appendix A.4: Test of linear cointegration}

Johansen's $(1991 ; 1995)$ trace test for cointegration indicates that the null of no cointegration is rejected for 364 hog price pairs at the $1 \%$ level of significance, and 44 price pairs at the $5 \%$ level, and for another 10 pairs at the $10 \%$ level; in 17 of the 435 price pairs are the null hypothesis of no cointegration not rejected at conventional levels of significance for China.

For 152 of the 253 price pairs of the 23 EU member states, there is no cointegration at conventional levels of significance; Only in 101 price pairs that the null hypothesis of no cointegration is rejected at conventional levels of significance (81 pairs at the $1 \%$ level of significance; 13 price pairs at the $5 \%$ and the left 7 pairs at the $10 \%$ ).

Overall, for the Chinese setting, we estimated the 435 bivariate VECMs in equation (A1) using Johansen's $(1991,1995)$ maximum likelihood method to retrieve $\beta_{i j, 1}$.

$$
\left[\begin{array}{l}
\Delta \ln p_{i, t} \\
\Delta \ln p_{j, t}
\end{array}\right]=\left[\begin{array}{l}
\varphi_{i} \\
\varphi_{j}
\end{array}\right]+\left[\begin{array}{l}
\alpha_{i} \\
\alpha_{j}
\end{array}\right]\left[\ln p_{i, t-1}-\beta_{i j, 0}-\beta_{i j, 1} \ln p_{j, t-1}\right]+\sum_{k=1}^{l}\left[\begin{array}{ll}
\delta_{i k} & \rho_{i k} \\
\delta_{j k} & \rho_{j k}
\end{array}\right]\left[\begin{array}{l}
\Delta \ln p_{i, t-k} \\
\Delta \ln p_{j, t-k}
\end{array}\right]+\left[\begin{array}{l}
\varepsilon_{i, t} \\
\varepsilon_{j, t}
\end{array}\right](\mathrm{A} 1)
$$


The lag-length $l$ in equation (A1) is chosen using the Schwarz Bayesian Information Criteria (SBIC: Lütkepohl 2005, pp. 156-157).

For the EU setting, we hereafter conduct a bound test for all the pairs with $\mathrm{I}(0)$ and $\mathrm{I}(1)$ series by comparing the F-statistic for the joint significance of the lagged levels in Equation (A2) with the asymptotic critical values tabulated by Pesaran et al. (2001).

$$
\Delta \ln p_{i, t}=c_{i j, 0}+\alpha_{i j, 1}\left(\ln p_{i, t-1}-\beta_{i j, 1} \ln p_{j, t-1}-\beta_{i j, 0}\right)+\sum_{k=1}^{q} \delta_{i j, k} \Delta \ln p_{i, t-k}+\sum_{k=0}^{p} \rho_{i j, k} \Delta \ln p_{j, t-k}+\varepsilon_{t}(\mathrm{~A} 2)
$$

The asymptotic critical value bounds with a constant and without a time trend are 4.04 as lower and 4.78 as upper bound at the $10 \%$ significance level. The calculated F-statistics exceed the upper bound for these specifications, no long-run level relationship for these pairs is rejected. This confirms the presence of a non-spurious long-run relationship for these pairs. We retrieve $\beta_{i j, 1}$ for pairs of hog prices by estimating the ARDL model (Pesaran et al., 2001) in equation (A2). $p$ is the lag order of independent series $p_{j}, q$ is the autoregressive order. ${ }^{1}$

So for all the 253 market pairs of the EU, we estimate for 153 OLSs following equation (1); 4 bivariate VECMs following equation (A1); and the left 96 ARDLs following equation (A2) by using Pesaran et al. (2001).

\section{Appendix A.5: Description of variables and sources}

China/EU: Price transmission elasticities estimates $\left(\hat{\beta}_{i j, 1}\right)$ between markets $i$ and $j$ for each market pair $i, j$.

\section{Hog price}

The hog price data for both China and the EU are producer prices, what farmers get when they sell their pigs. And the data are carried out weekly and weighted average for monthly, which makes our analysis comparable. The Chinese provincial monthly averages are based on weekly observations monitored by the Ministry of Agriculture of China at hundreds of markets in all provinces of China. The EU monthly hog prices are the weighted average of the weekly data reported from the Member States to the European Commission.

\footnotetext{
${ }^{1}$ We choose $(0,1)$ as lag order for $(p, q)$ after comparing the results estimated by using BIC lag orders and OLS estimation, we risk under estimating $\hat{\beta}_{i j, 1}$ if we increase the lag orders for ARDL estimations.
} 
China: Hog prices (Yuan/kg) are from the Ministry of Agriculture of China and were collected from 30 provinces. Source: http://www.moa.gov.cn/

$E U$ : Hog prices (Euro/kg) for EU (23 members in our analysis) are from the European Commission database and were collected from the Member States by Article 11 of EU Regulation $2017 / 1185$.

Source:https://agridata.ec.europa.eu/extensions/DashboardPrice/DashboardMarketPrices.html

\section{Distance}

China: road distance (1 000 kilometers) between markets $i$ and $j$; calculated as road distance between capitals of provinces. Source: Baidu Map (https://map.baidu.com/).

$E U$ : road distance (1 000 kilometers) between markets $i$ and $j$; calculated as road distance between capitals of member states. Sources: Google Map (www.google.com/maps).

\section{Common border $\left(\boldsymbol{B}_{\boldsymbol{i j}}\right)$}

China (interprovincial border): a dummy variable, which is equal to 1 provinces $i$ and $j$ is observed in a market pair that share a common border and is equal to 0 otherwise. 66 provincial pairs are sharing common borders.

EU (international border): a dummy variable, which is equal to 1 member state $i$ and $j$ is observed in a market pair share a common border and is equal to 0 otherwise. There are 32 states' pairs sharing common borders.

Table A.3: Summary statistics of variables

\begin{tabular}{lcccc}
\hline Variable & Mean & Std.Dev. & Min & Max \\
\hline & \multicolumn{3}{c}{ China } \\
Distance (1000 km) & 1.89 & 1.05 & 0.07 & 5.11 \\
Common border & 0.12 & 0.32 & 0 & 1 \\
& \multicolumn{5}{c}{$\boldsymbol{U}$} & \\
Distance (1000 km) & 1.61 & 0.85 & 0.14 & 4.40 \\
Common border & 0.13 & 0.34 & 0 & 1 \\
\hline
\end{tabular}


Table A.4: Statistics for characteristics of hog market in China and the EU

\begin{tabular}{|c|c|c|c|c|c|c|}
\hline Market & $\begin{array}{l}\text { Slaughter no. } \\
\text { (million } \\
\text { heads) }\end{array}$ & $\begin{array}{l}\text { Inventory no. } \\
\text { (million } \\
\text { heads) }\end{array}$ & $\begin{array}{l}\text { Pigs/100 } \\
\text { habitants }\end{array}$ & $\begin{array}{l}\text { Pork } \\
\text { production } \\
\text { (million } \\
\text { tonnes) }\end{array}$ & $\begin{array}{l}\text { Pork } \\
\text { consumption } \\
\text { (million } \\
\text { tonnes) }\end{array}$ & $\begin{array}{l}\text { Averag } \\
\text { Carcass } \\
\text { weight }\end{array}$ \\
\hline \multicolumn{7}{|c|}{ China } \\
\hline Beijing & 0.19 & 1.12 & 5.17 & 0.19 & 0.44 & 79.31 \\
\hline Tianjin & 0.23 & 1.80 & 11.56 & 0.23 & 0.32 & 76.04 \\
\hline Hebei & 2.92 & 19.58 & 26.03 & 2.92 & 1.51 & 77.01 \\
\hline Shanxi & 0.63 & 5.44 & 14.70 & 0.63 & 0.75 & 76.20 \\
\hline \multicolumn{7}{|l|}{ Inner } \\
\hline Mongolia & 0.74 & 5.06 & 19.99 & 0.74 & 0.51 & 79.98 \\
\hline Liaoning & 2.21 & 13.08 & 29.94 & 2.21 & 0.88 & 84.08 \\
\hline Jilin & 1.36 & 9.11 & 33.53 & 1.36 & 0.55 & 80.45 \\
\hline Heilongjinag & 1.59 & 14.34 & 37.84 & 1.59 & 0.76 & 76.20 \\
\hline Shanghai & 0.15 & 1.11 & 4.60 & 0.15 & 0.49 & 76.96 \\
\hline Jiangsu & 2.14 & 16.40 & 20.43 & 2.14 & 1.63 & 76.39 \\
\hline Zhejiang & 0.83 & 5.43 & 9.59 & 0.83 & 1.15 & 81.47 \\
\hline Anhui & 2.43 & 14.17 & 22.66 & 2.43 & 1.26 & 85.79 \\
\hline Fujian & 1.28 & 9.22 & 23.57 & 1.28 & 0.79 & 79.95 \\
\hline Jiangxi & 2.50 & 16.21 & 35.08 & 2.50 & 0.93 & 78.45 \\
\hline Shandong & 4.27 & 30.40 & 30.38 & 4.27 & 2.02 & 82.50 \\
\hline Henan & 4.67 & 43.90 & 45.93 & 4.67 & 1.92 & 75.06 \\
\hline Hubei & 3.39 & 25.79 & 43.69 & 3.39 & 1.19 & 76.28 \\
\hline Hunan & 4.50 & 39.68 & 57.84 & 4.50 & 1.38 & 73.51 \\
\hline Guangdong & 2.78 & 21.33 & 19.10 & 2.78 & 2.26 & 74.89 \\
\hline Guangxi & 2.55 & 22.94 & 46.95 & 2.55 & 0.98 & 76.00 \\
\hline Hainan & 0.44 & 4.00 & 43.15 & 0.44 & 0.19 & 81.05 \\
\hline Chongqing & 1.30 & 11.92 & 38.75 & 1.30 & 0.62 & 74.24 \\
\hline Sichuan & 4.72 & 43.77 & 52.72 & 4.72 & 1.67 & 71.77 \\
\hline Guizhou & 1.60 & 15.97 & 44.61 & 1.60 & 0.72 & 87.72 \\
\hline Yunnan & 3.20 & 30.29 & 63.10 & 3.20 & 0.96 & 84.37 \\
\hline Shaanxi & 0.86 & 8.54 & 22.28 & 0.86 & 0.77 & 75.20 \\
\hline Gansu & 0.50 & 5.51 & 20.99 & 0.50 & 0.53 & 73.09 \\
\hline Qinghai & 0.09 & 0.83 & 13.83 & 0.09 & 0.12 & 78.66 \\
\hline Ningxia & 0.09 & 0.81 & 11.88 & 0.09 & 0.14 & 78.28 \\
\hline \multirow[t]{2}{*}{ Xinjiang } & 0.36 & 3.43 & 14.02 & 0.36 & 0.49 & 72.21 \\
\hline & \multicolumn{6}{|c|}{$E U$} \\
\hline Belgium & 10.95 & 6.11 & 53.70 & 1.04 & 0.46 & 95.40 \\
\hline Czechia & 2.34 & 1.53 & 14.46 & 0.21 & 0.44 & 90.26 \\
\hline Denmark & 17.47 & 12.83 & 222.59 & 1.53 & 0.48 & 87.60 \\
\hline Germany & 57.87 & 27.58 & 33.36 & 5.46 & 4.53 & 94.27 \\
\hline Estonia & 0.52 & 0.29 & 21.95 & 0.04 & 0.06 & 80.87 \\
\hline
\end{tabular}




\begin{tabular}{lllllll} 
Ireland & 3.36 & 1.62 & 33.62 & 0.29 & 0.15 & 87.68 \\
Greece & 1.36 & 0.74 & 6.92 & 0.08 & 0.28 & 59.79 \\
Spain & $\mathbf{5 0 . 0 7}$ & $\mathbf{2 9 . 9 7}$ & $\mathbf{6 4 . 3 3}$ & $\mathbf{4 . 3 0}$ & $\mathbf{2 . 9 4}$ & $\mathbf{8 5 . 8 5}$ \\
France & $\mathbf{2 3 . 4 0}$ & $\mathbf{1 3 . 3 5}$ & $\mathbf{1 9 . 9 5}$ & $\mathbf{2 . 1 8}$ & $\mathbf{2 . 0 5}$ & $\mathbf{9 3 . 0 3}$ \\
Italy & 11.38 & 8.57 & 14.16 & 1.47 & 2.34 & 128.90 \\
Latvia & 0.42 & 0.32 & 11.33 & 0.03 & 0.06 & 80.21 \\
Lithuania & 0.77 & 0.61 & 31.50 & 0.06 & 0.12 & 79.17 \\
Luxembourg & 0.15 & 0.09 & 15.25 & 0.01 & 0.01 & 83.55 \\
Hungary & 4.76 & 2.87 & 29.32 & 0.43 & 0.00 & 91.38 \\
Netherlands & 15.17 & 12.30 & 71.78 & 1.46 & 0.83 & 95.96 \\
Austria & 5.15 & 2.82 & 32.06 & 0.51 & 0.49 & 98.05 \\
Poland & $\mathbf{2 2 . 0 7}$ & $\mathbf{1 1 . 9 1}$ & $\mathbf{3 1 . 3 6}$ & $\mathbf{1 . 9 9}$ & $\mathbf{2 . 1 8}$ & $\mathbf{9 0 . 2 0}$ \\
Portugal & 5.47 & 2.17 & 21.02 & 0.36 & 0.43 & 65.13 \\
Slovenia & 0.25 & 0.26 & 12.45 & 0.05 & 0.07 & 89.17 \\
Slovakia & 0.53 & 0.61 & 11.30 & 0.02 & 0.17 & 92.50 \\
Finland & 1.96 & 1.11 & 20.12 & 0.18 & 0.17 & 91.43 \\
Sweden & 2.58 & 1.38 & 13.74 & 0.24 & 0.30 & 93.06 \\
\hline
\end{tabular}




\title{
V Measuring Time-Varying Market Efficiency
}

Authors: Yali Mu and Stephan von Cramon-Taubadel

\begin{abstract}
This paper proposes the idea for benchmarking time-varying market efficiency. Using timevarying VECM coupled with stochastic frontier models, we benchmark speeds of restoring market efficiency for different periods. We use price data from 30 provincial pork markets in China from 2000 to 2017. The time-varying VECM results reveal that for the great majority of market pairs, between $20 \%$ and $40 \%$ of any deviation from the long-run equilibrium are corrected within one month. We find that the estimated individual speed of restoring market efficiency varies over space (provinces in China) and time (years). And the estimated frontiers for the speed of restoring market efficiency fall as distances increase between markets. We also find that the estimated frontier shifts down over periods. This reflects the effect of distance falls over periods. However the overall speeds of restoring market efficiency scatter with a downward trend. This suggests other factors such as government interventions, pig industry restructure under environmental pressure, trade delayed by traffic jams or food safety checks, might impede the speeds of price transmission in general.
\end{abstract}

Keywords: market efficiency, time-varying VECM, state-space modeling, benchmark

\section{Introduction}

The basic benchmarking idea and procedure have been presented in Chapters III and IV. It generates some useful insights. The empirical applications are based on assumptions that the elasticities and adjustment parameters that describe pork price transmission between markets have been constant over the 2000-2017 sample period. However, China has experienced rapid economic growth and restructuring over this period, transportation and communication networks have gone from the third world to the first world, which has led to regional pork supply and demand shifts during the period.

Consequently, the elasticities and adjustment parameters estimated and analysed for measuring market efficiency in the previous chapters may have changed over the sample period. In this chapter, we divide the whole sample period into four sub-periods and focus on evaluating price transmission and market efficiency by loosening one of those assumptions (i.e. the adjustment 
parameters change over time) and exploring the implications. So we have two important objectives, (i) generating time-varying error correction parameters by following (Adämmer and Bohl, 2015, 2018) to estimate time-varying VECMs and (ii) incorporating frontier techniques for different periods to study how the market efficiency frontiers have shifted over time.

The state space estimation of VECM has been used to analyze price discovery (Silverio and Szklo, 2012; Caporale et al., 2014; Adämmer and Bohl, 2015, 2018; Vollmer et al., 2020). Estimates of price transmission using time-varying VECM under state-space form make it appealing to investigate whether the contributions of markets to price transmission shift over time (Adämmer and Bohl, 2018; Vollmer et al., 2020).

As China is the biggest pork producer and consumer globally, our sample set (30 provinces) is suited for this benchmarking study with abundant observations. In addition, we apply a timevarying VECM to overcome previous limitations of methods. It enables us to investigate the market integration process by quantifying the speeds of restoring market efficiency during the study period.

For the rest of this article, section 2 outlines the methodology and the data. In section 3, we show empirical results. Second 4 discuss the results. Finally, section 5 ends with conclusions and limitations of this research.

\section{Methodology and data}

\subsection{Unit root test}

We do Kwiatkowski-Phillips-Schmidt-Shin tests (KPSS, Kwiatkowski et al., 1992) to confirm the unit root of the price series. To detect potential structural breaks, we employ the Zivot and Andrews (1992) test of the null hypothesis of a unit root process against the alternative of a stationary process that allows for a break in both the level or/and the trend. The break date is selected where the t-statistic from the ADF test of unit root is at a most negative value. 


\subsection{Estimating time-varying market efficiency}

Following the bivariate VECM used in Chapter III, the long-run cointegrating relationship between prices is assumed to be time-invariant. We estimate time-varying VECM to get the short-run interactions between prices which vary over time.

So we follow Adämmer and Bohl $(2015 ; 2018)$ rewrite the model as:

$$
\begin{aligned}
& \Delta \ln p_{i, t}=\varphi_{t}^{i j}+\alpha_{t}^{i} e c_{t-1}+\sum_{k=1}^{l} \delta_{t, k}^{i i} \Delta \ln p_{i, t-k}+\sum_{k=1}^{l} \delta_{t, k}^{i j} \Delta \ln p_{j, t-k}+\varepsilon_{i j, t} \\
& \Delta \ln p_{j, t}=\varphi_{t}^{j i}+\alpha_{t}^{j} e c_{t-1}+\sum_{k=1}^{l} \delta_{t, k}^{j i} \Delta \ln p_{i, t-k}+\sum_{k=1}^{l} \delta_{t, k}^{j j} \Delta \ln p_{j, t-k}+\varepsilon_{j i, t}
\end{aligned}
$$

Where $\Delta$ notes the first difference of logarithmic pork prices in question. $l$ is the lag order. The parameters $\delta_{t, k}^{i i}, \delta_{t, k}^{j j} \delta_{t, k}^{i j}$ and $\delta_{t, k}^{j i}$ in (1a) and (1b), measure the short-run dynamics of the system at each $t$.Time-varying adjustment parameters $\alpha_{t}^{i}$ and $\alpha_{t}^{j}$ measure the speed of restoring market efficiency after deviations from the long-run equilibrium at each $t$ (i.e., how $\ln p_{i, t}$ and $\ln p_{j, t}$ change in period $t$ in response to any disequilibrium $\left(e c_{t-1} \neq 0\right)$ in the previous period $\left.t-1\right)$. The error correction terms

$$
e c_{t-1}=\ln p_{i, t-1}-\beta_{i j, 0}-\beta_{i j, 1} \ln p_{j, t-1}
$$

capture the temporary deviations from the long-run equilibrium $\left(\ln p_{i, t-1}=\beta_{i j, 0}+\beta_{i j, 1} \ln p_{j, t-1}\right)$. We normalize the long-run equilibrium relationship on the higher of the two prices so that $\beta_{i j, 1}$ is expected to be less than or equal to 1, thus the adjustment parameters $\alpha_{t}^{i}$ are expected to be negative and $\alpha_{t}^{j}$ are expected to be positive in equations (1a) and (1b).

To get time-varying speeds of adjustment parameters, we, therefore, reformulate the VECM in state-space form and apply the Kalman filter to estimate. Then the dynamic VECM measurement equation:

$$
\ln p_{t}=Z_{t} \xi_{t}+\varepsilon_{t}
$$

Where,

$$
\varepsilon_{t} \mid \psi_{t-1} \sim N\left(0, H_{t}\right)
$$


Where $\ln p_{t}=\left[\begin{array}{l}\Delta \ln p_{i, t} \\ \Delta \ln p_{j, t}\end{array}\right]$ is the vector of price differences on the LHS of equations (1a) and (1b); $Z_{t}=\left[\begin{array}{cccccc}1 e c_{t-1} \Delta \ln p_{i, t-1} \Delta \ln p_{j, t-1} 0 & 0 & 0 & 0 \\ 0 & 0 & 0 & 0 & 1 e c_{t-1} \Delta \ln p_{i, t-1} \Delta \ln p_{j, t-1}\end{array}\right]$ arrays the RHS variables in equations (1a) and (1b). $\xi_{t}$ represents the vector of time-varying coefficients.

The Kalman filter is a recursive algorithm that computes the optimal estimates of state variables for each observation $t$, conditional on the information set available up to time $t$. The filtering updates our knowledge of the system each time a new observation is brought in (Durbin and Koopman, 2012). The transition equation:

$$
\xi_{t}=F \xi_{t-1}+v_{t}
$$

Where,

$$
v_{t} \mid \psi_{t-1} \sim N\left(0, Q_{t}^{*}\right)
$$

$F$ is the identity matrix with $2 *(2 l+1)$ dimension, which corresponds to dimensions of the column of $Z_{t}$ and the row of $\xi_{t}$.

We estimate adjustment parameters $\alpha_{t}^{i}$ and $\alpha_{t}^{j}$ for a total of 435 unique pairs of pork markets in China at each observation time $t$ from January 2000 to December 2017. We sum the estimated adjustment parameters $\alpha_{t}^{i}$ and $\alpha_{t}^{j}$ for all $i \neq j$ to provide an estimate of the aggregate speeds of adjustment for each unique pair of markets at each period. Accounting for the expected signs of the estimated adjustment parameters,

$$
\alpha_{i j, t}=\alpha_{t}^{j}-\alpha_{t}^{i}
$$

the total speed of price transmission between markets $i$ and $j$, which is expected to be larger than 0 and less than 1, measures the total proportion of any disequilibrium that is corrected per $t$. 


\subsection{Stochastic frontier of time-varying market efficiency}

The result of our first stage generates of $93090(214 \times 435)$ estimated adjustment coefficients $\alpha_{i j, t}$ from 435 bivariate time-varying VECMs. ${ }^{1}$ Since the data frequency is monthly, we generate adjustment parameters for each month $t$.

In the second stage of our analysis, we first aggregate the estimated monthly adjustment parameters for each period $y$.

$$
\alpha_{i j, y}=\sum_{t}^{t+47} \alpha_{i j, t}
$$

The result is a panel of $1740(4 \times 435)$ adjustment parameters $\alpha_{i j, y}$ for four periods $y=2002$ 2005, 2006-2009, 2010-2013 and 2014- 2017.

Table 1: The Panel of estimated $\sum \alpha_{i j, y}$

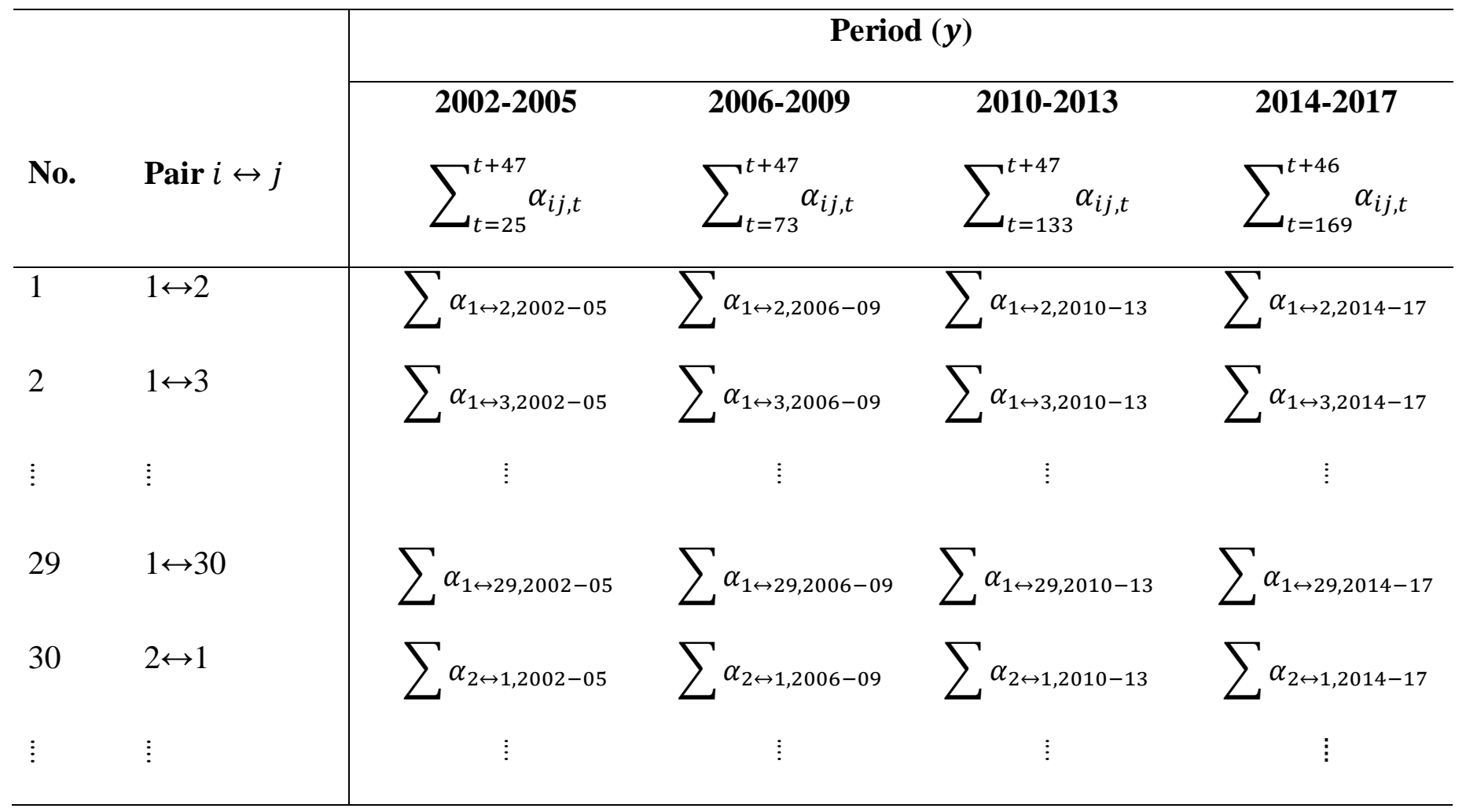

\footnotetext{
${ }^{1}$ As described in section 3 of Chapter III, in 385 of 435 cases (89\%) the SBIC criterion selects the lag-length $1=2$, we choose lag=2 for all pairs, so the estimated $\alpha_{i j, t}$ in time-varying VECM starts at the second month $(t=2)$ and ends up at the month last second observation $(t=215)$ for each pair. We drop the first three-year unstable estimates of adjustment parameters for each pair.
} 


\begin{tabular}{ll|l}
\hline $435 \quad 29 \leftrightarrow 30$ & $\sum \alpha_{29 \leftrightarrow 30,2002-05} \quad \sum \alpha_{2 \leftrightarrow 1,2006-09} \quad \sum \alpha_{29 \leftrightarrow 30,2010-13} \quad \sum \alpha_{29 \leftrightarrow 30,2014-17}$
\end{tabular}

\section{Source: Own expression.}

We estimate stochastic frontiers for aggregated adjustment parameters $\alpha_{i j, y}$. We prefer stochastic frontier methods following the procedure proposed in Chapter III, the difference is we extend the estimation for four periods. And one limitation is that we do not account for the measurement errors of the aggregated $\alpha_{i j, y}$. Our dependent variable, the adjustment parameters $\alpha_{i j, y}$ are estimated and are therefore subject to measurement error, which is explicitly accounted for in stochastic frontier specification in previous chapters. But in this chapter, we do not account for the standard errors of time-varying speeds of adjustment parameters. ${ }^{2}$

The frontier for the aggregated adjustment parameters $\alpha_{i j, y}$,

$$
\alpha_{i j, y}=f\left(d_{i j}, B_{i j}\right) \exp \left(u_{i j, y}, v_{i j, y}\right)
$$

Where $f()$ includes a vector of variables that are expected to influence the speeds of restoring market efficiency $\left(\alpha_{i j, y}\right)$, such as distance $d_{i j}$ and dummy $B_{i j}$ (the same variables used in Chapter III). $u_{i j, y}$ is inefficiency term and $v_{i j, y}$ is the statistical noise which captures the measurement errors. Unlike previous chapters, we do not include variables to explain the two error components $u_{i j, y}$ and $v_{i j, y}$ in equation (7).

\subsection{Data}

We estimate the bivariate VECMs and time-varying VECMs with logarithms of monthly pork prices of 30 provinces in China, documented in China Livestock and Veterinary Yearbook (Ministry of Agriculture of China, 2001-2018). The provincial monthly average data are aggregated from weekly retail prices collected in 470 markets nationwide. All of the pork price series start in January 2000 and end in December 2017. It is the same data set as used in Chapter III. In addition to the price series shown in Figure 1 of Chapter III, we present another three typical monthly pork price series chosen from the whole sample set of 30 . We measure distance in $1000 \mathrm{~km}$ between province capitals.

\footnotetext{
${ }^{2}$ We are facing a problem of calculating a complete set of standard error for estimated $\alpha_{i j, y}$.
} 
Figure 1: Three monthly pork prices series from Jan. 2000 to Dec. 2017

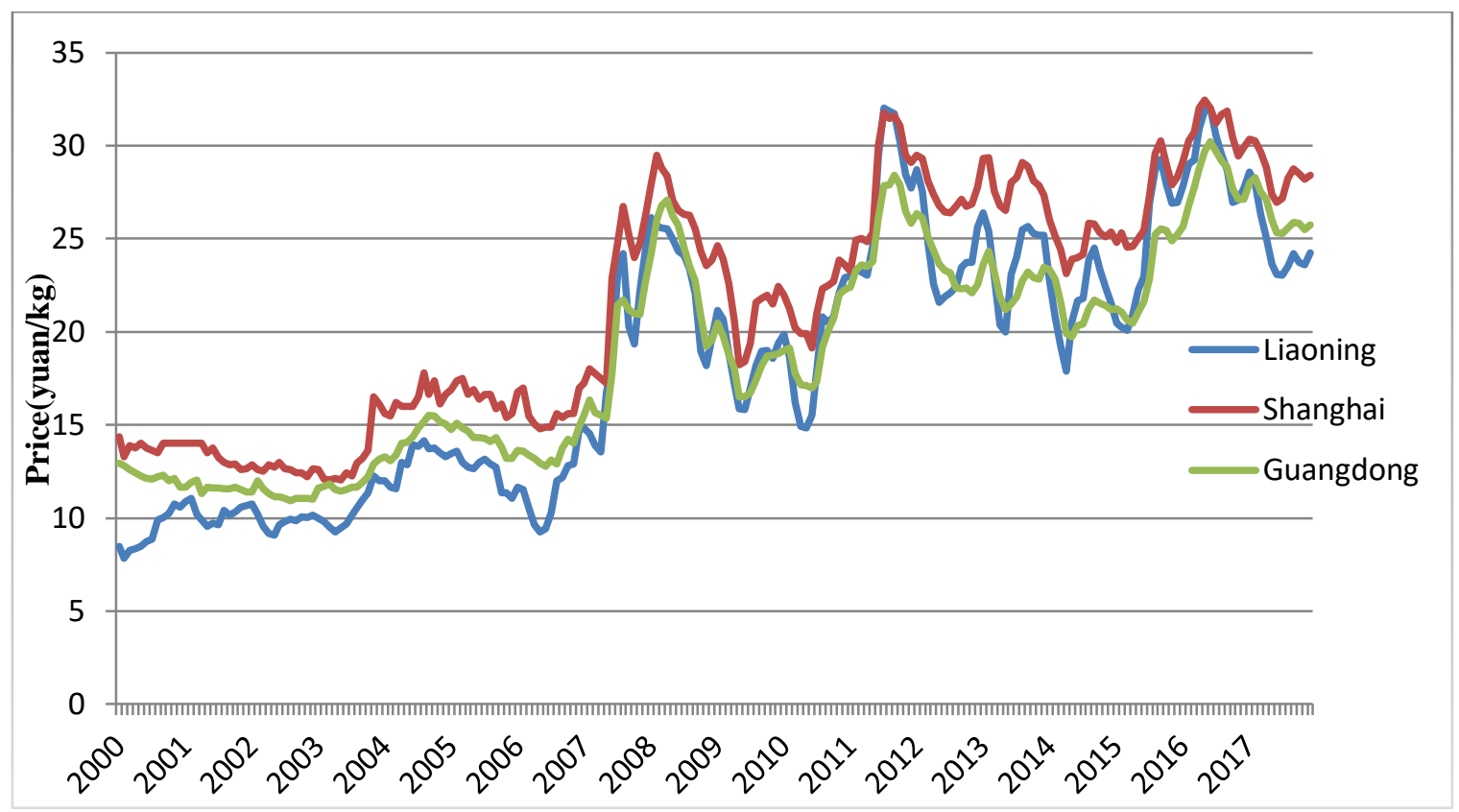

Source: Ministry of Agriculture of China (2001-2018).

\section{Results}

KPSS stationarity tests reject the null of stationarity for all the 30 price series, confirming the ADF test results showed in Chapter III. The Zivot and Andrews (1992) tests also confirm the ADF test results by ruling out the alternative of a stationary series with a breakpoint on a $5 \%$ significance level (Table A. 1 in appendix of this chapter). ${ }^{3}$

First step: We estimate 435 bivariate VECMs in state space form for all pairs. And then aggregate $\alpha_{i j, t}$ to $\alpha_{i j, y}$.

Figure 2 depicts the speeds of price transmission $\left(\alpha_{i j, t}\right)$ for two sample pairs at each observation $t$ (June of each sample year). Overall the speed of price transmission between Beijing and Guangdong (sharing a distance of $2122 \mathrm{~km}$ ) is lower than Jiangsu and Guangdong (with a distance of $1362 \mathrm{~km}$ ), which indicates the deviation from the long-run equilibrium is corrected faster within one month for the pair Jiangsu and Guangdong than Beijing and Guangdong.

\footnotetext{
${ }^{3}$ Results of the ADF and Johansen trace test are in Appendix of Chapter III.
} 
For the pair Beijing and Guangdong, the speeds of price transmission vary roughly between 0.2 and 0.25, which indicates that Beijing and Guangdong, around 20\% to 25\% of the deviation from long-run equilibrium is corrected at June for each year. For the pair Jiangsu and Guangdong, the speed of price transmission varies roughly between 0.3 and 0.4 in the selected sample months, which indicates that at least $30 \%$ of any deviation from long-run equilibrium is corrected within one month, most of the time it is corrected by around $40 \%$.

The variations between 2003 and 2007 for Beijing-Guangdong and Jiangsu and Guangdong are striking. Perhaps pork markets are intervened to keep prices stable in some markets.

Figure 2: Examples of time-varying $\sum \alpha_{i j, t}$

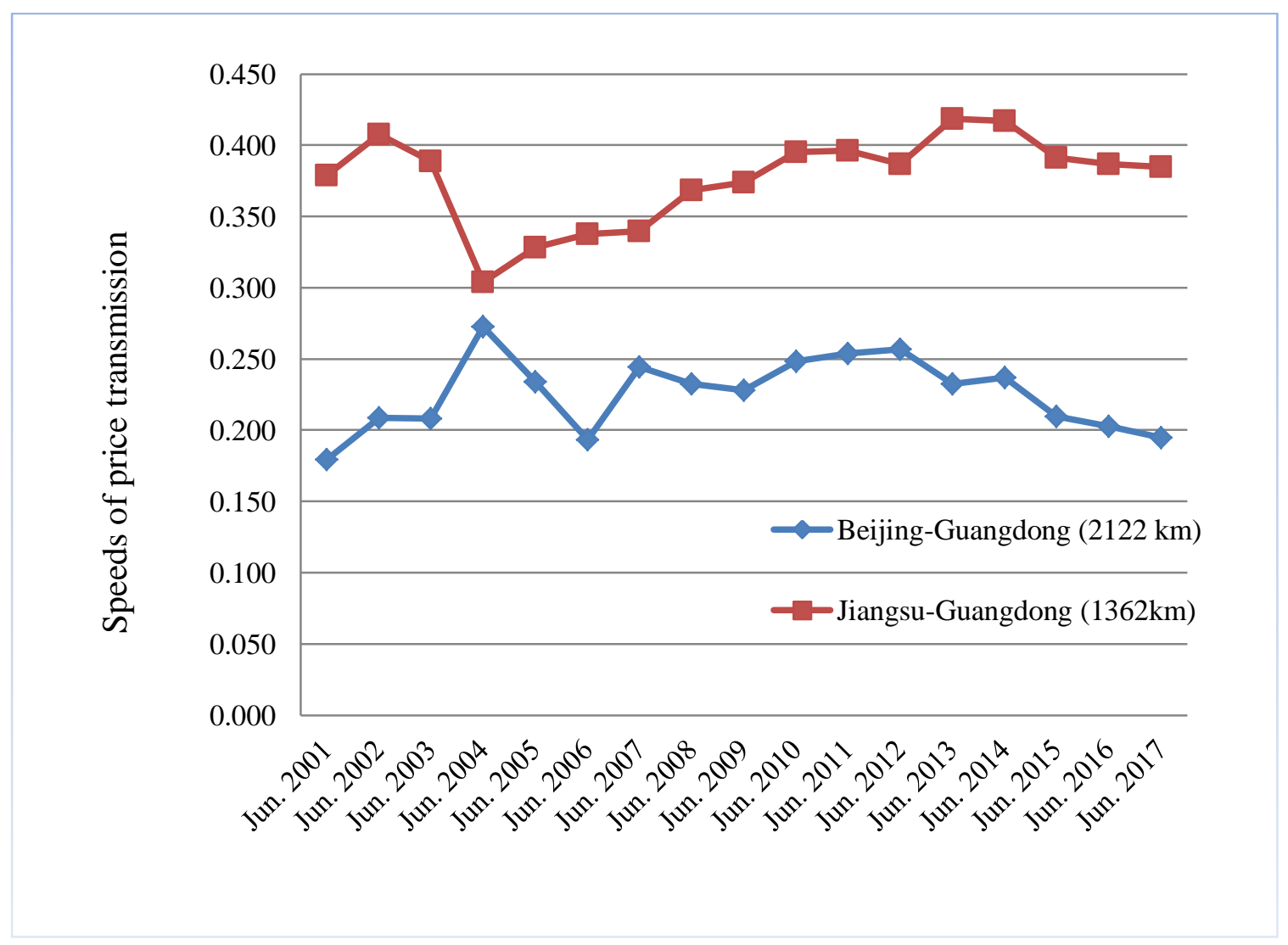

Source: Own estimations.

Figure 3 presents the entire periodical average set of estimated speed of price transmission $\left(\alpha_{i j, y}\right)$. For the great majority of 435 market pairs over the four periods, between $20 \%$ and $40 \%$ of any deviation from the long-run equilibrium is corrected within one month. Some high speeds of adjustment (over 60\%) show up in the earlier periods. 
Figure 3: Distribution of estimated speeds of price transmission $\left(\alpha_{i j, y}\right)$ in different periods

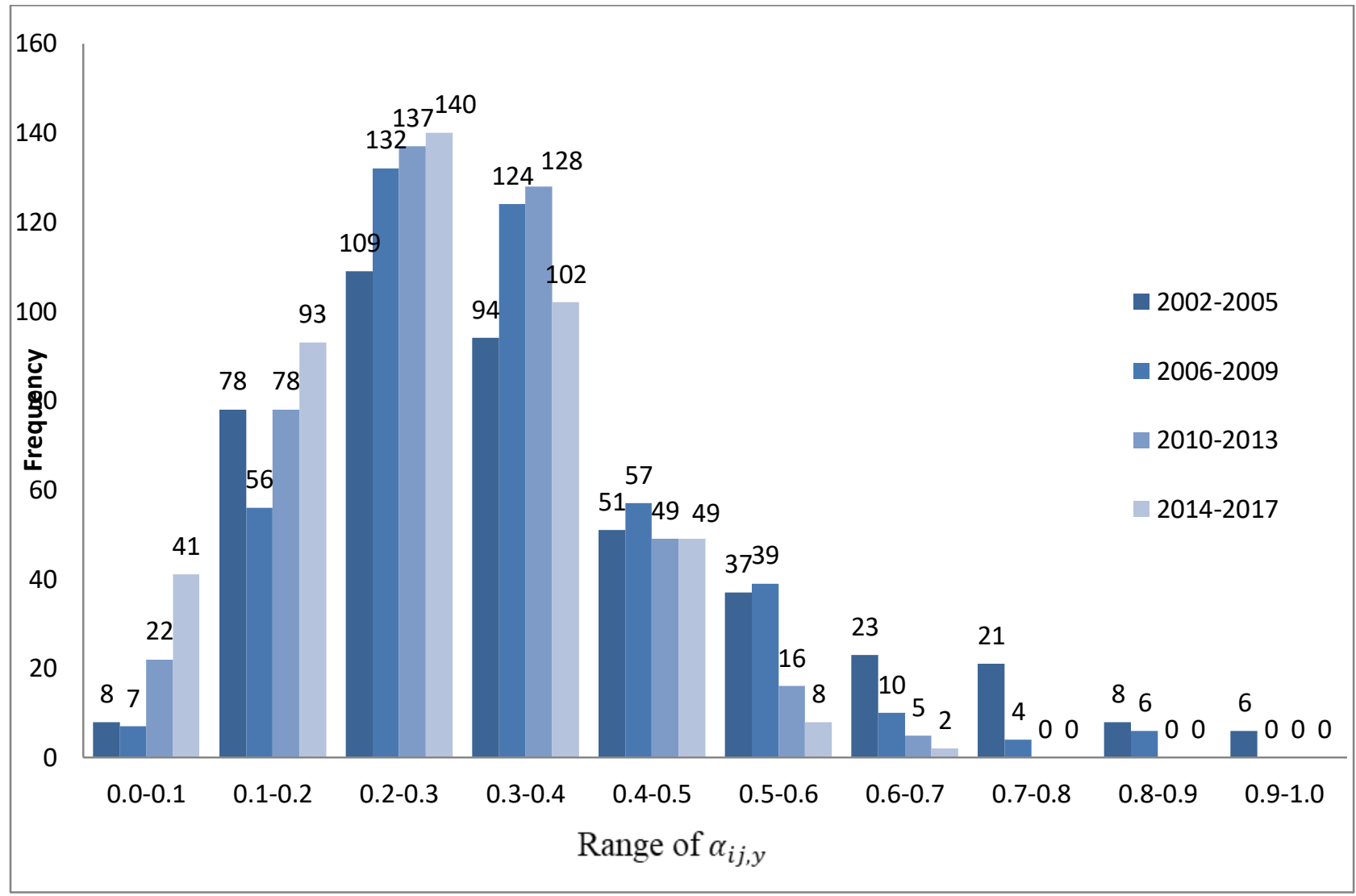

Source: Own calculations.

Table 2: Summary statistics of $\alpha_{i j, y}$ for four periods

\begin{tabular}{lllll}
\hline Period & Mean & Std. Dev. & Min. & Max. \\
$2002-2005$ & 0.364 & 0.196 & 0.01 & 1.00 \\
$2006-2009$ & 0.336 & 0.142 & 0.01 & 0.86 \\
$2010-2013$ & 0.291 & 0.119 & 0.01 & 0.69 \\
$2014-2017$ & 0.265 & 0.119 & 0.00 & 0.74 \\
\hline
\end{tabular}

Table 2 presents the summary statistics of estimated speeds of adjustment over four periods. According to these statistics, the average speeds of price transmission drop from $36.4 \%$ in the period 2002-2005 to $26.5 \%$ in the most recent period. It indicates that deviation from the long-run equilibrium is corrected slower within one month during the recent period compared to those in the earlier periods. 
Second step: Table 3 presents the estimation results of the frontier models for the speeds of restoring market efficiency (equation (7), the dependent variable $\alpha_{i j, y}$ ) for different periods. According to these results, the frontier $\alpha_{i j, y}$ falls by 0.055 per $1000 \mathrm{~km}$ of distance between two markets during 2002-2005, i.e. the proportion of a deviation from the long-run equilibrium that is corrected per month drops by $5.5 \%$ for each extensional $1000 \mathrm{~km}$ of distance. Over time, we see the effect of distance is falling down. The frontier $\alpha_{i j, y}$ falls by 0.046 per $1000 \mathrm{~km}$ of distance between two markets during 2006-2009, 0.035 during 2010-2013 and 0.029 during the most recent period.

Table 3: Estimated speed of restoring market efficiency frontier for four periods

\begin{tabular}{|c|c|c|c|c|}
\hline 2002-2005 & Coef. & Std. Err & $\mathbf{t}$ & P-value \\
\hline$d_{i j}$ & -0.055 & 0.012 & -4.530 & 0.000 \\
\hline$B_{i j}$ & 0.022 & 0.029 & 0.770 & 0.441 \\
\hline Constant & 0.450 & 0.076 & 5.950 & 0.000 \\
\hline$/ \ln \operatorname{sig} 2 \mathrm{v}$ & -3.329 & 0.068 & -49.070 & 0.000 \\
\hline$/ \ln \operatorname{sig} 2 \mathrm{u}$ & -13.483 & 152.335 & -0.090 & 0.929 \\
\hline sigma_v & 0.189 & 0.006 & & \\
\hline sigma_u & 0.001 & 0.090 & & \\
\hline sigma2 & 0.036 & 0.002 & & \\
\hline lambda & 0.006 & 0.090 & & \\
\hline 2006-2009 & Coef. & Std. Err & $\mathbf{t}$ & P-value \\
\hline$d_{i j}$ & -0.046 & 0.009 & -5.210 & 0.000 \\
\hline$B_{i j}$ & -0.002 & 0.021 & -0.080 & 0.939 \\
\hline Constant & 0.411 & 0.053 & 7.730 & 0.000 \\
\hline$/ \operatorname{lnsig} 2 \mathrm{v}$ & -3.982 & 0.068 & -58.660 & 0.000 \\
\hline$/ \operatorname{lnsig} 2 \mathrm{u}$ & -13.251 & 95.154 & -0.140 & 0.889 \\
\hline sigma_v & 0.137 & 0.005 & & \\
\hline sigma_u & 0.001 & 0.063 & & \\
\hline sigma2 & 0.019 & 0.001 & & \\
\hline lambda & 0.010 & 0.063 & & \\
\hline $2010-2013$ & Coef. & Std. Err & $\mathbf{t}$ & P-value \\
\hline$d_{i j}$ & -0.035 & 0.008 & -4.610 & 0.000 \\
\hline$B_{i j}$ & -0.030 & 0.018 & -1.680 & 0.093 \\
\hline Constant & 0.352 & 0.053 & 6.660 & 0.000 \\
\hline$/ \operatorname{lnsig} 2 \mathrm{v}$ & -4.301 & 0.068 & -63.210 & 0.000 \\
\hline$/ \operatorname{lnsig} 2 \mathrm{u}$ & -12.827 & 77.613 & -0.170 & 0.869 \\
\hline sigma_v & 0.116 & 0.004 & & \\
\hline sigma_u & 0.002 & 0.064 & & \\
\hline
\end{tabular}




\begin{tabular}{crrrr}
\hline sigma2 & 0.014 & 0.001 & & \\
lambda & 0.014 & 0.064 & & \\
\hline $\mathbf{2 0 1 4 - 2 0 1 7}$ & Coef. & Std. Err & \multicolumn{1}{c}{ t } & P-value \\
\hline$d_{i j}$ & -0.029 & 0.007 & -3.920 & 0.000 \\
$B_{i j}$ & -0.054 & 0.018 & -3.070 & 0.002 \\
Constant & 0.321 & 0.063 & 5.130 & 0.000 \\
/lnsig2v & -4.305 & 0.068 & -63.230 & 0.000 \\
/lnsig2u & -13.023 & 102.779 & -0.130 & 0.899 \\
sigma_v & 0.116 & 0.004 & & \\
sigma_u & 0.001 & 0.076 & & \\
sigma2 & 0.014 & 0.001 & & \\
lambda & 0.013 & 0.077 & & \\
\hline
\end{tabular}

Source: Own estimations.

Sharing a common border has no significant effect in the first two periods, but has unexpected negative effect in the last two periods.

Figure 4 sketches the 1740 estimates of $\alpha_{i j, y}$ against distance, as well as the estimated frontier based on the results in Table 3. It highlights the fact that while the estimated effect of distance on the speed of restoring market efficiency is significant, the magnitude decreases over periods. Improved infrastructure might lead to a decline in distance effects over time. However, the overall $\alpha_{i j, y}$ shifts down over periods, this indicates other factors might also play a role.

We have to admit several limitations for the estimation results showed here. First, we do not account for the standard errors for estimated $\alpha_{i j, y}$ which makes us lose the advantage of using frontier estimation. Second, LR test of sigma_u=0 cannot be rejected, so we do not find inefficiency from these estimations. Third, we only use one variable to explain $\alpha_{i j, y}$, so the frontiers are simply illustrated on Figure 4 as we estimate. The insights generated from this part are limited. We need to explore more factors that determines the frontier of $\alpha_{i j, y}$. 
Figure 4: $\alpha_{i j, y}$ and distance

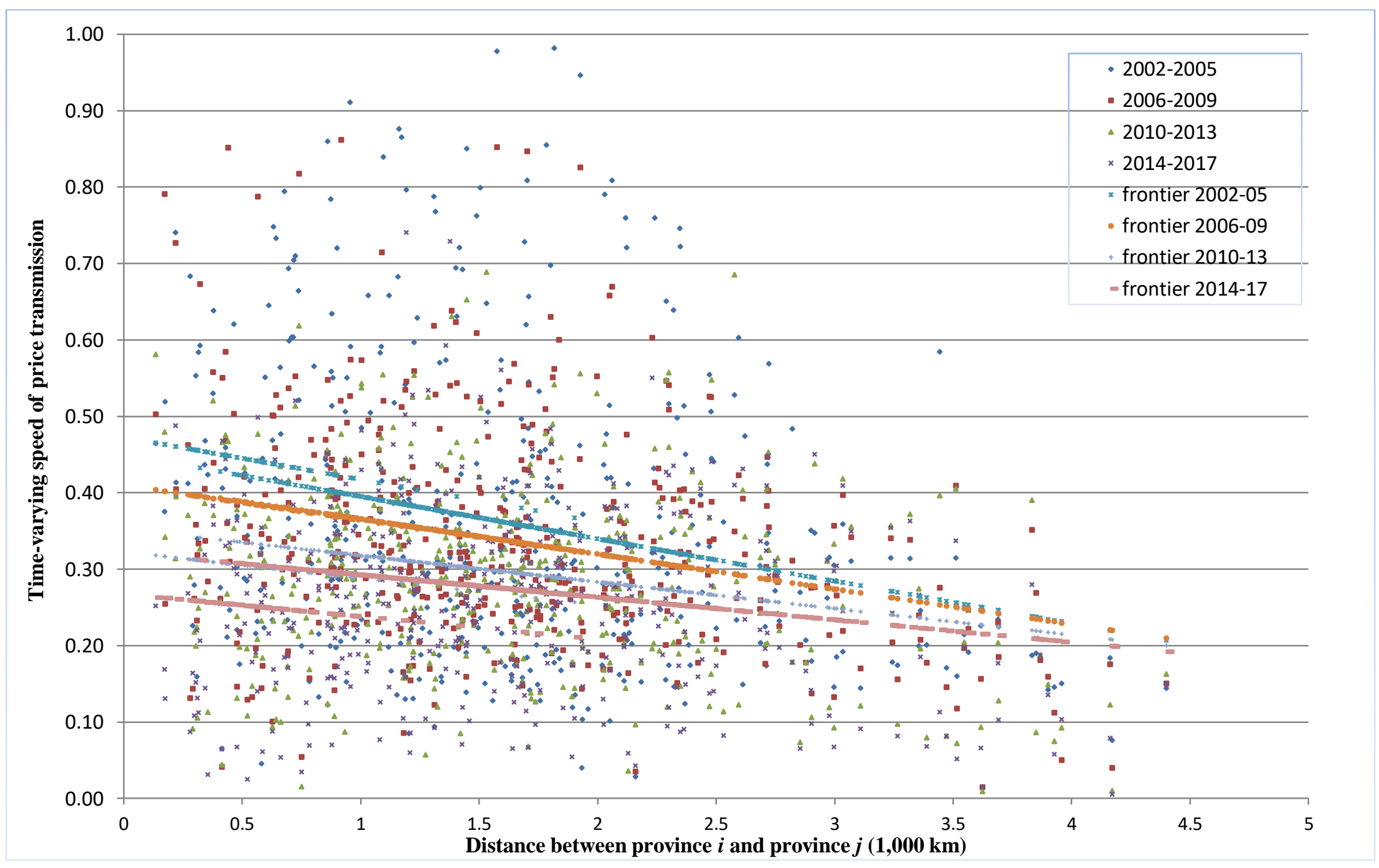

Source: Own estimations. 


\section{Discussion}

Table 4 presents the summary statistics of predicted frontier of the speed of restoring market efficiency for four periods. For all the periods, the minimum values are almost the same around 0.2 . It drops around 0.03 per period.

Table 4: Summary of predicted frontier of $\alpha_{i j, y}$ for four periods

\begin{tabular}{lllll}
\hline Period & Mean & Std. Dev. & Min. & Max. \\
2002-2005 & 0.364 & 0.051 & 0.207 & 0.465 \\
$2006-2009$ & 0.337 & 0.039 & 0.209 & 0.403 \\
$2010-2013$ & 0.292 & 0.026 & 0.200 & 0.341 \\
$2014-2017$ & 0.266 & 0.023 & 0.192 & 0.312 \\
\hline
\end{tabular}

Distance accounts for variable trade costs related to shipping agricultural commodities between spatially separated markets, we see that distance plays a major role in earlier periods, probably because the provinces are primarily linked via physical pork trade flows. Over time. People's diet shifts, pork is not the predominant protein source for people especially those are in capital cities. So price transmission between provinces is mainly guided by information flows, then distance would play a relatively minor role in correcting disequilibrium since there are information costs which could not be accounted for by distance.

Definitely distance is one of the most important factors. For markets sharing a shorter distance (within $1500 \mathrm{~km}$ ), the frontier shifts down with a large magnitude; for markets which are far apart (over $3500 \mathrm{~km}$ ), the frontier drops in a relatively lower magnitude. We find distance effects fall over time. Since we have not accounted for the standard errors in the estimation, it is not highly comparable to the results of Chapter III.

Aggregating the average estimates of $\alpha_{i j, t}$ for different periods is rough and gives rise to information loss on month-to-month or year-to-year changes within those complete periods. 
The main innovation of this paper is to consider time-varying parameters, however there are many specific questions waiting for us to answer. What are the roles of regional dummies in chapter III; can we confirm the overall pattern of efficiency across provinces? Have some province been improving their efficiency compared with other provinces over time?

It is true there is no equivalent theoretical foundation for deriving a frontier for speeds of price transmission. This study implies that other factors influence the speeds of restoring market efficiency than merely the level of proximity. Trade dependency, market infrastructure, roads quality, market information could also have effects. Factors such as dramatic changes in diesel fuel prices over the study period, delayed transport time due to traffic jams lead by increasing numbers of vehicles on the way for shipping, more strict food safety control, local preference consumption by substituting pork with other meat (e.g. beef, lamb), deserve to be analyzed and geared towards generating insights into our research question.

\section{Conclusion and limitations}

We benchmark speeds of restoring market efficiency using time-varying VECM estimations coupled with frontier estimations for different periods. The use of frontier methods for different periods allows us to estimate benchmarks for the speed of restoring market efficiency by considering time effects and market specific effects.

Several limitations should be pointed out and addressed in future research. First, we could extend to benchmark speeds of restoring market efficiency using time-varying VECM estimations coupled with panel frontier estimations instead of frontier estimation for different periods. By aggregating the estimated monthly speeds of adjustment to periodical ones, we lose some of the advantage of time varying parameters. If a critical break/shock occurred in an unpredictable month of a year, this aggregation means that the effect is averaged out or smoothed. Data on further explaining speeds of restoring market efficiency are available with annual frequency.

Second, in this application, we did not incorporate information on the standard errors of our estimates $\alpha_{i j, y}$ into the frontier estimation as we did in Chapter III. We have some 
information on the standard error of each observation of the dependent variable from the first stage VECM estimation in Chapter III. So we know that some of $\alpha_{i j, y}$ are estimated with more precision than others, and it would make sense to use the information of timevarying VECM estimates to improve the frontier estimation for this chapter (i.e. $\alpha_{i j, y}$ with smaller standard errors are more reliable, and we should give them relatively greater weights in the estimation of the location and shape of the frontier). And it would be useful to have standard errors for the aggregated speeds of adjustment, to see how reliable the estimates are and whether trends that we see in Figure 4 are significant.

In addition, we do not deal with spatial correlation (if moving from $\mathrm{A}$ to $\mathrm{C}$ means going through $\mathrm{B}$, then the efficiency of $\mathrm{AC}$ will depend on $\mathrm{AB}$ and $\mathrm{BC}$ ) in this application. If trade is going on by passing through $\mathrm{B}$ on the shortest route from $\mathrm{A}$ to $\mathrm{C}$, then the efficiency of transmission between $\mathrm{A}$ and $\mathrm{C}$ will depend on the efficiencies between $\mathrm{A}$ and $\mathrm{B}$, and $\mathrm{B}$ and $\mathrm{C}$. For example, we have Anhui province, Jiangsu province and Shanghai, if we transport pork from Anhui province to Shanghai, we must go through Nanjing bridge (Jiangsu) because the Yangtze River divided this southeast part to north and south. So the efficiency of price transmission between Anhui and Shanghai will depend on the efficiency between Anhui and Jiangsu and Jiangsu and Shanghai.

Finally, we follow Adämmer and Bohl (2015, 2018) that assume the long-run cointegration relationship between prices is constant and this relationship is disturbed by transient shocks. The time-varying VECM that we estimate enables us to have short-run interactions between prices in question vary over time. However, the assumption of a time-invariant long-run relationship might be not plausible for heterogeneous agricultural commodities, and the relationship between prices in different markets probably is subject to shocks that could lead to persistent changes in price relationship (Vollmer et al., 2020). For example, the relative availabilities of different pork carcass weights on producing markets could vary over years due to farmland restructuring, animal disease, etc. The resulting changes in quantity could influence the relationship between import prices and export prices. Changes in commodity prices also spur the reallocation of resources in the agricultural producing sector in response to changing demand patterns. Changes in trade direction and partners could have similar influence. Investments in infrastructure, 
changes in interruptions during trade, could lead to changes in the basis between a delivery market specified in the destination market. Further research would loosen the assumption of a constant and linear long-run relationship between pork markets in our research question, and then account for variation in the error correction terms that correct any deviations from the long-run relationship.

The old saw, "much remains to be done," is relevant here (Fama, 1970). In our case, the future endeavor is to look for factors that determine the dynamic market efficiency frontier and explanation of the associated inefficiency. 


\section{Appendix of Chapter V}

Table A1: KPSS test results

\begin{tabular}{|c|c|c|c|c|c|c|c|}
\hline \multirow[b]{2}{*}{ Price level } & \multirow[b]{2}{*}{ Lags } & \multicolumn{2}{|c|}{ Test statistics } & \multirow[b]{2}{*}{$\Delta$ price level } & \multirow[b]{2}{*}{ Lags } & \multicolumn{2}{|c|}{ Test statistics } \\
\hline & & constant & Constant\&trend & & & constant & Constant\&trend \\
\hline Beijing & 2 & 6.102 & 0.293 & $\Delta$ Beijing & 1 & 0.046 & 0.033 \\
\hline Tianjin & 1 & 9.099 & 0.436 & $\Delta$ Tianjin & 1 & 0.045 & 0.026 \\
\hline Hebei & 4 & 3.639 & 0.262 & $\Delta$ Hebei & 3 & 0.049 & 0.029 \\
\hline Shanxi & 3 & 4.526 & 0.352 & $\Delta$ Shanxi & 2 & 0.050 & 0.025 \\
\hline Inner Mongolia & 2 & 6.246 & 0.465 & $\Delta$ Inner Mongolia & 1 & 0.061 & 0.037 \\
\hline Liaoning & 4 & 3.722 & 0.302 & $\Delta$ Liaoning & 3 & 0.054 & 0.026 \\
\hline Jilin & 4 & 3.706 & 0.235 & $\Delta$ Jilin & 3 & 0.047 & 0.024 \\
\hline Heilongjiang & 3 & 4.601 & 0.326 & $\Delta$ Heilongjiang & 2 & 0.053 & 0.024 \\
\hline Shanghai & 2 & 6.227 & 0.485 & $\Delta$ Shanghai & 1 & 0.053 & 0.051 \\
\hline Jiangsu & 3 & 4.618 & 0.280 & $\Delta$ Jiangsu & 2 & 0.047 & 0.047 \\
\hline Zhejiang & 2 & 6.345 & 0.428 & $\Delta$ Zhejiang & 1 & 0.059 & 0.050 \\
\hline Anhui & 2 & 6.094 & 0.440 & $\Delta$ Anhui & 1 & 0.051 & 0.036 \\
\hline Fujian & 2 & 6.176 & 0.266 & $\Delta$ Fujian & 1 & 0.053 & 0.052 \\
\hline Jiangxi & 2 & 6.217 & 0.459 & $\Delta$ Jiangxi & 1 & 0.056 & 0.045 \\
\hline Shandong & 4 & 3.776 & 0.240 & $\Delta$ Shandong & 3 & 0.042 & 0.028 \\
\hline Henan & 2 & 6.089 & 0.451 & $\Delta$ Henan & 1 & 0.061 & 0.049 \\
\hline Hubei & 3 & 4.650 & 0.378 & $\Delta$ Hubei & 2 & 0.054 & 0.039 \\
\hline Hunan & 3 & 4.633 & 0.378 & $\Delta$ Hunan & 2 & 0.057 & 0.040 \\
\hline Guangdong & 2 & 6.095 & 0.385 & $\Delta$ Guangdong & 2 & 0.057 & 0.058 \\
\hline Guangxi & 3 & 4.503 & 0.423 & $\Delta$ Guangxi & 2 & 0.061 & 0.047 \\
\hline Hainan & 1 & 9.724 & 0.340 & $\Delta$ Hainan & 1 & 0.073 & 0.066 \\
\hline Chongqing & 2 & 6.100 & 0.425 & $\Delta$ Chongqing & 1 & 0.047 & 0.039 \\
\hline Sichuan & 3 & 4.763 & 0.437 & $\Delta$ Sichuan & 2 & 0.057 & 0.040 \\
\hline Guizhou & 3 & 4.905 & 0.371 & $\Delta$ Guizhou & 2 & 0.063 & 0.043 \\
\hline Yunnan & 2 & 6.481 & 0.399 & $\Delta$ Yunnan & 1 & 0.096 & 0.093 \\
\hline Shaanxi & 2 & 6.224 & 0.456 & $\Delta$ Shaanxi & 1 & 0.048 & 0.029 \\
\hline Gansu & 2 & 6.265 & 0.457 & $\Delta$ Gansu & 1 & 0.052 & 0.039 \\
\hline Qinghai & 1 & 9.246 & 0.771 & $\Delta$ Qinghai & 1 & 0.052 & 0.035 \\
\hline Ningxia & 1 & 9.341 & 0.930 & $\Delta$ Ningxia & 2 & 0.043 & 0.028 \\
\hline Xinjiang & 2 & 6.283 & 0.323 & $\Delta X$ injiang & 1 & 0.138 & 0.042 \\
\hline
\end{tabular}

Note: a) Number of lags is chosen by SBIC criterion. c) KPSS test with constant: $0.74(1 \%), 0.46(5 \%), 0.35$ (10 \%);

KPSS test with constant and trend: $0.22(1 \%), 0.15(5 \%), 0.12(10 \%)$. 
Table A2: Zivot and Andrews test results

\begin{tabular}{|c|c|c|c|c|c|c|c|}
\hline \multirow[b]{2}{*}{ Price level } & \multicolumn{3}{|c|}{ Test statistics } & \multicolumn{2}{|c|}{ Test statistics } & \multicolumn{2}{|c|}{ Test statistics } \\
\hline & lag & Intercept & Month & trend & Month & both & Month \\
\hline Beijing & 2 & -4.26 & 2007.04 & -3.54 & 2011.09 & -4.25 & 2007.04 \\
\hline Tianjin & 1 & -4.19 & 2007.04 & -3.24 & 2011.07 & -4.19 & 2007.04 \\
\hline Hebei & 4 & -3.95 & 2007.04 & -3.15 & 2011.06 & -4.03 & 2007.04 \\
\hline Shanxi & 3 & -4.24 & 2007.03 & -3.58 & 2011.06 & -4.40 & 2007.04 \\
\hline Inner Mongolia & 2 & -4.95 & 2007.04 & -3.63 & 2011.07 & -5.03 & 2007.04 \\
\hline Liaoning & 4 & -4.28 & 2007.04 & -3.15 & 2011.06 & -4.37 & 2007.04 \\
\hline Jilin & 4 & -4.51 & 2007.04 & -3.28 & 2011.06 & -4.51 & 2007.04 \\
\hline Heilongjiang & 3 & -4.67 & 2007.03 & -3.81 & 2011.06 & -4.78 & 2007.03 \\
\hline Shanghai & 2 & -4.43 & 2007.05 & -3.57 & 2011.06 & -4.67 & 2007.05 \\
\hline Jiangsu & 3 & -4.10 & 2007.04 & -3.37 & 2008.01 & -4.20 & 2007.04 \\
\hline Zhejiang & 2 & -4.31 & 2007.03 & -3.50 & 2007.12 & -4.49 & 2007.03 \\
\hline Anhui & 2 & -4.54 & 2007.03 & -3.83 & 2011.06 & -4.70 & 2007.03 \\
\hline Fujian & 2 & -4.02 & 2006.07 & -3.37 & 2008.02 & -4.01 & 2006.07 \\
\hline Jiangxi & 2 & -4.35 & 2007.04 & -3.53 & 2011.06 & -4.54 & 2007.04 \\
\hline Shandong & 4 & -4.36 & 2007.03 & -3.19 & 2011.06 & -4.40 & 2007.03 \\
\hline Henan & 2 & -4.13 & 2007.03 & -3.39 & 2011.06 & -4.30 & 2007.03 \\
\hline Hubei & 3 & -3.95 & 2007.04 & -3.23 & 2011.06 & -4.17 & 2007.04 \\
\hline Hunan & 3 & -3.89 & 2006.06 & -3.31 & 2007.12 & -4.01 & 2006.11 \\
\hline Guangdong & 2 & -3.89 & 2006.11 & -3.22 & 2008.02 & -4.01 & 2007.05 \\
\hline Guangxi & 3 & -3.63 & 2006.07 & -3.10 & 2007.12 & -3.94 & 2007.04 \\
\hline Hainan & 1 & -3.92 & 2007.04 & -3.32 & 2011.10 & -3.81 & 2007.04 \\
\hline Chongqing & 2 & -4.97 & 2007.03 & -3.91 & 2011.07 & -5.01 & 2007.03 \\
\hline Sichuan & 3 & -4.53 & 2007.04 & -3.55 & 2011.06 & -4.84 & 2007.05 \\
\hline Guizhou & 3 & -4.26 & 2007.04 & -3.33 & 2011.07 & -4.40 & 2007.04 \\
\hline Yunnan & 2 & -4.17 & 2006.11 & -3.24 & 2011.07 & -4.16 & 2007.04 \\
\hline Shaanxi & 2 & -4.63 & 2007.03 & -4.15 & 2011.07 & -4.88 & 2007.03 \\
\hline Gansu & 2 & -5.11 & 2007.03 & -3.54 & 2011.06 & -5.11 & 2007.03 \\
\hline Qinghai & 1 & -4.42 & 2007.04 & -3.45 & 2011.04 & -4.61 & 2007.04 \\
\hline Ningxia & 1 & -4.77 & 2006.10 & -4.03 & 2011.06 & -5.17 & 2007.04 \\
\hline Xinjiang & 2 & -4.02 & 2007.05 & -3.46 & 2012.09 & -4.04 & 2011.03 \\
\hline
\end{tabular}




\section{General Conclusion}

\section{Summary of results}

The main objective of this dissertation is to propose a new method for benchmarking dynamic market efficiency and implement the proposed procedure to pork markets and hog markets to have a better understanding of spatial market efficiency in China and the EU as well. The application is constituted by pork markets in China during the period 2000-2017, hog markets in the EU at the international level and China at the interprovincial level in the years 2004-2017.

This study first review the testing work of the Law of One Price and find mixed and controversial evidence from previous empirical analysis. Many factors are supposed to violate this "Law", amongst them, trade costs, trade delay and policy measures play essential roles. So instead of testing the LOP, a theoretical benchmark is built based on transport costs and Gardner's (1975) model. Trade cost is a function of distance between two markets. And the theoretical long-run elasticity of price transmission for each market pair is calculated as the cost share of agricultural commodity in the lower-price market $j$ in the price of the commodity in the higher-price market $i$.

In the first empirical article (Chapter III), "Estimating dynamic market efficiency frontiers", an empirical application is illustrated to the example of pork markets in China. The estimated frontier of the magnitude of market efficiency of Chinese pork markets lies just slightly below the theoretical frontier based on transport costs. This provides some support for the validity of the estimated frontier and suggests that transport accounts for most of the total costs of pork trade between provinces in China. And the estimated frontier differs considerably from the OLS estimate of price transmission elasticity on distance that has been used in past studies. However, there is no equivalent theoretical foundation for deriving a frontier for the speed of price transmission since it depends on a complex set of logistic factors such as transport capacities and speeds, and the time it takes to initiate and execute transactions.

This analysis provides a convenient way of accounting for sampling error in estimated measures of price transmission. The estimated standard errors of both magnitude and speed of market efficiency from the first step have a significant positive influence on the variance of random error of their frontier estimations. We also find that the estimated inefficiency from the frontier of the magnitude of market efficiency has a significant effect on the variance of the inefficiency term of 
the speed of restoring market efficiency, this indicates that unobserved factors that reduce the magnitude of market efficiency also reduce the speed of restoring market efficiency.

Significant province effects are found, market pairs involving provinces located in the Northeast of China are characterized by the highest magnitude of market efficiency, and that the magnitude of market efficiency tends to be lower for provinces located farther to the South and West. Factors such as ethnicity and dietary customs, relative remoteness might contribute to these results.

The second article (Chapter IV), "Comparing market efficiency frontiers" further explores the benchmarking market efficiency method proposed in Chapter III by extending applications to international hog markets within the EU and interprovincial markets in China from the year 2004 to 2017. Stochastic frontier techniques enable to estimate a 'best practice' frontier for the estimated price transmission elasticities for both China and the EU.

The results show that for most market pairs the estimated elasticity of price transmission is below the empirical frontier, so there is evidence of 'inefficiency' or less than perfect adherence to the LOP on both Chinese hog markets and the EU hog markets. The results suggest that the magnitudes of market efficiency are characterized by higher heterogeneity in the EU than the Chinese ones.

Significant provincial effects (China) and member-state effects (EU) in market efficiency are found. Provinces located in the northeast or central China (e.g. Liaoning and Henan) are characterized by higher magnitude of market efficiency, while the very southern and western (e.g. Guangdong, Fujian and Gansu) parts tend to have relatively lower efficiency. For the EU, member states such as Hungary, Czech Republic and Austria located in the central are with higher magnitude of market efficiency. Member states located farther to the North (e.g. Sweden, UK) or South (e.g. Greece) tend to be less efficient.

Furthermore, comparing the two benchmarks, results show that the empirical frontier for the EU lies below the one for China. For most market pairs in the EU, the distance (within 0.1) to the frontier is farther than China (within 0.05). The estimated average inefficiency is $8 \%$ for China and $11 \%$ for the EU. The effect of distance is considerably higher in the EU than China. This 
result may imply higher transport costs and more stringent animal welfare-based restrictions on transporting live hogs in the EU.

The third article (Chapter V) "Measuring time-varying market efficiency", proposes for benchmarking time-varying market efficiency. Using time-varying VECM coupled with stochastic frontier models for different periods, we benchmark speeds of restoring market efficiency during the study period 2000-2017. The time-varying VECM results reveal that for the great majority of market pairs, between $20 \%$ and $40 \%$ of any deviation from the long-run equilibrium are corrected within one month. We find that the estimated individual speed of restoring market efficiency vary over space (provinces in China) and time (periods). And the estimated frontiers for the speed of restoring market efficiency fall as distances increase between markets. We also find that the estimated frontier shifts down over periods.

\section{Future research outlook}

Several aspects deserve further investigation based on this research progress and results:

\section{Extension of the used price data, trade flow data and transport cost data}

The analyses suffer from data limitations to some degree. Whereas in this dissertation monthly price data are used, weekly or daily data would help to get more observations, to lose less information through timely aggregation. Especially in the second empirical article, dealing with hog prices for China and the EU, weekly hog prices had to be aggregated for the EU to monthly prices because only monthly hog prices for China are available. These pig meat carcass prices are also very heterogeneous across space, because they vary in lean meat percentage, carcass size, etc. Based on this experience, I started to collect daily price data by retrieving price data through web to tackle some limitations of currently used data sources.

In addition, in the application to hog markets in the EU, the data for transport costs between the EU member states are not collected, part of trade cost associated with animal welfare regulations during transport in the EU which need to be specified more carefully.

\section{Meta frontier}

Though hog market efficiency frontiers are estimated for both China and the EU, only the distribution could be compared from summary statistics under different frontiers. The frontier 
method that proposed would be extended using meta-frontier techniques (Battese et al., 2004; O'Donnell et al., 2008) to compare between-country benchmarks and thus investigate whether there are indications that markets in some countries are systematically more or less efficient than markets in others.

\section{Benchmark vertical market efficiency frontiers}

Benchmark market efficiency frontiers in a vertical setting rather than a spatial setting would be another novelty. Piglet-pig and pig-pork stages in the chain would both be possible for vertical estimates. If data are available on the costs of pig production (the share of piglet costs in total costs) and the costs of pork production (the share of slaughter pigs in total costs), which would be theoretical cost share (Gardner, 1975) for the two stages in the chain. We could also estimate the level of the vertical price transmission elasticities against market-specific covariates that might be expected to influence it. The costs shares might vary across regions and there are also quantifiable differences in the market structure in the different regions (e.g. market power) and market arrangements with the producers (contracts, spot markets, etc.) that could lead to differences in the amount of competition, which would influence the vertical prices transmission (McCorriston et al., 1998; Weldegebriel, 2004). Thus, there would be a benchmark from the Gardner (1975) model. Some vertical price transmission elasticities are higher and closer to the theoretical cost share level, and some are lower and farther away.

\section{African Swine Fever and Coronavirus 2019 impact on Chinese and the EU pig industry}

The outbreak of African Swine Fever (ASF, 2018) has infected pigs, and coronavirus 2019 (COVID-19) that is affecting humans and imaginably pigs as well and has had major economic impacts (Laborde et al., 2020). Each of them represents a path-breaking opportunity for researchers to incorporate effects into the market analysis. The implications of ASF on domestic pork market and global pork market are not extensively explored (Mason-D'Croz et al., 2020). To investigate major structural breaks on pork/hog markets due to the ASF outbreak in 2018 and COVID-19 in China, in the EU as well, empirical applications would be carried out by adding hog price data from 2018 onward.

Mason-D'Croz et al. (2020) use equilibrium models to compare the state of system before the ASF shock with the state of the system after it has entered into a new equilibrium state. They 
found the production shock in Chinese pig production tends to increase global food expenditures. Ramsey et al. (2021) characterize US beef, pork, and poultry price series behavior and dynamic linkages of these meat prices before COVID-19 and then compare these meat price movements under COVID-19 to model predictions. They found a resilient U.S. livestock sector.

Both of them tell us little about the dynamic path that the market takes between equilibrium states and how long it takes to adjust back to the equilibrium after the shock. As time passes and more available price data during and after ASF and COVID-19 show up, we could test for the structural changes in the pork/hog price series and extend nonlinear models such as smooth transition models (Teräsvirta, 1994), Bayesian error correction and threshold models developed by Greb et al. (2013) to analyze the Chinese and the EU pork/hog markets. 


\section{References}

Abdulai, A. (2000). Spatial price transmission and asymmetry in the Ghanaian maize market. Journal of development economics, 63(2), 327-349.

Adämmer, P., and Bohl, M. T. (2018). Price discovery dynamics in European agricultural markets. Journal of Futures Markets, 38(5), 549-562.

Adämmer, P., and Bohl, M. T. (2015). Price Discovery in European Agricultural Markets: When Do Futures Contracts Matter?. Center for Quantitative Economics (CQE), University of Muenster, (4415).

Ardeni, P. G. (1989). Does the law of one price really hold for commodity prices?. American Journal of Agricultural Economics, 71(3), 661-669.

Asche, F., Bremnes, H., and Wessells, C. R. (1999). Product aggregation, market integration, and relationships between prices: an application to world salmon markets. American Journal of Agricultural Economics, 81(3), 568-581.

Asche, F., Bremnes, H., and Wessells, C. R. (2001). Product aggregation, market integration, and relationships between prices: An application to world salmon markets: Reply. American Journal of Agricultural Economics, 83(4), 1090-1092.

Asche, F., Gordon, D. V., and Hannesson, R. (2004). Tests for market integration and the law of one price: the market for whitefish in France. Marine resource economics, 19(2), 195-210.

Baffes, J. (1991). Some further evidence on the law of one price: The law of one price still holds. American Journal of Agricultural Economics, 73(4), 1264-1273.

Barrett, C. B. (2001). Measuring integration and efficiency in international agricultural markets. Applied Economic Perspectives and Policy, 23(1), 19-32.

Barrett, C. B., and Li, J. R. (2002). Distinguishing between equilibrium and integration in spatial price analysis. American Journal of Agricultural Economics, 84(2), 292-307.

Barrett, C. B. (1996). Market analysis methods: are our enriched toolkits well suited to enlivened markets?. American journal of agricultural economics, 78(3), 825-829.

Battese, G. E., Rao, D. P., and O'donnell, C. J. (2004). A metafrontier production function for estimation of technical efficiencies and technology gaps for firms operating under different technologies. Journal of productivity analysis, 21(1), 91-103.

Baulch, B. (1997a). Testing for food market integration revisited. The Journal of Development Studies, 33(4), 512-534. 
Baulch, B. (1997b). Transfer costs, spatial arbitrage, and testing for food market integration. American Journal of Agricultural Economics, 79(2), 477-487.

Blank, S. C., and Schmiesing, B. H. (1988). Modeling of agricultural markets and prices using causality and path analysis. Applied Economic Perspectives and Policy, 10(1), 35-48.

Bressler, R. G. and R. A. King (1970). Markets, Prices and Interregional Trade. John A. Wiley and Sons.

Brümmer, B., von Cramon-Taubadel, S., and Zorya, S. (2009). The impact of market and policy instability on price transmission between wheat and flour in Ukraine. European review of agricultural economics, 36(2), 203-230.

Caporale, G. M., Ciferri, D., and Girardi, A. (2014). Time-varying spot and futures oil price dynamics. Scottish Journal of Political Economy, 61(1), 78-97.

Choi, I. (2001). Unit root tests for panel data. Journal of international money and Finance, 20(2), 249-272.

Conforti, P. (2004). Price transmission in selected agricultural markets. FAO Commodity and trade policy research working paper, 7 .

Costantini, M., and Lupi, C. (2013). A simple panel - CADF test for unit roots. Oxford Bulletin of Economics and Statistics, 75(2), 276-296.

Crouhy-Veyrac, L., Crouhy, M., and Melitz, J. (1982). More about the law of one price. European Economic Review, 18(2), 325-344.

Dawson, P. J., and Dey, P. K. (2002). Testing for the law of one price: Rice market integration in Bangladesh. Journal of International Development, 14(4), 473-484.

Dercon, S., and Van Campuenhout, B. (1999). Dynamic price adjustment in spatially separated food markets with transaction costs. Onderzoeksrapport 99.09.

Dickey, D. A., and Fuller, W. A. (1979). Distribution of the estimators for autoregressive time series with a unit root. Journal of the American statistical association, 74(366a), 427-431.

Dillon, B. M., and Barrett, C. B. (2016). Global oil prices and local food prices: Evidence from East Africa. American Journal of Agricultural Economics, 98(1), 154-171.

Donaldson, D. (2018). Railroads of the Raj: Estimating the impact of transportation infrastructure. American Economic Review, 108(4-5), 899-934.

Dong, X., Brown, C., Waldron, S., and Zhang, J. (2018). Asymmetric price transmission in the Chinese pork and pig market. British Food Journal. 
Durbin, J., and Koopman, S. J. (2012). Time series analysis by state space methods. Oxford university press.

Emmanouilides, C. J., and Fousekis, P. (2012). Testing for the LOP under nonlinearity: an application to four major EU pork markets. Agricultural economics, 43(6), 715-723.

Emmanouilides, C. J., and Proskynitopoulos, A. (2019). Spatial Integration of Pig Meat Markets in the EU: Complex Network Analysis of Non-linear Price Relationships. In International Conference on Time Series and Forecasting (pp. 81-97). Springer, Cham.

Engle, R. F., and Granger, C. W. (1987). Co-integration and error correction: representation, estimation, and testing. Econometrica: journal of the Econometric Society, 251-276.

Enke, S. (1951). Equilibrium among spatially separated markets: Solution by electric analogue. Econometrica: Journal of the Econometric Society, 40-47.

European Commission (2021). Slaughtering in slaughterhouses - annual data https://ec.europa.eu/eurostat/databrowser/view/APRO_MT_PANN_custom_237456/default/t able?lang=de

European Commission (2021). Agricultural Markets - Prices. https://agridata.ec.europa.eu/extensions/DashboardPrice/DashboardMarketPrices.html

European Commission (2020). European Parliamentary Research Service (EPRS). https://www.europarl.europa.eu/RegData/etudes/BRIE/2020/652044/EPRS_BRI(2020)652044 _EN.pdf.

European Commission (2004). Guide to good practices for the transport of pigs http://animaltransportguides.eu/wp-content/uploads/2016/05/Guides-Pig-EC-Templ.pdf p.24

European Commission (2005). Council Regulation (EC) No 1/2005 of 22 December 2004 on the protection of animals during transport and related operations and amending Directives 64/432/EEC and 93/119/EC and Regulation (EC) No 1255/97 http://ec.europa.eu/eurostat/documents/272892/272992/Consumer_Prices_Research_2013.pdf/ 0effc4ed-134c-4af4-a401-1a72fc74db8c

European Commission (2013). Detailed Average Prices Report. November. https://ec.europa.eu/eurostat/documents/272892/272992/Consumer_Prices_Research_2013.pd f/

Fackler, P. L., and Goodwin, B. K. (2001). Spatial price analysis. Handbook of agricultural economics, 1, 971-1024. 
Fama, E. F. (1970). Efficient capital markets: a review of theory and empirical work', Journal of Finance, 25.Faminow, M. D., and Benson, B. L. (1990). Integration of spatial markets. American Journal of Agricultural Economics, 72(1), 49-62.

Fousekis, P. (2007). Multiple Markets Within the EU? Empirical Evidence from Pork and Poultry Prices in 14 EU Member Countrties. Economics Bulletin, 3(65), 1-12.

Frenkel, J. A., and Levich, R. M. (1975). Covered interest arbitrage: Unexploited profits?. Journal of Political Economy, 83(2), 325-338.

Gardner, B. L. (1975). The farm-retail price spread in a competitive food industry. American Journal of Agricultural Economics, 57(3), 399-409.

Getnet, K., Verbeke, W. and Viaene, J. (2005). Modeling spatial price transmission in the grain markets of Ethiopia with an application of ARDL approach to white teff. Agricultural economics, 33, 491-502.

Gilbert, M., Conchedda, G., Van Boeckel, T. P., Cinardi, G., Linard, C., Nicolas, G., Thanapongtharm, W., D’Aietti, L., Wint, W., Newmann, S. H. and Robinson, T. P. (2015). Income disparities and the global distribution of intensively farmed chicken and pigs. PLoS One, 10(7), e0133381.

Giovannini, A. (1988). Exchange rates and traded goods prices. Journal of international Economics, 24(1-2), 45-68.

Góes, C., and Matheson, T. (2017). Domestic market integration and the law of one price in Brazil. Applied Economics Letters, 24(5), 284-288.

Gonzalo, J., and Pitarakis, J. Y. (2006). Threshold effects in cointegrating relationships. Oxford Bulletin of Economics and Statistics, 68, 813-833.

Goodwin, B. K. (1990). Empirically testing the law of one price in an international commodity market: a rational expectations application to the natural rubber market. Agricultural Economics, 4(2), 165-177.

Goodwin, B. K. (1992). Multivariate cointegration tests and the law of one price in international wheat markets. Applied Economic Perspectives and Policy, 14(1), 117-124.

Goodwin, B. K., Grennes, T., and Wohlgenant, M. K. (1990a). Testing the law of one price when trade takes time. Journal of international money and finance, 9(1), 21-40. 
Goodwin, B. K., Grennes, T. J., and Wohlgenant, M. K. (1990b). A revised test of the law of one price using rational price expectations. American Journal of Agricultural Economics, 72(3), 682-693.

Goodwin, B. K., and Piggott, N. E. (2001). Spatial market integration in the presence of threshold effects. American Journal of Agricultural Economics, 83(2), 302-317.

Goodwin, B. K., Grennes, T. J., and Craig, L. A. (2002). Mechanical refrigeration and the integration of perishable commodity markets. Explorations in Economic History, 39(2), 154182.

Gordon, D. V., and Hannesson, R. (1996). On prices of fresh and frozen cod fish in European and US markets. Marine Resource Economics, 11(4), 223-238.

Greb, F., von Cramon-Taubadel, S., Krivobokova, T., and Munk, A. (2013). The estimation of threshold models in price transmission analysis. American Journal of Agricultural Economics, 95(4), 900-916.

Guney, S., Goodwin, B. K., and Riquelme, A. (2019). Semi-Parametric Generalized Additive Vector Autoregressive Models of Spatial Basis Dynamics. American Journal of Agricultural Economics, 101(2), 541-562.

Hadri, K. (1999). Estimation of a doubly heteroscedastic stochastic frontier cost function. Journal of Business \& Economic Statistics, 17(3), 359-363.

Harriss, B. (1979). There is method in my madness: Or is it vice versa? Measuring agricultural market performance. Food Research Institute Studies, 17(1387-2016-116163), 197-218.

Hartung, J. (1999). A note on combining dependent tests of significance. Biometrical Journal: Journal of Mathematical Methods in Biosciences, 41(7), 849-855.

Hillen, J. (2019). Market integration and market efficiency under seasonal tariff rate quotas. Journal of Agricultural Economics, 70(3), 859-873.

Holst, C., and Cramon-Taubdel, S. V. (2014). Trade, market integration and spatial price transmission on EU pork markets following eastern enlargement (No. 871-2016-60784).

Hu, Z., and Brorsen, B. W. (2017). Spatial price transmission and efficiency in the urea market. Agribusiness, 33(1), 98-115.

Isard, P. (1977). How Far Can We Push the "Law of One Price"?. The American Economic Review, 67(5), 942-948.

ITC, 2021. Trade map (International Trade Center). URL: https://www.trademap.org. 
Jabara, C. L., and Schwartz, N. E. (1987). Flexible exchange rates and commodity price changes: the case of Japan. American journal of agricultural economics, 69(3), 580-590.

Johansen, S. (1991). Estimation and hypothesis testing of cointegration vectors in Gaussian vector autoregressive models. Econometrica: journal of the Econometric Society, 1551-1580.

Johansen, S. (1995). Likelihood-based inference in cointegrated vector autoregressive models. Oxford University Press on Demand.

Johansen, S. (1988). Statistical analysis of cointegration vectors. Journal of economic dynamics and control, 12(2-3), 231-254.

Kinnucan, H. W., and Zhang, D. (2015). Notes on farm-retail price transmission and marketing margin behavior. Agricultural Economics, 46(6), 729-737.

Kouyaté, C., and von Cramon-Taubadel, S. (2016). Distance and border effects on price transmission: A meta-analysis. Journal of Agricultural Economics, 67(2), 255-271.

Kouyaté, C., von Cramon-Taubadel, S., and Fofana, I. (2016). Proximity and price co-movement in West African rice markets. African Journal of Agricultural and Resource Economics, 11(311-2016-5661), 167-182.

Kripfganz, S., and Schneider, D. C. (2018). ardl: Estimating autoregressive distributed lag and equilibrium correction models. In Proceedings of the 2018 London Stata Conference.

Kumbhakar, S. C. (1990). Production frontiers, panel data, and time-varying technical inefficiency. Journal of econometrics, 46(1-2), 201-211.

Kumbhakar, S. C., and Heshmati, A. (1995). Efficiency measurement in Swedish dairy farms: an application of rotating panel data, 1976-88. American Journal of Agricultural Economics, 77(3), 660-674.

Laborde, D., Martin, W., Swinnen, J., and Vos, R. (2020). COVID-19 risks to global food security. Science, 369(6503), 500-502.

Le Mouël, C., and Forslund, A. (2017). How can we feed the world in 2050? A review of the responses from global scenario studies. European Review of Agricultural Economics, 44(4), 541-591.

Lewis, J. B., and Linzer, D. A. (2005). Estimating regression models in which the dependent variable is based on estimates. Political analysis, 13(4), 345-364.

Liefert, W. M. (2009). Decomposing changes in agricultural price gaps: An application to Russia. Agricultural Economics, 40(1), 15-28. 
Lloyd, T. (2017). Forty years of price transmission research in the food industry: Insights, challenges and prospects. Journal of Agricultural Economics, 68(1), 3-21.

Lütkepohl, H. (1985). Comparison of criteria for estimating the order of a vector autoregressive process. Journal of time series Analysis, 6(1), 35-52.

Lütkepohl, H. (2005). New introduction to multiple time series analysis. Springer Science \& Business Media.

Ma, M., Wang, H., Hua, Y., Qin, F., and Yang, J. (2020). African Swine Fever in China: Shocks, Responses, and Implications on Trade.

Marshall, A. (2009). Principles of economics: unabridged eighth edition. Cosimo, Inc..

Maruyama, M., Wu, L., and Huang, L. (2016). The modernization of fresh food retailing in China: The role of consumers. Journal of Retailing and Consumer Services, 30, 33-39.

Mason-D’Croz, D., Bogard, J. R., Herrero, M., Robinson, S., Sulser, T. B., Wiebe, K., Willenbockel, D. and Godfray, H. C. J. (2020). Modelling the global economic consequences of a major African swine fever outbreak in China. Nature Food, 1(4), 221-228.

McCorriston, S., Morgan, C. W., and Rayner, A. J. (1998). Processing technology, market power and price transmission. Journal of Agricultural Economics, 49(2), 185-201.

McNew, K. (1996). Spatial market integration: Definition, theory, and evidence. Agricultural and Resource Economics Review, 25(1), 1-11.

McNew, K., and Fackler, P. L. (1997). Testing market equilibrium: Is cointegration informative?. Journal of Agricultural and Resource Economics, 191-207.

Meulenberg, M. T., and Pennings, J. M. (2002). A marketing approach to commodity futures exchanges: A case study of the Dutch hog industry. Journal of Agricultural Economics, 53(1), 51-64.

Meyer, J. (2004). Measuring market integration in the presence of transaction costs - a threshold vector error correction approach. Agricultural Economics, 31(2-3), 327-334.

Miljkovic, D. (1999). The law of one price in international trade: A critical review. Applied Economic Perspectives and Policy, 21(1), 126-139.

Miljkovic, D., and Paul, R. J. (2001). Product aggregation, market integration, and relationships between prices: An application to world salmon markets: Comment. American Journal of Agricultural Economics, 83(4), 1087-1089. 
Ministry of Agriculture of China. (2001-2018). China Animal Husbandry Yearbook (China Agriculture Press, Annual, Beijing).

$\mathrm{Mu}$, Y. (2018). Pork price transmission and efficiency in China. Paper prepared for presentation at the 30th ICAE conference.

Newell, G., Chau, K. W., and Wong, S. K. (2009). The significance and performance of infrastructure in China. Journal of Property Investment \& Finance.

Nielsen, M. (2005). Price formation and market integration on the European first-hand market for whitefish. Marine Resource Economics, 20(2), 185-202.

O’Donnell, C. J., Rao, D. P., and Battese, G. E. (2008). Metafrontier frameworks for the study of firm-level efficiencies and technology ratios. Empirical economics, 34(2), 231-255.

Officer, L. H. (1986). The law of one price cannot be rejected: two tests based on the tradable/nontradable price ratio. Journal of Macroeconomics, 8(2), 159-182.

Pan, F., and Li, C. (2019). Evolution of Agricultural Spatial Market Integration: Evidence from the Hog Market in China. Journal of Agricultural and Applied Economics, 51(3), 349-367.

Park, A., Jin, H., Rozelle, S., and Huang, J. (2002). Market emergence and transition: arbitrage, transaction costs, and autarky in China's grain markets. American Journal of Agricultural Economics, 84(1), 67-82.

Pesaran, M. H., and Shin, Y. (1995). An autoregressive distributed lag modelling approach to cointegration analysis.

Pasaran, S. H., Shine, Y., and Smith, R. J. (2001). Bound Testing Approach to the Analysis of level Relationship. Journal of Applied Econometrics, 16, 289-326.

Pesaran, M. H. (2007). A simple panel unit root test in the presence of cross-section dependence. Journal of applied econometrics, 22(2), 265-312.

Protopapadakis, A. A., and Stoll, H. R. (1986). The law of one price in international commodity markets: a reformulation and some formal tests. Journal of International Money and Finance, 5(3), 335-360.

Protopapadakis, A., and Stoll, H. R. (1983). Spot and futures prices and the law of one price. The Journal of Finance, 38(5), 1431-1455.

Ramsey, A. F., Goodwin, B. K., Hahn, W. F., and Holt, M. T. (2021). Impacts of COVID-19 and price transmission in US meat markets. Agricultural Economics, 52(3), 441-458. 
Rapsomanikis, G., Hallam, D., and Conforti, P. (2006). Market integration and price transmission in selected food and cash crop markets of developing countries: review and applications. Agricultural commodity markets and trade, 187-217.

Ravallion, M. (1986). Testing market integration. American Journal of Agricultural Economics, 68(1), 102-109.

Reuters (2020). https://www.reuters.com/article/businessNews/idCAKCN2500H3 ?editionredirect $=\mathrm{ca}$

Richardson, J. D. (1978). Some empirical evidence on commodity arbitrage and the law of one price. Journal of International Economics, 8(2), 341-351.

Said, S. E., and Dickey, D. A. (1984). Testing for unit roots in autoregressive-moving average models of unknown order. Biometrika, 71(3), 599-607.

Samuelson, P. A. (1952). Spatial price equilibrium and linear programming. The American economic review, 42(3), 283-303.

Sanjuán, A. I., and Gil, J. M. (2001). Price transmission analysis: a flexible methodological approach applied to European pork and lamb markets. Applied Economics, 33(1), 123-131.

Serra, T., Gil, J. M., and Goodwin, B. K. (2006). Local polynomial fitting and spatial price relationships: price transmission in EU pork markets. European Review of Agricultural Economics, 33(3), 415-436.

Serra, T., Goodwin, B. K., Gil, J. M., and Mancuso, A. (2006). Non-parametric Modelling of Spatial Price Relationships. Journal of Agricultural Economics, 57(3), 501-522.

Sexton, R. J., Kling, C. L., and Carman, H. F. (1991). Market integration, efficiency of arbitrage, and imperfect competition: methodology and application to US celery. American journal of agricultural economics, 73(3), 568-580.

Silverio, R., and Szklo, A. (2012). The effect of the financial sector on the evolution of oil prices: Analysis of the contribution of the futures market to the price discovery process in the WTI spot market. Energy Economics, 34(6), 1799-1808.

Smith, H. H. (1988). US agricultural export competitiveness: export levels, trade shares, and the law of one price. Economic Review-Federal Reserve Bank of Dallas, 14.

Sosvilla-Rivero, S., and Gil-Pareja, S. (2004). Price convergence in the European Union. Applied Economics Letters, 11(1), 39-47. 
Spiller, P. T., and Huang, C. J. (1986). On the extent of the market: wholesale gasoline in the northeastern United States. The Journal of Industrial Economics, 131-145.

Stata. (2020). Stata Base Reference Manual, Release 15 Stata Press, College Station, Texas.

Stephens, E. C., Mabaya, E., Cramon-Taubadel, S. V., and Barrett, C. B. (2012). Spatial price adjustment with and without trade. Oxford Bulletin of Economics and Statistics, 74(3), 453469.

Stępień, S., and Polcyn, J. (2016). Pig meat market in selected EU countries under the conditions of economic integration: a comparative analysis of old and new Member States.

Suzhou Dongchen Refrigerated Logistics Company. (2019). Personal communication.

Svanidze, M., and Götz, L. (2019a). Determinants of spatial market efficiency of grain markets in Russia. Food Policy, 89, 101769.

Svanidze, M., and Götz, L. (2019b). Spatial market efficiency of grain markets in Russia: Implications of high trade costs for export potential. Global Food Security, 21, 60-68.

Takayama, T., and Judge, G. G. (1971). Spatial and temporal price and allocation models.

Teräsvirta, T. (1994). Specification, estimation, and evaluation of smooth transition autoregressive models. Journal of the american Statistical association, 89(425), 208-218.

Tian, X., \& von Cramon-Taubadel, S. (2020). Economic consequences of African swine fever. Nature Food, 1(4), 196-197.

Thompson, S. R., Sul, D., and Bohl, M. T. (2002). Spatial market efficiency and policy regime change: Seemingly unrelated error correction model estimation. American Journal of Agricultural Economics, 84(4), 1042-1053.

USDA(2015).https://apps.fas.usda.gov/newgainapi/api/report/downloadreportbyfilename?filenam e=Pork\%20Markets\%20Swimming\%20in\%20EU\%20Pork_Brussels\%20USEU_EU-28_9-42015.pdf

USDA (2016). China - Peoples Republic of Livestock and Products Annual https://apps.fas.usda.gov/newgainapi/api/report/downloadreportbyfilename?filename=Livestoc k\%20and\%20Products\%20Annual_Beijing_China\%20-\%20Peoples\%20Republic\%20of_1014-2016.pdf

USDA (2020). Livestock and Annual https://apps.fas.usda.gov/newgainapi/api/Report/DownloadReportByFileName?fileName=Liv estock\%20and\%20Products\%20Annual_The\%20Hague_European\%20Union_09-09-2020 
Vinuya, F. D. (2007). Testing for market integration and the law of one price in world shrimp markets. Aquaculture Economics \& Management, 11(3), 243-265.

Vollmer, T., Herwartz, H., and von Cramon-Taubadel, S. (2020). Measuring price discovery in the European wheat market using the partial cointegration approach. European Review of Agricultural Economics, 47(3), 1173-1200.

von Cramon-Taubadel, S., (1998). Estimating asymmetric price transmission with the error correction representation: An application to the German pork market. European review of agricultural economics, 25(1), 1-18.

von Cramon-Taubadel, S., (2019). Market integration and price transmission lecture, Goettingen. von Cramon-Taubadel, S., and Goodwin, B. K. (2021). Price Transmission in Agricultural Markets. Annual Review of Resource Economics, 13.

Weldegebriel, H. T. (2004). Imperfect price transmission: is market power really to blame?. Journal of Agricultural Economics, 55(1), 101-114.

Williamson, J. (1986). Target Zones and the Management of the Dollar. Brookings Papers on Economic Activity, 1986(1), 165-174.

Xiao, H., Wang, J., Oxley, L., and Ma, H. (2012). The evolution of hog production and potential sources for future growth in China. Food Policy, 37(4), 366-377.

Zanias, G. P. (1993). Testing for integration in European Community agricultural product markets. Journal of Agricultural Economics, 44(3), 418-427.

Zant, W. (2018). Trains, trade, and transaction costs: How does domestic trade by rail affect market prices of Malawi agricultural commodities?. The World Bank Economic Review, 32(2), 334-356.

Zhang, Cungen, Liang, Zhenhua, Wang, Jimin. (2016). An Analysis on Regional Change of China Hog Production, Study on Animal Husbandry Economy in the New Era. China Agricultural Press, Beijing, 505-527. (in Chinese language).

Zhang, Y., Rao, X., and Wang, H. H. (2019). Organization, technology and management innovations through acquisition in China's pork value chains: The case of the Smithfield acquisition by Shuanghui. Food policy, 83, 337-345.

Zivot, E., and Andrews, D.W.K. (1992). Further Evidence on the Great Crash, the Oil-Price Shock, and the Unit-Root Hypothesis, Journal of Business \& Economic Statistics, 10(3), 251270. 


\section{Declaration of the personal contribution to the work}

Chapter II "Literature Review on the Law of One Price", is written by Yali Mu. The author is grateful for valuable comments from Stephan von Cramon-Taubadel.

Chapter III "Estimating Dynamic Market Efficiency Frontiers", is written by Yali Mu and Stephan von Cramon-Taubadel. $\mathrm{Mu}$ managed and collected the data. $\mathrm{Mu}$ and von CramonTaubadel conceptualized the research idea, developed the theoretical framework and the empirical strategy and implemented the econometric modeling in both $\mathrm{R}$ and Stata software. Both interpreted the results, edited the manuscript. This paper is under revision at the Journal of Agricultural Economics. The authors are grateful for valuable comments from Bernhard Brümmer from Göttingen University and Rico Ihle from Wageningen University who discussed earlier versions of the paper at doctoral seminar presentations in Göttingen.

Chapter IV "Comparing Market Efficiency Frontiers", is written by Yali Mu. I managed and collected the data with assistant from Manuel Droste. I conceptualized the research idea, developed the theoretical framework and the empirical strategy, implemented the econometric modeling in both $\mathrm{R}$ and Stata software, interpreted the results. I am grateful for all suggestions for the whole procedure of this work from Stephan von Cramon-Taubadel. I am also grateful for valuable comments of the paper from Stephan von Cramon-Taubadel and Bernhard Dalheimor at the doctoral seminar presentation in 2021, Göttingen. This paper was presented at 31st International Conference of Agricultural Economists conference, August, 2021.

Chapter V "Measuring Time-Varying Market Efficiency", is written by Yali Mu and Stephan von Cramon-Taubadel. $\mathrm{Mu}$ managed and collected the data. $\mathrm{Mu}$ and von Cramon-Taubadel conceptualized the research idea, developed the theoretical framework and the empirical strategy. $\mathrm{Mu}$ implemented the econometric modeling in both $\mathrm{R}$ and Stata software. Both interpreted the results, edited the manuscript. The authors are grateful for consultative time and guidance for the estimation of the preliminary version of this paper from Luis Alberto De Los Santos-Montero, Teresa Vollme from Agricultural faculty, and Alexander Silbersdorff from the Economics faculty. The authors are also grateful for valuable comments from Bernhard Brümmer from Göttingen University and Rico Ihle from Wageningen university who discussed earlier versions of the paper at doctoral seminar presentations in Göttingen. Previous version of this paper was presented by Yali $\mathrm{Mu}$ at doctoral seminar discussed by Bernhard Brümmer and at the 30th International Conference of Agricultural Economists in Vancouver, Canada, and also presented by Stephan von Cramon-Taubadel at the Zhongshan International Forum, November 2018 in Nanjing, China. 


\section{Declarations}

1. I, hereby, declare that this Ph.D. dissertation has not been presented to any other examining body either in its present or a similar form.

Furthermore, I also affirm that I have not applied for a Ph.D. at any other higher school of education.

2. I, hereby, solemnly declare that this dissertation was undertaken independently and without any unauthorised aid. 